Portland State University

PDXScholar

Spring 6-5-2015

\title{
Gifted Black and Biracial Students at a Predominantly White Gifted School
}

Clair Elizabeth Pople

Portland State University

Follow this and additional works at: https://pdxscholar.library.pdx.edu/open_access_etds

Part of the Bilingual, Multilingual, and Multicultural Education Commons, and the Gifted Education Commons

Let us know how access to this document benefits you.

\section{Recommended Citation}

Pople, Clair Elizabeth, "Gifted Black and Biracial Students at a Predominantly White Gifted School" (2015). Dissertations and Theses. Paper 2347.

https://doi.org/10.15760/etd.2344

This Dissertation is brought to you for free and open access. It has been accepted for inclusion in Dissertations and Theses by an authorized administrator of PDXScholar. Please contact us if we can make this document more accessible: pdxscholar@pdx.edu. 
Gifted Black and Biracial Students at a Predominantly White Gifted School

by

Clair Elizabeth Pople

A dissertation submitted in partial fulfillment of the requirements for the degree of

Doctor of Education

in

Educational Leadership: Curriculum and Instruction

\author{
Dissertation Committee: \\ Jason Ranker, Chair \\ Samuel Henry \\ Olivia Murray \\ Lisa Bates
}

Portland State University

2015 


\begin{abstract}
The underrepresentation of gifted Black and Biracial students is a pervasive problem in and of itself, and indicates a much larger struggle of disproportionality of Black and Biracial students who are not called upon or supported in efforts to meet their academic potential. Therefore, an evaluation of the inequity generated by gifted education is warranted. It is true that the majority of gifted programs are often predominantly White. Accordingly, Black and Biracial students who qualify for gifted programs may face unique challenges in their development of racial identity and their socio-emotional health.
\end{abstract}

Using ethnographic techniques, this case study explored the ways that Discovery School, a predominantly White gifted school (PWGS), addresses race. It asked how Black and Biracial students at Discovery School understood themselves as racial beings. The fundamental research questions that guided this study were: (1) how is race addressed at a PWGS, and (2) how does a student of color feel Otherness at a PWGS? The case study was designed, and findings were analyzed, through the theoretical lens of critical race theory.

Data was collected through several means, including interviews, surveys, direct observation, and email prompts. Interviews were conducted with four gifted students of color, three teachers, and three parents. Surveys were sent home for student participants and their parents to fill out together. Teachers and administrators were asked to complete two email interview questions. Throughout the data collection, I frequently observed students learning and playing at the school and recorded field notes. 
Findings indicate that:

1. Talented and gifted students thrive in programs that are uniquely tailored to meet their advanced academic and cognitive needs.

2. Policies and inadequate communication act as barriers for gifted Black and Biracial students.

3. Within a positive educational community, racial microaggressions-including the silencing of racial dialogue and individual bullying - exist.

The results of this study suggest that Discovery School operates in ways that benefit the participants of the study. Overall, the student participants (and most parent participants) were satisfied with their experiences at Discovery School. Additionally, results indicate that Discovery School could strengthen their program with a commitment to diversifying the student population and implementing culturally responsive pedagogy and antiracist practices that change the consciousness of education professionals and offer support systems for gifted Black and Biracial students, and develop curriculum that is more reflective of students of color. 


\section{Dedication}

This work is dedicated to Winston and all of those like him. May this system be something that eventually works in your favor. May I be your ally, never impeding your greatness. 


\section{Acknowledgements}

Foremost I would like to express my gratitude to Jason Ranker, the chairperson of my committee, for being a consistent sounding board and support, ever patient and encouraging. I was honored to be guided through this process by a researcher of such high caliber.

I also profoundly thank my committee members: Olivia Murray, Samuel Henry, and Lisa Bates. Such a varied and rich source of insight was a true gift through this process. Specifically, I am grateful for Dr. Henry’s optimism and support, even driving through rush hour traffic to share salad rolls with me and remind me that I was capable. I believe I owe you lunch, Dr. Henry. I also appreciate Dr. Murray’s attention to detail, willingness to put in a few hours editing, and the resulting 200 or so comments that guided me in polishing this work. Finally I appreciate Dr. Bates interest in this work and pragmatic guidance, especially in the area of methodology. It has been an honor working with you.

I am indebted to Dr. Emily de la Cruz whose selflessness and graceful spirit taught me what it means to be an educator. Although she passed away before I finished this process, I know that her patient guidance and teashop meetings were pivotal to this experience. I am eternally grateful to my colleagues Katie Statman-Weil, KD Parman, and Dustin Bindriff for checking in, camping with laptops, Monday writing sessions, and sharing laughter and frustration. This is a collaborative process after all.

Finally, Dan Roix, you have my gratitude and my heart. This was your sacrifice too. 


\section{Table of Contents}

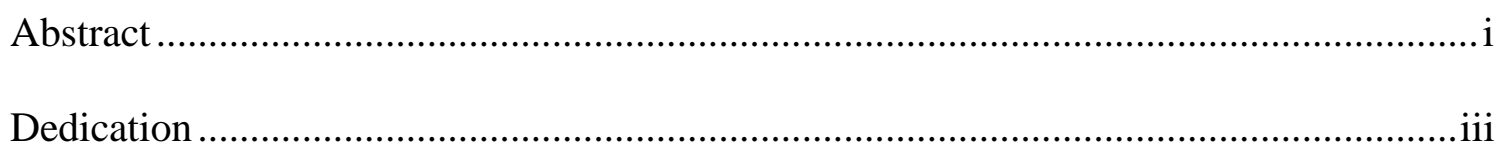

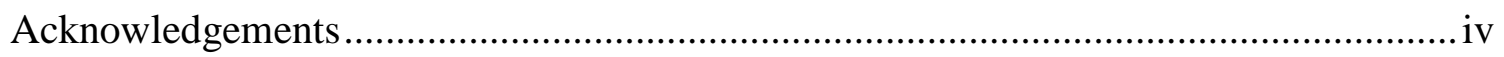

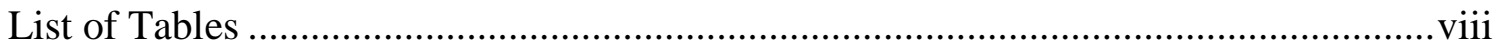

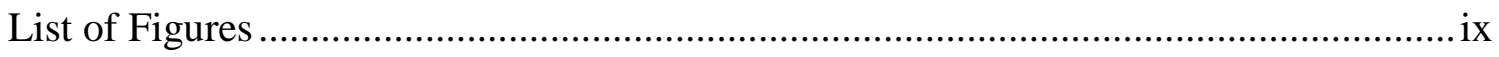

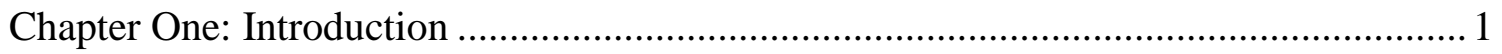

Statement of the Problem ................................................................................... 1

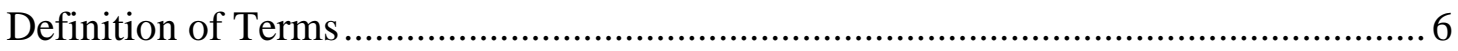

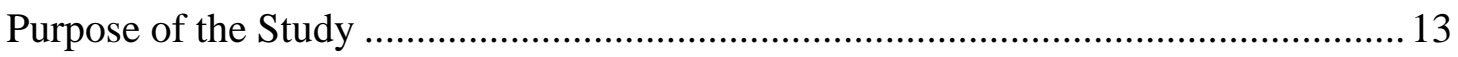

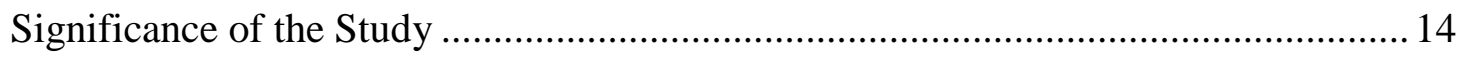

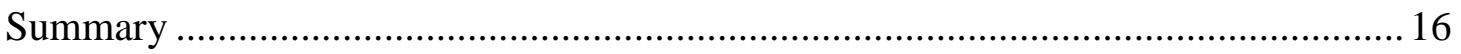

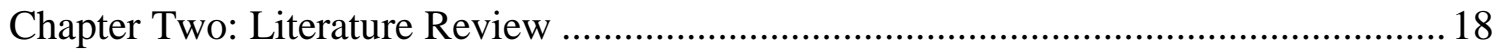

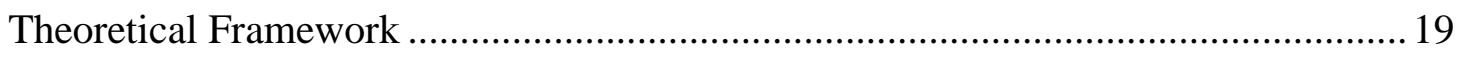

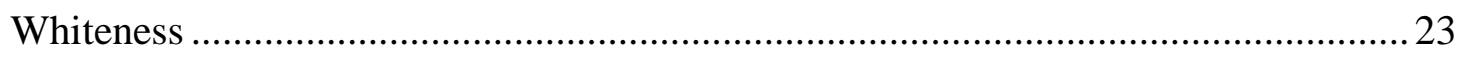

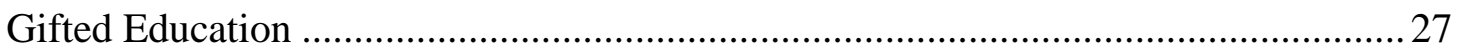

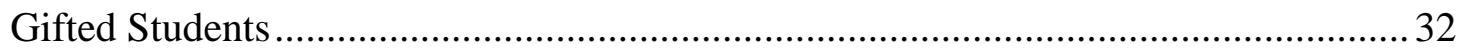

Gifted Students of Color ............................................................................. 34 
PREDOMINANTLY WHITE GIFTED SCHOOL vi

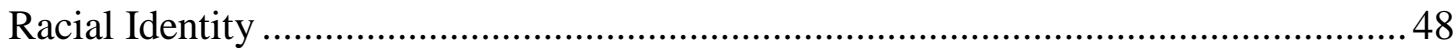

Social, Psychological, and Academic Health of Gifted Black and Biracial Students.. 58

Review of Methodological Literature .......................................................................63

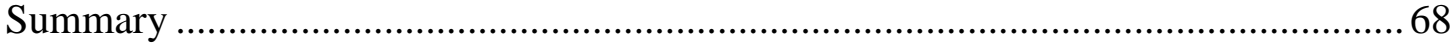

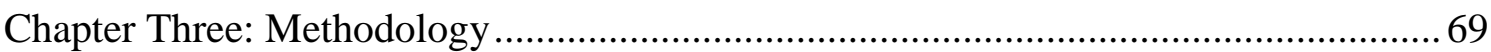

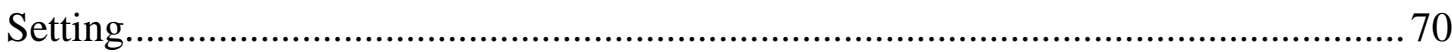

Research Design ....................................................................................................... 72

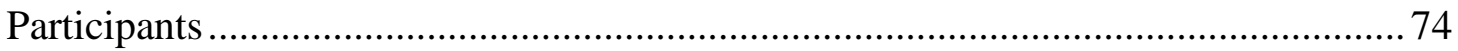

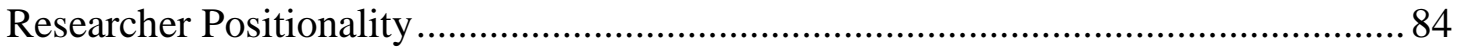

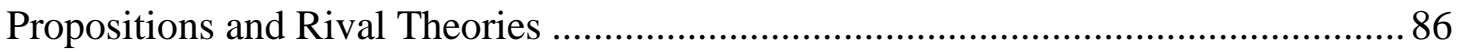

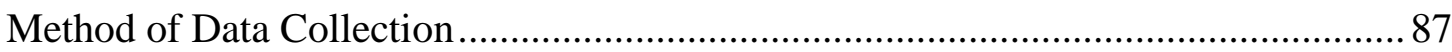

Data Analysis Procedures......................................................................................... 92

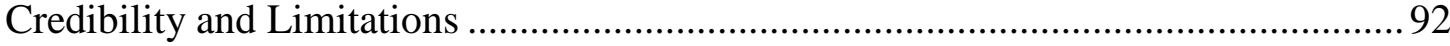

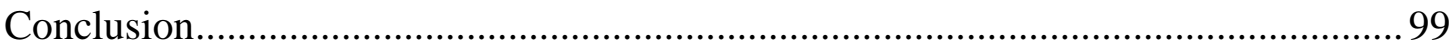

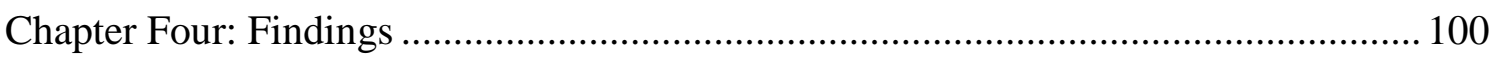

How is Race Addressed at a Predominantly White Gifted School? ............................. 101

How Do Gifted Black and Biracial Students Feel Othering at a PWGS?................... 117

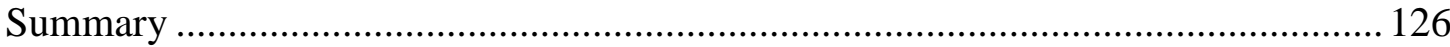

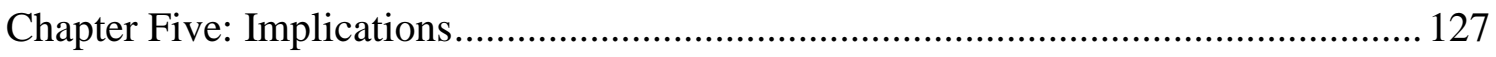




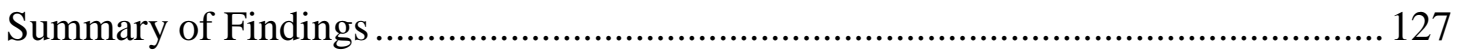

Suggestions for Future Research............................................................. 146

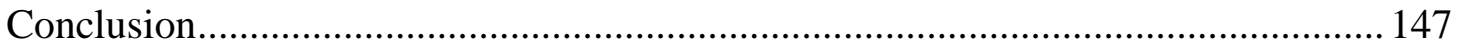

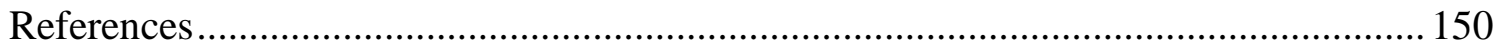

\section{Appendices}

A. Letter of Informed Consent......................................................................... 180

B. Letter of Informed Consent (Student Version) .......................................... 181

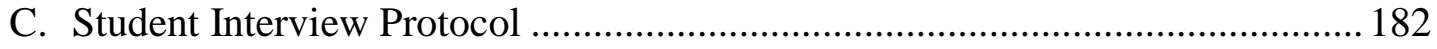

D. Teacher Interview Protocol.......................................................................... 184

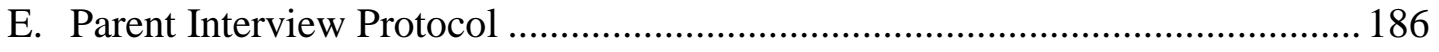

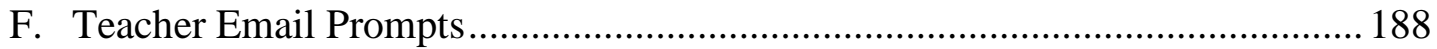

G. Parent/Student Survey ........................................................................ 190 
List of Tables

Table 1. Comparison of demographics: District-wide and Discovery School.................... 4

Table 2. Discovery School demographics ………………….......................................... 71

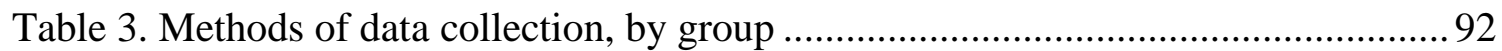

Table 4. Initial codes, resulting categories....................................................................94 


\section{List of Figures}

Description

Page \#

Figure 1. Five major tenets of critical race theory ................................................. 20

Figure 2. Internal and external factors affecting Black and Biracial students .................34

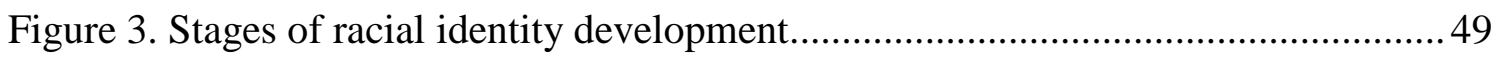




\section{Chapter One: Introduction}

Despite the effort of educational researchers to create racial equity in gifted education, the issue persists and as a result, there are many predominantly White gifted schools (PWGS) and programs across the nation. Because levels of cognition are not divided along racial lines, and research has disproven a White monopoly of giftedness, it is important to look at how this disproportionality is born, and (more relevant to this study) how PWGSs respond to issues of race. This inquiry was an exploration of how race is addressed at Discovery School, a PWGS in the Pacific Northwest region of the United States. Discussion in this chapter is organized in the following way: (a) statement of the problem, (b) definition of terms. (c) theoretical framework, (d) purpose of the study, (e) significance of the study, and (f) limitations of the study.

\section{Statement of the Problem}

Gifted education, which targets students with advanced development in areas such as cognition and leadership, is reported to be the most racially segregated arena in the educational field (Borland, 2003; Ford, 1994, 1996, 1998, 2003; Sapon-Shavin, 2003). According to the National Center for Educational Statistics (2006), White students make up 61 percent of the total student population, and 67 percent of the group of students who have been labeled as talented and gifted (TAG). Black students, on the other hand, make up 16 percent of the total student population in the U.S., and nine percent of talented and gifted students. Further, recent data suggests that students of color, including Black students, Latino students, and others, are half as likely as White students to be placed in gifted education (Children’s Defense Fund, 2011). 
Often gifted Black and Biracial students find themselves in PWGS and face unique internal and external challenges (Ford, 1994, 1996, 1998, 2003; Ford, Grantham, \& Whiting, 2008). In analyzing disproportionality in gifted education and the impact on gifted Black and Biracial students who learn in PWGSs, researchers have examined structural and individual policies, ideologies, and behaviors regarding the impact of race on educational experience. Some researchers (Bierda, 2011; Dennis, 1995; Perry, 2003; Perry, Steele, \& Hilliard, 2003) cite the inability of educational professionals to overcome the historical stigma surrounding the intelligence of people of color as one factor. Others (Cross, 2003; Sapon-Shevin, 1994) blame biased assessment policies and procedures, and still others (Ford, 1994, 1996; Ladson-Billings \& Tate, 1995) believe that gifted education operates under a meritocratic, colorblind perspective that does not value the unique experiences of people of color. Essentially, all of these perspectives hold valuable insight into challenges faced by gifted students of color in PWGS.

A troublesome, and well-documented perspective is low expectation for Black and Biracial students (Bireda, 2011; Chikkatur, 2012; Hargrove \& Seay, 2011; Howard, 2014; Ladson-Billings, 2009). The assumption of inferiority of Black and Biracial students is deeply ingrained in U.S. society and often undetected even by those who carry it. Howard (2014) reports that White teacher attitudes favor White students and have a negative effect on Black and Biracial students. For example, racial disparity in suspensions and expulsions, inadequate resources for urban schools that primarily serve Black students, and personal injustices for Black students at the hands of educational professionals all have been linked to teacher assumptions and expectations (Skiba, 
2011). Hargrove and Seay (2011) acknowledge that White teachers were more likely than Black teachers to hesitate to refer Black or Biracial students for gifted testing based on non-school factors, such as home, parents, and community. This deficit-orientation continues to influence educational practices and procedures and creates harmful learning environments for students of color (Bireda, 2011; Foster, 2005; Kumashiro, 2009).

Further perpetuating inequities in gifted education is adherence to rigid, outdated grouping policies as a gateway to gifted education services. Biased assessments favor students who have experience with normative academic culture (Burley, Barnard-Brak, Marbley, \& Deason, 2010; Lynch \& Baker, 2005). As a result, programs that serve gifted students are more often than not predominantly White, and gifted Black and Biracial students face educational experiences that do not reflect their histories or communities. While gifted White students’ realities are affirmed, gifted Black and Biracial students often find themselves in the role of the Other and face barriers to healthy racial identity and social lives (Ford, 1996; Ford, Grantham \& Whiting, 2010; Ladson-Billings \& Tate, 1995; Perry, Steele, \& Hilliard, 2002).

Theoretically, and barring other social inequities, the demographics of gifted education programs should be reflective of the demographics of the larger school district. However, despite previous efforts by researchers and practitioners to expose and eliminate inequities, disproportionality persists and begs for critique of structural policies that bolster unequal access to gifted education programs, often marginalizing gifted Black and Biracial students and restricting access to programs that are tailored for 
their high cognitive and academic needs (Borland, 2003; Ford, 1994, 1998, 2003; Ford, Grantham, \& Whiting, 2008; Sapon-Shavin, 2003).

Therefore, this study attempted to analyze the way that race is addressed at Discovery School, a PWGS in a Pacific Northwest school district. (To ensure confidentiality, I am using a pseudonym for the name of the school.) This school serves students who score in the $99^{\text {th }}$ percentile on an achievement or aptitude test (e.g., Cognitive Ability Test (CogAT), Iowa Test of Basic Skills (ITBS)). Discovery School has been an alternative school for talented and gifted students in the district for twelve years. It has been housed in many different school buildings, often co-locating with a neighborhood school. In 2013, Discovery School moved into an empty school building in an upper middle class neighborhood.

According to the district's data and policy analysis (2013), shown in Table 1, of

Table 1

Comparison of district-wide demographics and Discovery School

\begin{tabular}{|c|c|c|}
\hline \multicolumn{3}{|c|}{ Demographics } \\
\hline Discovery School & & District \\
\hline Total Students: 236 & & $\begin{array}{c}\text { Total Students: } \\
48,745\end{array}$ \\
\hline \% of students & Subgroup & \%of students \\
\hline $2.5 \%$ & African American & $10.6 \%$ \\
\hline $14.4 \%$ & Asian & $7.9 \%$ \\
\hline $4.2 \%$ & Hispanic & $16.2 \%$ \\
\hline $10.6 \%$ & Multiracial & $7.4 \%$ \\
\hline $68.2 \%$ & White & $55.8 \%$ \\
\hline $100 \%$ & $\begin{array}{l}99^{\text {ti }} \text { percentile on } \\
\text { nationally } \\
\text { normed test }\end{array}$ & $\mathrm{NA}$ \\
\hline $12.3 \%$ & $\begin{array}{l}\text { Free/reduced } \\
\text { lunch }\end{array}$ & $44.8 \%$ \\
\hline $12.3 \%$ & Special education & $14 \%$ \\
\hline
\end{tabular}

the 236 students who attended the

Discovery School in 2013-2014, six students (2.5 percent) self-identified as Black and 25 students (10.6 percent) selfidentified as multiracial. Although the data on multiracial students does not specify which racial categories students identify with, I was able to seek out the six (2.5 percent) Biracial students who selfidentified as Black plus one other race for 
this inquiry. The total percentage of Black students in the district is 11 percent, and multiracial students comprise 7.4 percent. These numbers demonstrate the pervasive racial disproportionality in this gifted school.

I used a holistic approach to explore policies and practices that created and sustained Discovery School as a PWGS and the impact felt by the Black and Biracial students who attend there. Throughout the inquiry, it was clear to me that the administration at Discovery School prioritized equity work. The principal was open to conversations about equity and made efforts to increase representation of communities of color within the Discovery School student body. The school leaders participated in an Equity and TAG focus group with stakeholders from local organizations, universities, and parent groups. They also established a teacher-led equity team that regularly met to discuss issues of diversity as they arose. Also, the faculty and staff at Discovery School participated in Courageous Conversations (Singleton \& Linton, 2006), a training which boasts the goal of achieving equity in schools. This focus on equity within the school created an open and willing partnership between the administration, teachers, parents and students at the school and me throughout the research process.

While not downplaying the consequences of inequitable assessment procedures, the focus of this study was not gifted testing or admissions policies. Instead, this study examined the role that race played in a gifted school, one that was specifically tailored to meet the needs of TAG students. Previous studies have documented challenges that the intersection of race and giftedness may pose for TAG Black and Biracial students including: (a) struggle with racial identity, (b) social isolation, and (c) internal conflict in 
working to maintain identity both as a person of color and a gifted student (Ford, 1996, 1998, 2002; Hensfield, Moore, \& Wood, 2008; Morris, 2004; Van Tassal-Baska, 2003; Winston, 2004). Also, as gifted students often boast high levels of sensitivity, it is argued that gifted students of color have an acute awareness of Othering and strongly desire fairness for themselves and justice within larger society (Blatt, 1995; Dixon \& Scheckel, 1996; Ford, 2002; Jackson, 1998; VanTassal-Baska, 2003).

Before continuing the discussion, the next section will define concepts that are foundational to the review of the literature and description of study. In the next chapter, the following definitions will be discussed: race, racism, institutional racism, students of color, and giftedness because they are fundamental to the upcoming literature review and description of the study.

\section{Definition of Terms}

Race. Contrary to the deeply ingrained ideology that humans are divided into biological subgroups that are distinct, exclusive, and unchanging, geneticists and biologists have never established a significant link between biology and race (Blakely, 1999; Gravelee, 2009; Hartigan, 2006). In fact, racial categories were first devised in the Enlightenment era to categorize and organize humans (Blakely, 1999). By the midtwentieth century, cultural anthropologists dismissed any link between biology and race, arguing that society, not nature, created the subgroups in which physical attributes were used to lump certain people together (Blakely, 1999; Gravelee, 2009; Nayak, 2006).

Researchers such as Omi and Winant (1994), Mipoori (2012), and Brayboy, Castango, and Maughan (2007) maintain that race is a socially, politically, and 
historically constructed concept. This is not to suggest that due to its lack of biological significance that race should be dismissed. The opposite is true! As a sociohistorical construct, race is used to represent humans in such ways that create and maintain political and economic inequities (Omi \& Winant, 1994; Gravelee, 2009). In fact, Omi and Winant (1994) define race as “a concept that signifies and symbolizes social conflicts and interests by referring to different types of human bodies” (p. 55). During an interview with Omi, he discussed with me the ever-changing racial categories on statistical data collection techniques as an example of the socially and politically constructed nature of race (personal communication, March 2012). In all, race is an ideological construction, and as such carries political and social weight that benefits people who adhere to dominant culture (Ladson-Billings \& Tate, 1995; Omi \& Winant, 1994).

Racism. Race is a way of assigning value to categories of people and as such some categories are celebrated and some are stigmatized (Ladson-Billings \& Tate, 1995; Mipoori, 2012; Omi \& Winant, 1994; Tatum, 1997). In other words, race is used to divide people into social constructions of "superior" and "inferior," often based on perceived ability and intelligence (Bireda, 2011; Dennis, 1995; Perry, 2003). For the purposes of this study, racism will be defined using these ideas as well as Brayboy, Castango, and Maughan’s (2007) definition of racism, a system of values and practices that perpetuate an unequal distribution of power, favoring the dominant class.

For several decades, the nature of racism has been changing from overt to covert, from personal to structural (Blank, Knowles, \& Prewitt, 1970; D’Souza, 1995; Omi \& 
Winant, 1996; Perry, 2003). Microaggressions, or unintended acts of discrimination, are endemic, as is colorblind racism, or the silencing of race matters under the justification that personal merit and not race account for successes and failures. While these acts of racism are harder to pinpoint, their frequent occurrences not only marginalize people of color, but they also trivialize the experiences that members of the Black community have because of their race, dismissing language that could be useful in exploring the issue (Bonilla-Silva, 2003; Roberts, Bell, \& Murphy, 2008). Racism may have changed forms in the last several decades, but the outcome remains_oppression of members of Black and Biracial communities and the silencing of dissention or protest.

Systemic racism. The difference between individual and systemic racism is not visibility or intent, as both types of racism may be covert. Instead, the difference is found at the level at which racism is carried out (Blank, Knowles, \& Prewitt, 1970). At the macro level, systemic racism is a set of ideologies, policies, and procedures that yields barriers for communities of color (Barker, 1996; Blank, Knowles, \& Prewitt; D’Souza; Foster, 2006). MacPherson (1999) explains systemic racism as:

the collective failure of an organization to provide an appropriate and professional service to people because of their color, culture, or ethnic origin. It can be seen or detected in processes, attitudes and behavior which amounts to discrimination through unwitting prejudice, 
ignorance, thoughtlessness and racist stereotyping which

disadvantages minority ethnic people (p. 29).

Systemic racism carries an enormous weight for communities of color, and acts as an ever-present barrier (Foster, 2005; Howard, 2014). In education, systemic racism is the most significant force behind the disproportionality in gifted education programs. It drives policies surrounding referral rate for gifted programs, test achievement, and retention in programs. Ideologies are at play that suggest who can learn and achieve and who is "at risk," "in crisis," or "left behind” (Howard, 2014). Steele (1992) argues:

Doing well in school requires a belief that school achievement can be a promising basis of self-esteem and that belief needs constant reaffirmation even for advantaged students. Tragically...the lives of Black Americans are still haunted by a specter that threatens this belief and the identification that derives from it at every level of schooling (p. 72).

Currently, education is operating within a paradigm that, intentional or not, does very little to support students of color in their learning (Howard, 2014). Certainly changes are in order to adequately meet the needs of Black and Biracial students.

Black and Biracial students. For the purposes of this study, I will discuss the participants of my study as gifted Black and Biracial students. In this study, Black refers to a group of people who have similar experiences based on their relationship with European Americans, which is wrought with current and historical oppression (Omi \& Winant, 1994). While race has no biological basis, it is still used to categorize people, 
and therefore has social and political impact (Omi \& Winant, 1994). For this inquiry, Biracial is defined as those students who claim Black plus one other category on a demographic survey distributed by the county. Certainly other groups, specifically Native American and Hispanic, have similar experiences as the Other in relation to White European Americans (Moore, Ford, \& Milner, 2005); however, this research study focuses on the experiences of Black and Biracial students.

Giftedness. The definition of giftedness is inconsistent and controversial. Historically, giftedness has been understood as two standard deviations above the normal Intelligence Quotent (IQ) score (Dai \& Renzulli 2008; Borland, 2009). However current research points to fundamental flaws in such thinking, namely the implication that intelligence is innate—-some have it, and others do not (Perry, Steele, \& Hilliard, 2002). Instead, current advocates of giftedness suggest that talents are nurtured and developed. Furthermore, IQ assessments are bent severely in favor of White normative culture, and benefit students who are familiar with these norms, while those from other worldviews are left at a disadvantage (Tozer, Sensese, \& Violas 2009).

Current definitions of giftedness recognize that gifted behavior may be visible in a variety of areas that are not tested by traditional intelligence tests. The National Association of Gifted Children (2012) identifies domains such as mathematics, music, language, painting, dance, and sports in which students may demonstrate giftedness. Other researchers (Gardner, 1983; Renzulli, 1986; Sternberg, 1995) point to areas such as interpersonal skills, leadership, and creativity, emphasizing combinations of such attributes. Unlike traditional definitions of giftedness that highlighted White middle 
class normalized manifestations, current definitions of giftedness also emphasize that different subgroups of people may have different ways of expressing advanced levels of cognition (Bodmer \& Cavalli-Sforza, 1970; Fish, 2002; VanTassel-Baska, 2003).

Because gifted education, and the funding and implementation thereof, is the responsibility of state and local governments (and up until this point common national definitions do not exist), this inquiry will use the definition of giftedness provided by the State Board of Education in the area where data collection took place. This definition is used by the local school district for the Discovery School:

Talented and gifted children means those children who require special educational programs or services, or both, beyond those normally provided the regular school program in order to realize their contribution to self and to society and who demonstrate outstanding ability or potential in one or more of the following areas:

- General intellectual ability as commonly measured by measures of intelligence or aptitude.

- Unusual academic ability in one or more academic areas.

- Creative ability in using original or nontraditional methods in thinking and producing.

- Leadership ability in motivating the performance of others either in educational or non-educational settings. 
- Ability in the visual or performing arts, such as dance, music or art

(Oregon Definition of Giftedness, ORS 343.495, 2012).

Chapter two discusses scientific evidence that supports the entity of highly developed learners. However, it is important to note that science did not warrant the introduction of the label gifted. In fact, the gifted label is a social construct that carries connotations of elitism and power that have made the label, not the high levels of cognition, problematic (Jolly, 2009; VanTassel-Baska, 2003).

Despite problematic connotations inherent in the gifted label, numerous studies point to the benefit of offering differentiated quality instruction and services—-whether in an isolated program, pullout design, or in-class differentiation (Gallagher, 1996, 2000; King, Kozleski, \& Lansdowne, 2009; Swaitek \& Lupkowski-Shoplik, 2003; Thompson \& Oehlert, 2009). Gifted students themselves have voiced their testimony to the importance of gifted programs by reporting that non-gifted content courses focused on redundancy and low-level thought and often incited boredom for the students (Gallagher, 2000).

This argument (and assumption under which this inquiry operates) is important because it counters a popular ideology suggesting that gifted students are successful with or without special attention to their cognitive, social, and emotional needs (Clark, 1997). Unfortunately, due to lack of funding, gifted students often find themselves in school settings in which educational professionals have neither the resources nor the training to 
adequately meet gifted students’ needs (Swaitek \& Lupkowski, 2003). Without programs uniquely tailored to the needs of cognitively advanced students, potential is left unfulfilled academic needs unmet (Feldhusen, 2003). Although gifted programs and services are far from perfect, they offer opportunities for cognitive growth and social and emotional support that gifted students very likely would not receive (Clark, 1997; Gallagher, 2000).

\section{Purpose of the Study}

The purpose of this study was to explore ways in which a PWGS addresses race. It also illuminated the experience of the Black and Biracial students who attend the PWGS. Using critical race theory, I believe this inquiry could contribute to the conversation about race and gifted education by reinforcing the positive and suggesting ways to repair the negative educational experiences of cognitively advanced Black and Biracial students. I hope this inquiry adds new perspectives and creates new avenues for gifted education to honor diversity and empower all gifted students regardless of color. Furthermore, I hope this study helps challenge current power systems and potentially harmful mis-knowledge that affect these unique learners.

Research questions. The two research questions that guided this study are:

1. How is race addressed at a PWGS?

2. How does a student feel Otherness, defined previously as the way that a person internalizes social categories (Zevallos, 2013).

Using case study methodology, I explored and described the way that race is addressed at a PWGS. I also drew upon tools and constructs used in ethnographic 
inquiry, prioritizing participant-observation and interpretations of patterns found in the “culture-sharing group” of Discovery School, which acted as the bound system (Creswell, 2007, p. 68). Self-described experiences of Black and Biracial students at Discovery School with special attention to their social, emotional, and cognitive selves, as well as counternarratives—stories from individuals that have not been told and that challenge the dominant narrative (delgando, 1999)—from parents and teachers, direct observation, and survey data helped create a rich depiction of the way that race is addressed at Discovery School.

The patterns and the themes that emerged from the study elucidated shared values, behaviors, and beliefs among those who work and learn at Discovery School, with attention to the experiences, both positive and negative, of gifted Black and Biracial students participants. Analysis of the data provided insight into policy and procedures that affect this particular school.

\section{Significance of the Study}

Although numerous scholars have examined racial issues within education (Baker, 2005; Castango, 2008; Howard, 2002, 2104; King, 1991; Ladson-Billings, 1999, 2000, 2009; Kumashiro, 2004; Ogbu, 1981, 1995i, 1995ii, 1998, 2004; Perry, 2003; Perry, Steele, \& Hilliard, 2003; Toshalis, 2014), the intersection of race and gifted education has not been adequately explored. If inequities in gifted education remain, great potential may be lost, and Black and Biracial gifted students may experience social, cultural, and psychological stressors that often lead to underachievement or dropping out (Ford, 1998; Moore, Ford, \& Milner, 2005). 
This inquiry is also important because it adds unique perspective to the current body of literature through a holistic approach. By emphasizing context and connectedness, interrelated elements of the school—district policies, teacher and parent perspectives, as well as student voice—were all important in creating a rich picture of how race is addressed and specifically the experiences of gifted Black and Biracial student participants (Wolcott, 1999). An increased understanding of the interrelatedness of various systemic elements of PWGSs may contribute to an important dialogue regarding equity in gifted programs.

As evidenced in the body of literature surrounding race and gifted education (e.g., Ford, 1994, 1996; Ford, Grantham, \& Whiting, 2003) racial equality has not yet been achieved. Furthermore, critical race theorist argue that racism is endemic and often practiced in covert ways such as colorblind policies regarding use of traditional intelligence assessment measures and curriculum (DeCuir \& Dixon, 2004; Delgado \& Stefancic, 2001). Thus, increased understanding about race and gifted education could be influential in decisions regarding the needs of gifted students of color.

As discussed in the subsequent chapter, gifted education is wrought with controversy and is often under-supported (Borland, 2003). However, this study may reflect the value of an educational approach that meets the needs of advanced learners (Ford, 1996, 1998; Sapon-Shevin, 2003; VanTassel-Baska, 2004). It is important to emphasize that this study is not a defense of gifted education as it currently stands. (As discussed in chapter two, the gifted label is wrought with biased connotations, and there is an obvious racial disparity in gifted education programs.) However, this study does 
defend appropriate educational opportunities for all students, including those that are advanced in areas such as cognition, creativity, and leadership. It is my hope that one outcome of this study will be a renewed appreciation for appropriately challenging curricula and equitable access to these learning situations for talented and gifted students.

Finally, one possible benefit of the inquiry is an extension of this particular case study research. I hope to use the findings of this research study to drive another case study inquiry that will examine the experiences of gifted Black and Biracial students at their neighborhood schools. Eventually by using comparative methods, greater understanding of systemic factors as well as patterns of phenomenon may be realized (Wolcott, 1999).

\section{Summary}

Gifted education is one of the most segregated sectors of our educational system (Borland, 2003; Ford, 1993, 2003; Sapon-Shavin, 2003). While the impact of race on general educational experiences is well documented (Baker, 2005; Castango, 2008; Howard, 2002; King, 1991; Ladson-Billings, 1999, 2000, 2009; Ogbu, 1981, 1995i, 1995ii, 1998, 2004; Perry, 2003; Perry, Steele, \& Hilliard, 2003), a gap in the literature exists in the intersection of race and gifted education. Through the use of critical race theory and case study methodology, this inquiry attempted to describe the way that a PWGS addresses racial issues. The experiences of gifted Black and Biracial students, their parents, and teachers were highlighted in order to learn about Othering and systemic policies and ideologies that contribute to the students' experiences. Further, 
this inquiry explored what is currently being done by Discovery School to create equitable learning situations for all gifted students of color.

The next chapter offers a review of the literature on topics that are pertinent to this study. Beginning with a synthesis of the literature on critical race theory, the literature review moves into a conversation about race and gifted education, including the internal and external factors that influence the cognitive, social, and emotional health of gifted students of color. Finally chapter two reviews the literature on case study methodology and data collection instruments that I employed during the study. 


\section{Chapter Two: Literature Review}

Researchers have previously explored issues of race and education (Baker, 2005; Castango, 2008; Howard, 2002; King, 1991; Ladson-Billings, 1999, 2000, 2009; Ogbu, 1981, 1995i, 1995ii, 1998, 2004; Perry, 2003; Perry, Steele, \& Hilliard, 2003), Black students in predominantly White schools (Andrews, 2012; Duttin, Singer, \& Devlin, 1998; Fordham \& Ogbu, 1986; Foster, 2005; Sapon-Sheven, 2003), gifted education (Borland, 1997, 2003; Cohen, 1996; Cross, 2003; Feldhusen, 2003; Fetterman, 2003; Gallagher, 1988, 1996, 2000; Irvine, 1991; Jolly, 2009; Moon, 1991; Preckel, Gotz, \& Frenzel, 2010; Reis \& McCoach, 2000; Renzulli \& Reis, 1997; Rogers, 2007; Shields, 2002; VanTassel-Baska, 2003), and other topics related to this inquiry.

However, at present, efforts have not been adequately made to examine the intersection of gifted education and race in order to shed light on the experiences of gifted Black and Biracial students in PWGSs. Thus, the following literature review is an attempt to synthesize findings from previous research on the topics listed above, as well as race, Otherness, and the colorblind perspective, that provide the foundation for this study.

This chapter first synthesizes seminal and current literature on the theoretical framework that drives this study, critical race theory. The rest of the chapter is organized as follows: impact of Whiteness, historical and current state of gifted education in the U.S., gifted education in a racialized society, the ideology of inferiority, colorblind racism, internal and external factors that may impact gifted Black and Biracial students. The chapter continues with a discussion of racial identity 
PREDOMINANTLY WHITE GIFTED SCHOOLS

development and effective practices and policies that meet the needs of gifted Black and Biracial students, including culturally responsive pedagogy and anti-racist practices. Finally, the chapter presents literature that was foundational in planning the research methodology.

\section{Theoretical Framework}

Critical race theoretical framework "challenges dominant ideology, provides transdisciplinary modes of inquiry, and suggests space for insiders' accounts of their experience” (Howard, 2014, p. 48). In educational research, critical race theory (CRT) is used to centralize racial discourse and use race as a lens through which to examine and critique the values, beliefs, and practices characteristic of schools. Using CRT as a framework for inquiry, an educational researcher aims to counteract "the neutrality with which questions of 'diversity' are presented in politics and in the curricular [that] hide[s] critical issues such as sexism, racism, gender hierarchies, disability, among others” (Mateus \& Infante, 2011, p. 293).

In other words, this critical stance analyzes and contests the structure of schooling, especially (in this case) gifted education where normalization of White middle class values place Black and Biracial students in relationship with the school that has potential to be ostracizing and harmful (DeCuir \& Dixson, 2004; Matus \& Infante, 2011; Toshalis, 2014). Education is not a race neutral institution, and gifted education is one of the most inequitable sectors (Borland, 2003; Ford, 1994, 2003; Howard, 2014; Sapon-Shavin, 2003). Therefore, using CRT to explore salient literature on the intersection of race and gifted education illuminates broad inequalities, often disguised 
as mainstream, and offers opportunity to critique the current situation in a move towards social justice in gifted education (Taylor, 1999).

Researchers use CRT framework to explore the significance of race and racism in contemporary society and to use their work as catalyst for the creation of more equitable power relationships (Gillborn, 2005; Ladson-Billings, 1999). Although CRT established its roots in the legal realm, it is important to the field of education because, like the legal system, it offers a counterscript to mainstream realities, acknowledging the pervasiveness of racism, discrimination, and hegemony (Howard, 2014; Roithmayr, 1999). As shown in Figure 1, there are five major tenets of CRT. The following section will discuss the ways that each of these tenets drove the planning stages of the inquiry and influenced data collection methods and informed data analysis to challenge racial injustice.

Figure 1. Five Major Tenets of Critical Race Theory

\begin{tabular}{|l|l|}
\hline 1. Racism & Critical Race Theory \\
\hline 2. Critique of liberalism & $\begin{array}{l}\text { Racism is a prevalent and } \\
\text { permanent reality in our } \\
\text { society. }\end{array}$ \\
\hline 3. Interest convergence & $\begin{array}{l}\text { Neo-liberal views suggest } \\
\text { that we live in a post-racist } \\
\text { society. This colorblind } \\
\text { ideology is harmful to } \\
\text { communities of color. }\end{array}$ \\
\hline 4. Social justice & $\begin{array}{l}\text { Policy is created and } \\
\text { maintained that benefits the } \\
\text { dominant class. }\end{array}$ \\
\hline $\begin{array}{l}\text { We are responsible for } \\
\text { working towards equity } \\
\text { within situations of } \\
\text { inequitable distribution of } \\
\text { power and resources. }\end{array}$ \\
\hline
\end{tabular}


5. Counternarratives There is power to change in the counternarratives of people of color.

Most notably, critical race theorists acknowledge the perniciousness of racism (Banning, 1999; Delgado, 1995; Ladson-Billings \& Tate, 1995; Villenas, Deyhle, \& Parker, 1999). Common practices and perspectives, values and beliefs belong to the dominant group — that is, White middle class. Thus, dominant ideology is normalized, and deviance is labeled problematic, an issue that needs to be fixed (Howard, 2014). Because White middle- and upper-class culture is the proverbial water for fish, neglect of those outside the norm is often left unacknowledged, or dys-conscious (King, 1991; Taylor, 1999). The cycle, then, is born, as unconscious (or dys-concious) racism begets racism (King, 1991).

Another important CRT principle is the critique of liberalism, which suggests that society is fair and egalitarian, and that citizens rise and fall as a direct result of their own merits (Gillborn, 2005; Travino, Harris, \& Wallace, 2008; Zamudio, Russell, Rios, \& Bridgeman, 2011). Howard (2014) suggests that "race still remains one of the least understood, yet most provocative and divisive, elements in our society” (p. 51); however, our society often fails to engage in significant, honest dialogues about race. In fact, this popular neo-conservative perspective argues that in present society, race no longer holds enough weight to influence lives (Gillborn, 2005; Travino, Harris, \& Wallace, 2008). In short, colorblind. Alternatively, critical race theorists are ever-wary of neutrality, and see the potential harm in colorblindness as it trivializes individual 
voices who tell of pain and frustration (DeCuir \& Dixon, 2004; Ladson-Billings \& Tate, 1995)

The third CRT tenet is interest convergence, or belief that creation and maintenance of polities are motivated by the interest of the dominant group (Gillborn, 2005; Ladson-Billings \& Tate, 1995; Taylor, 1999). This tenet suggests that reform to policies affecting people of color actually benefit those of the dominant class (Taylor, 1999). Using this lens, educational professionals can reinterpret civil rights laws, understanding that civil rights laws either created new opportunities, or sustained old, that benefitted White students at a greater rate than the communities of color for whom gain was touted (Ladson-Billings \& Tate, 1995). For example, the 1954 landmark case Brown v. Board of Education of Topeka that resulted in desegregation of schools was grossly misused, and employed discriminatory bussing and tracking practices. The result was personal injustices and oppression for communities of color (Bireda, 2011; Ladson-Billings \& Tate, 1995).

Critical race theorists believe that there is a group of people that are excluded from the benefits that our society offers—-life, liberty and the pursuit of happiness are privileges saved only for a few (Howard, 2014). Theorists such as Hackman (2005) contend that it is a social responsibility to work towards empowerment of the marginalized and equal distribution of resources. Change begins with a critical examination of structures that disenfranchise various groups and works towards transformation of power relationships (Creswell, 1998; Delgado, 1995). In the case of educational research, critical race theory suggests that educational professionals must 
look beyond the false comfort that is found in diversity and multiculturalism, and pay careful attention to the power structures that give rise to social inequality (Hackman, 2005).

The last tenant of CRT is that the experiential knowledge of people of color is a legitimate inquiry tool for analyzing and challenging dominant discourse (Delgado, 1995; Howard, 2014; Ladson-Billings \& Tate, 1995). Counternarratives are stories from people of color that contradict mainstream discourse. Using voices of traditionally marginalized people offers important insight, reporting individual experiences and reflecting existing social and structural realities from a unique lens (Bell, 2003; Moore, 2011; Roberts, Bell, \& Murphey, 2008). Ladson-Billings and Tate (1995) posit that counternarratives can be used as a powerful tool to call attention to racial oppression and injustices, as well as highlight the inequities found in normative discourse. Hence, critical race theorists employ narratives as a methodological tool, employing in-depth interviews, focus groups, and journal writing, and prioritizing voices of the participants (Howard, 2014). As a result of situating this inquiry in CRT framework, this study aimed to challenge prevalent normative discourses, focus on the experiences of Black and Biracial students, and work towards transformation of structural and institutional inequities (Ladson-Billings \& Tate, 1995; Smith-Maddox \& Salzano, 2002).

\section{Whiteness}

A newer subset of critical race theory is critical White theory, suggests that Whiteness is a social and political construct that affects the lived experiences of both White people and people of color (Helm, 1984; Jay, 2005; Wise, 2008). While the effect 
that Whiteness has on a person is context specific, and dependent on gender, sexual orientation, socioeconomic status, and a multitude of other factors (Jay, 2005).

Furthermore, those in the White community (like people of other races) go through a series of stages in the development of their racial identity (Helms, 1984).

Often conversations about racial diversity focus on the disadvantages of people of color or the ways in which all people can benefit from racial inclusivity. Omitted from these conversations is an analysis of White privilege, or the benefits that Whites receive as a result of their being born into a system that is set up for them (Wise, 2008). Because White privilege affects all individuals and our relationships, it should take a central part of racial dialogue. Clearly not all members of the White community are rich or free from misfortunes; however, they are privileged in ways such as: normalcy, assumption of innocence, and freedom from the need to disprove negative stereotypes (Cabrera, 2012; MacFarlane, 2008; Wise, 2008).

In Revealing Whiteness, Sullivan (2006) uses the metaphor of a habit to understand White privilege. As a habit, White privilege goes largely unnoticed by those that benefit from it the most (Sullivan, 2006; Wise, 2008). In fact, White people commonly deny privilege, inadvertently perpetuating systemic oppression of other racial groups simply because they deny that it exists in the first place (Sullivan, 2006; White, 2013; Wise, 2008). In other words, an unwillingness to confront White privilege invites further marginalization of communities of color by erroneously suggesting that the playing field is even (Sullivan, 2006; White, 2013; Wise, 2008). 
As within society as a whole, White privilege is thoroughly ingrained in our education system and the interpretations and assumptions thereof allows for the reproduction of social hierarchies in schools (Toshalis, 2014). For example, punitive measures are disproportionally doled out to students of color (Toshalis, 2014; Townsend, 2000), poor performance may be thought to be a product of "dysfunctional” families, and many teachers carry an ideology of inferiority for students of color (White, 2013). High-stakes testing, underfunded schools, inadequately trained teachers, zerotolerance policies, and the "school to prison" pipeline are other manifestations of White privilege playing out within our education system (Howard, 2014). Furthermore, the Eurocentric curriculum is often touted as being multicultural if there is a smattering of diverse "foods, fabrics, and festivals" thrown in (Cabrera, 2012, p. 19). (Think of the “diversity days” and other such festivals that you encountered during your schooling.)

Often the most dedicated antiracist teacher inadvertently reinforces racism though his/her actions, reactions, and presentation of the curriculum (Denevi, 2004; Wise, 2008; White, 2013). Left unchecked, teacher bias creates harmful learning situations for students of color (Toshalis, 2014). Often despite efforts to create safe environments for diverse groups of students, teachers often do not understand what it means to be antiracist (Denevi, 2004).

However, schools (and society, really) could and should be safe places where students can analyze and develop a critical stance towards racial issues (Denevi, 2004; Cabrera, 2012). The question, then, is what can a White person do? In the pursuit of racial justice, those in the White community must tread lightly. Inherent in the White 
antiracist's fight is the tension that arises from doing work to correct the problem, while also possibly contributing to it (Cabrera, 2012; Wise, 2008). Can a person who inherently benefits from privileges contribute to the resistance of those privileges? Freire (2000) argues that people of the privileged class are limited in the roles they can play in collective action because "the oppressor, who is himself dehumanized because he dehumanizes others, is unable to lead the struggle” (p. 47). Without knowledge of systemic, tacit racism, White liberals may mistake individual kindness with equity (Staiger, 2004; Sullivan, 2006; Wise, 2008). They may mistakenly assume that if they do not exhibit obvious racist behaviors, then racism must not be a problem.

Even those White antiracists who understand the larger nature of racism may inadvertently commit gross faux pas by suggesting that they can "fix this problem" (Cabrera, 2012; Wise, 2008). The struggle for racial justice is a long battle, and it is insulting to those who have fought before to adopt the attitude that this is a problem to be fixed by White people. The savior, or missionary, stance is disrespectful and illinformed (Cabrera, 2012). Instead, it is more beneficial and respectful for White antiracists to adopt the position of ally, campaigning against injustice alongside people of color (Cabrera, 2012).

Unlike Friere, some researchers (Cabrera, 2012; Wise, 2008) suggest that it is fully possible for Whites to contribute to antiracist efforts. The process begins with racial cognizance, stemming from self-reflection and education (White, 2013). Interracial connections and courses that require students to encounter and analyze critical justice issues are especially important in this process (Cabrera, 2013; White, 
2013). Those White allies who are careful in their approach do not have an easy task. Researchers cite a significant lack of white antiracist role models, feelings of fear and guilt, and disapproval from friends and family members as problems that will arise as Whites join the antiracist movement (Wise, 2008; Cabrera, 2013).

In all, though the path may be difficult, most of the literature is hopeful for White people who want to understand and work against the effects of White privilege. Through careful consideration of actions and much self-reflection, as well as a certain amount of confidence and tenacity, it is possible for White folks to avoid recreating oppressive situations and work for real change (Cabrera, 2012; Wise, 2008). "If we can inject enough self-consciousness and doubt into the minds of those who engage in racist behavior, we make it harder for such persons to practice it. And without practicing racism, they may just stop utilizing it altogether” (Wise, 2008, p. 106).

\section{Gifted Education}

Following discussions of critical race theory and the historical impact of Whiteness, a review of the literature on gifted education could be interpreted as contradictory. However, while debate abounds regarding the label talented and gifted (Borland, 2003; Renzulli \& Reis, 1997; Sapon-Shevin, 2003), scientific evidence not only points to the difference of cognitive, creative, social, and emotional rates of development (Gallagher, 2000; Thompson \& Oehlert, 2010; VanTassel- Baska, 2003), but also refutes any sort of grounds on which racial bias within the field is claimed (Ford, 1996, 1998, 2004; VanTassel-Baska, 2003; Sapon-Shevin, 2003). Nevertheless, labels and connotations must be accounted for and handled delicately. Therefore, the 
following section discusses gifted students as those who have ability (usually cognitive and academic, but also high levels of creativity and leadership could be included) that surpasses that of their same-age peers. As the field of education currently stands, I believe that talented and gifted youth are best served with differentiated programs and curricula that allow them to learn at their own pace, maintain autonomy in their learning, and see the value of their curiosity and potential (Renzulli \& Renzulli, 2010; VanTassel Baska, 2003).

The cognitive and academic needs of gifted students are enduring; however, gifted education programs and policies are susceptible to the ebbs and flows of politics and at the whim of public opinion (Jolly, 2009). In 1920, Therman and Hollingsworth conceptualized gifted education, and since then it has seen inconsistent spikes in popularity, peaking during political events such as the Cold War and left to the whims of the ever changing priorities of the country (Gallagher, 1988). For example, when Russia’s launch of Sputnik in 1957 a new sense of urgency for America to be competitive on an international level was instilled and the importance of gifted education was seen in an increase in money and training within the field (National Association for Gifted Children [NAGC], (2008). This sense of urgency was renewed in the 1970s with the Marland Report, and again in 1983 in response to the document $A$ Nation Deceived (NAGC, 2008). Each of these major U.S. events increased the popularity of gifted education based on the needs of the country.

Nevertheless, interest in gifted education inevitably wanes, and concern for advanced learners is replaced by an emphasis on standardized education and high stakes 
testing (Clark, 1997; Cohen, 1996). Standardization of education is unsuitable for meeting the needs of gifted students because the focus of educational professionals shifts to bringing the lower achieving students up (Fordham Institute, 2013). In fact, 81 percent of teachers report that low achieving students receive the most attention and the highest priority in their classrooms (Fordham Institute, 2013). Often, the pressure of high stakes testing requirements lead to the common sentiment among educational professionals that gifted students will learn anyway (Fisher-Doiron \& Irvine, 2009).

Current challenges in gifted education. Due to varying national priorities, public attitude towards gifted education is ambiguous and fickle (Gallagher, 1988; Jolly, 2009). Yet another cause of the inconsistencies surrounding the field is fragmented policies within the field itself. As mentioned in chapter one, federal legislation regarding gifted students is minimal, which relegates decision-making to state and local levels (Irvine, 1991). Although there is a suggested federal definition of giftedness, it is not required at the state and local levels, which leads to obscurity surrounding even the concept of giftedness as a whole. The result is, at best, fragmented educational experiences for gifted students, and at worst, maltreatment of the educational experiences of the gifted student (Howard, 2002). So much so that the National Association of Gifted Children (2011) reports that only sixteen states in America require their districts to accept gifted education decisions from other states. Consequently, students who receive gifted services in one state may not be eligible in another.

While inconsistencies across states in programming and assessment create obvious challenges for gifted education, lack of funding for gifted education is another 
problem faced by those in the field. Marshall and Gerstil-Pepin (2004) report that 50 percent or more of educational funding is provided by local taxes, sponsorships, and fundraising. While local and state school boards have control over budgets, most states face fiscal crises requiring prioritization of the most pressing issue of the time- - such as those students who are allegedly performing under grade level—rather than those issues that are seemingly not as urgent, but may have equal long term ramifications (Marshall \& Gerstl-Pepin, 2004). In fact, a biannual report from the National Association of Gifted Children (2008) reports that of the 36 states that keep data on gifted students, ten provide no funding.

Gifted education in Oregon. In Oregon, gifted services have been mandated since 1987 (Task Force on the Instruction of Gifted and Talented Children, 2012). In fact, the law states that "school districts shall provide educational programs or services to talented and gifted students enrolled in public schools” In the last 25 years, Oregon haltingly implemented talented and gifted education identification and programming. At one time state-supported grants for gifted education were available at approximately $\$ 200,000$ for six regional planning groups at state universities. That funding is no longer available (Davidson Institute for Talent Development, 2013). Oregon has not funded talented and gifted education to districts since 2004, making the state one of the ten that provides no funding for gifted education (Task Force on the Instruction of Gifted and Talented Children, 2012).

The paradox. Gifted education lives in a paradoxical state. On the one hand, supporters of gifted education such as Preckel, Gotz, and Frenzel (2010), Rogers (2007), 
and Shields (2002) argue that despite inequalities, gifted programs are essential because denying gifted learners services that meet their needs creates unjust educational experiences. Without gifted programs, students with high levels of cognition, creativity, and/or leadership may have needs that are left unmet by their academic experience (Ford, 1994, 1996). On the other hand, researchers such as Cross (2003), Perry, Steele, and Hilliard (2003), Sapon-Shevin (2003) maintain that despite significant research suggesting a lack of correlation between race and intelligence, creativity, and leadership, gifted programs disproportionately offer opportunities to upper- and middle-class White children.

Agreeing with the latter, Borland (2003) suggests that the very essence of giftedness is a means of perpetuating oppressive power. Relying heavily on the work of Foucault, Borland (2003) argues that current assumptions about giftedness are misguided and value-laden and an attempt to control populations of students. In concession with Foucault, Borland (2003) suggests that quantifying and ranking students in terms of intelligence perpetuates the power position of the dominant class by preventing historically marginalized students from receiving opportunities to work to their potential. Further, Borland suggests that gifted education sends implicit messages of inferiority to those students who have not been tested into gifted.

On the other hand, Gallagher (1996) poses the question, "is it truly inequitable for some people to do what most of us cannot?” (p. 244). He goes on to use the example of a Vonnegut (1968( short story in which people who run faster than others are required to wear sandbags on their feet, and people who are better looking wear masks so as not 
to demoralize the rest of the community. Certainly equity is not reached when high-end learners are not given opportunity to develop their talent (Renzulli \& Renzulli, 2010). Schools and programs that value the education of gifted students, such as the Davidson Institute, are recognizing the needs of gifted students to accelerate at their own rate, be grouped according to competency, not age, and nurture the talent that gifted students exhibit (Davidson \& Davidson, 2004). Proponents of gifted education programs argue that equity of opportunity (giving all students the opportunity to grow and realize their potential) requires that gifted students, as much as any other group of students, should be offered differentiated curriculum that speaks to their needs (Gallagher, 2000).

As a whole, current ideologies in gifted education are paradoxical. Inequities are created if gifted services are not provided because students with special academic needs are not being met (Preckel, Gotz, \& Frenzel, 2010; Rogers, 2007; Shields, 2002). However, inequities are also created if gifted services are provided, as they continue to overwhelmingly support the needs of those students who subscribe to the dominant norms at a much higher rate than those historically marginalized students (Ford, 1994, 1996, 1998, 2003; Ford \& Harris, 1999; Harmon, 2001).

\section{Gifted Students}

To further explore the controversy surrounding gifted education, consider some researchers (Borland, 2003, 1997; Renzulli \& Reis, 1997; Sapon-Shevin, 2003) doubt the effectiveness of labeling students "gifted learners." Sapon-Shevin (2003) suggest that the label gifted is an unnecessary construct, and argue that it is not useful or beneficial for the field of education; she argues that all students should be treated as 
gifted and presented with curricula that is challenging and creative. Renzulli and Reis (1997) posit that individuals are not gifted, and instead giftedness should be discussed as behaviors. In other words, Renzulli and Reis (1997) believe that giftedness is an action, not a state of being.

Admittedly, the label is problematic and the researchers above make strong arguments. However, it is hard to deny that different people develop at different rates (Gallagher, 2000; Thompson \& Oehlert, 2010; VanTassel Baska, 2003). The reasonsbiological or environmental—behind this discrepancy of development will be left to another discussion. What is important for this study is that because there are differences in abilities, it is logical to assume that there are those students whose ability surpasses that of their peers. Further, students with higher levels of ability benefit from academic situations that are responsive to their advanced learning needs (Gallagher, 1996, 2000; King, Kozleski, \& Lansdowne, 2009; Thompson \& Oehlert, 2010). In all, giftedness is not an essence—something fixed—but it is also not an illusion—something to be disregarded (Borland, 2003; Gallagher, 1988).

An important study by Alexander, O’Boyle, and Benbow (1996) demonstrates that those students who have high levels of cognitive functioning may need unique educational opportunities such as gifted programs. These researchers measured the activity of the frontal lobe in thirty adolescents who were tested into the gifted programs at their schools, thirty "non-gifted" adolescents, and thirty college students when given a series of cognitive tasks. The adolescents who were tested into gifted programs demonstrated frontal lobe activity that was more similar to the college students' than to 
that of their same-age peers, indicating that some learners are more developed than others. Consequently, these learners will be referred to throughout this paper as gifted students.

Likewise, researchers such as Gallagher (2000) and Feldhusen (2003) posit that the entity of the gifted student can be explained by the phenomenon of prodigies and savants. These extreme and remarkable cases make it difficult to deny the versatility in aptitude among learners. In sum, the assertions made regarding differences in cognitive abilities lead to the assumption that gifted students, as controversial and misinterpreted as the label may be, are a group of students whose educational needs must be met.

\section{Gifted Students of Color}

Gifted Black and Biracial students often experience high levels of stress because of the duality of being a student of color in a racialized society combined with having the

talented and gifted label

Figure 2. Internal and External Factors Affecting Black and Biracial Gifted Students

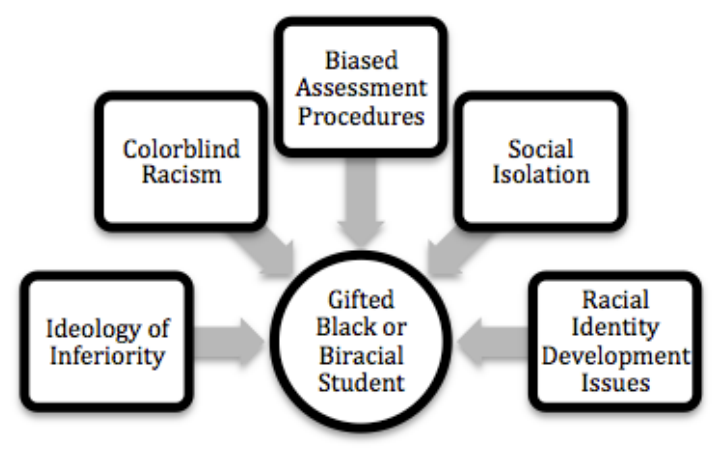

(Conchas, 2006; Ford, 1994,

1996, 1998, 2003; Ford,

Grantham, \& Whiting, 2008; Ford

\& Harris, 1999; Ford, Harris, \&

Schurger, 1993; Ford \& Whiting, 2010). In all likelihood, these

students possess characteristics common among all gifted students—average observation, intense interests, excellent reason skills, heightened sensitivity, interest in social and philosophical issues (Thurston, 2002). 
Additionally, they frequently are exposed to internal and external factors, as seen in Figure 2, that may contribute to a loss of their sense of cognitive, social, and affective wellbeing (Harmon, 2001; Ford, Harris, \& Schuerger, 1993; Morris, 2001).

External factors that affect gifted students of color. Epistemologically, two main ideologies are in place that perpetuate marginalization of gifted students of color and maintain power for the dominant group. The ideology of inferiority and colorblind racism will be discussed in the upcoming section, as well as how they show up in gifted education. Each of these worldviews acts as a force that is working against gifted students of color (Morris, 2001).

Ideology of inferiority. For this research study, race is defined as (1) a social construct, (2) consequential in the lives of all people, but especially impactful in the lives of marginalized groups, and (3) a political force that maintains that power and the resources of European-Americans (Brayboy, Castango, \& Maughan, 2007; Gravelee, 2009; Ladson-Billings \& Tate, 1995; Mipoori, 2012; Omi \& Winant, 1994; West, 2001). Thus, negative ideologies attached to certain racial groups are deeply engrained (Blakely, 1999; Ladson-Billings \& Tate, 1995; Omi \& Winant, 1996). Additionally, misinformation about the link between biology and race combined with the lack of clarity surrounding the concept of intelligence has resulted in a belief that race is a determiner of intellectual inferiority and superiority (Dennis, 1995; Perry, 2003). Three notable research studies, Jensen (1969), Sumner (1963), and Herrnstein and Murray (1994), used pseudoscientific methods and spurious assumptions to report differences in intellectual ability between races. These studies helped to establish an ideology of 
inferiority regarding the cognitive functioning of Blacks.

Jensen’s (1969) controversial study argues that not only are genetic racial differences "undoubtedly true” (p. 49), but that the average intelligence of Black people is one standard deviation below that of the average White population's IQs. Jensen argues that because the environment cannot assume sole responsibility for cognitive development, and because there is a genetic component to IQ, it is logical to suppose that genetics plays a role in the difference of IQ between Blacks and Whites (1969). Jensen (1969) is not alone in his theory that links race and human ability. Sumner (1963) maintained that because all people are born on equal footing, those with enough ability, motivation, and prudence will emerge as leaders, leaving othersspecifically African Americans-in inferior positions. Using pseudoscientific methods and fallible logic to argue for the superiority of the White dominant culture, the theories presented by Jensen and Sumner impacted current ideology regarding intellectuality and race, and led to scientific racism and eugenics.

Both Jensen (1969) and Sumner (1963) were influential in perpetuating, if not fabricating, conversation regarding inferiority and superiority between races. Unfortunately this line of thinking was not eliminated by the Civil Rights Movement or by the continued efforts of researchers and equity groups across the county. In fact, recently Herrnstein and Murray (1994) revived the idea that on average Black people’s IQ is lower than Whites'. Using findings from past research studies, Herrnstein and Murray argued that the average IQ of African Americans is 16 points lower than that of White Americans. 
While Jensen (1969), Sumner (1963), and Herrnstein and Murray (1994) used their findings to legitimize the intellectual inferiority of Blacks, all of the studies contain blatant inaccuracies (Morris, 2001). First, Herrnstein and Murray (1994) state that general intelligence is "beyond significant technical dispute” (p. 22). However, it is widely recognized that intelligence is complex and controversial, and that IQ assessments are inadequate in capturing significant dimensions of human capacity (Borland, 1997, 2003, 2009; Callahan \& Elchner, 2008; Feldman, 2003; Ford, 1998; Gallagher, 2000; Morris, 2001; Perry, Steele, \& Hilliard, 2002; Renzulli, 1986). Moreover, each of these researchers suggested that race is biological, which has been disproven by current literature. In short, Herrstein and Murrary (1994), Jensen (1969), and Sumner (1963) have delegitimize their findings in two important ways: first, they assume that race is biological, and second, they rely on a definition of intelligence as innate, static, and adequately measured by IQ tests.

Although the studies above may have succeeded in creating and maintaining the ideology of inferiority towards the intelligence of Black students, it is important to note that for many decades, researchers (e.g., Blakley, 1999; Bodmer \& Cavalli-Sforza, 1970) worked to combat incorrect messages regarding race and intelligence. As early as 1924, Mann spoke of intelligence tests as propaganda (Jolly, 2009), and in 1970, Bodmer and Cavalli-Sforza, geneticists argued against the correlation between IQ scores and race on the grounds that IQ tests are dependent on the culture of those whom they are designed to test. More recently, scholars such as Fish (2002) and Ogbu (2004), and many others have also concluded that there is no correlation between race and intelligence. 
Presently the lack of correlation between race and intelligence should be standard knowledge. However, despite the obvious flaws in assigning a relationship between race and intelligence, the ideology of inferiority towards African Americans' intellect remains intact (Bireda, 2011; Blakely, 1999; Perry, 2003). Questioning the cognitive capabilities of Black people is not only the norm in society, but it is subtle, influencing actions and reactions towards people of color, even among the most well-intentioned people (Perry, Steele, \& Hilliard, 2003; Perry, 2003). In fact, research suggests that within schools, Black students are evaluated based on the degree to which they embrace dominant cultural codes, and adhere to White European educational values (e.g., sitting in a row, raising ones had before speaking, using standard English dialect) often at the expense of a clear and accurate evaluation of their intellect (Carter, 2006).

The ideology of intellectual inferiority of Blacks continues to permeate gifted education (Ford, 1998; Ladson-Billings, 2010; Morris, 2001; Perry, Hilliard, \& Steele, 2003). At the institutional level, the overreliance on standardized measures and nomination processes that are based on normative educational behaviors creates inequities in the recruitment process for gifted programs (Ford, 1996; Ford \& Harris, 1999; Naglieri \& Ford, 2003). At the personal level, teachers often hold lower expectations for their Black students than they do for their Asian American and White students, even when they are labeled gifted and talented (Ford, 1998; Ford, Grantham, \& Whiting, 2008; Moore, Ford, \& Milner, 2005). In a study of gifted students of color who attended a predominantly White gifted school, Harmon (2002) asserts that gifted students of color often perceive White teachers as ineffective, and a common sentiment 
held among the gifted students of color that participated in the study is that "they won't teach us” (p. 72).

Colorblind racism. Like the ideology of inferiority, colorblind racism is a major challenge faced by gifted students of color (Morris, 2001). Colorblind ideology, also referred to as laissez-faire racism, and suggests that the attributes of an individual alone occasion his/her successes or failures (Ladson-Billings \& Tate, 1995; Lucas \& Beresford, 2010; McArdle, 2008; Mipoori, 2012; Tarca, 2005; Williams \& Land, 2006). While colorblindness is promoted by some as an equalizing power and a way to realize democratic ideals and end discrimination, it is problematic in its omission of the impact of race on one’s experience (Bonilla-Silva, 2003; Brayboy, Castango, \& Maughan, 2007; Carr, 1997).

Critics of colorblind ideology suggest that by adopting this worldview, advantages of the dominant class are overlooked (Carr, 1997; Tarca, 2005). Although Whites often receive benefits simply by being members of the dominant race, colorblind worldview allows privilege to remain unchecked and embraces the idea that Americans are on equal ground, and that individuals will succeed or fail based on their own merits or weakness (Bonilla-Silva, 2003; McArdle, 2008; McIntosh, 1990). With policies, procedures, and curricula bound by Eurocentric ideals, school systems give off the impression that White students succeed on their own merit, while Black and Biracial students are deficient (Brayboy, Castango, \& Maughan, 2007).

Commonly, the implication of colorblind racism is that because race cannot be held responsible for societal inequalities, other dynamics in a person's life are (Bonilla- 
Silva, 2003). Because this ideology fails to recognize structural racism as a force that marginalizes people based on group membership, and disregards the additional challenges faced by culturally, linguistically, and ethnically diverse people, it implies that successes and failures are equally easy to obtain for any individual, despite his/her association with a particular racial group (Tarca, 2005). Colorblind racism suggests that since discrimination is not the cause of racial inequality, people of color are to blame (Desai, 2010).

Moreover, those who subscribe to colorblind ideals eliminate race from discourse and research (Brayboy, Castango, \& Maughan, 2007). As a result, people of color and social justice advocates lack a language to communicate their racialized experiences. By resisting attempts to address race, disproportionality in some facets of American society—housing, socioeconomic, academic — are attributed to the individual (Tarca, 2005). In the field of education, a teacher who declares that he/she does not see race in his/her classroom eliminates racial discourse as a means for understanding the impact of race on students (Williams \& Land, 2006). Often removing race from the conversation is done with the best intentions, and popular belief is that race-related conversations are disrespectful. Commonly, people report that they do not see color; however, in doing so, they eliminate opportunities for rich conversations about race that could lead to greater understanding and equality (Tarca, 2005).

In the field of education, colorblind racism can be seen in the system's "reliance on testing, a focus on education as a vehicle for placing persons into jobs, the global competition and international hierarchy of education prowess, mechanisms of 
standardization in education exemplified by No Child Left Behind Act, and an ideology of underserving poor in which individuals end up where they should” (Lucas \& Beresford, 2010, p. 58). Black students are disempowered by colorblind ideology because they are left without a frame of reference that can be to understand structural racism and resist its effects on their educational experiences (Desai, 2010; Williams \& Land, 2006).

Gifted education, as it currently stands, is both the result of colorblind racism and the perpetuation of this ideology. In gifted education, common meritocratic procedures are evident in the referral process and in identification procedures that are bent towards normative culture and the reliance on teacher recommendations that may be unchecked in regards to bias (King, Kozleski, \& Lansdowne, 2009). As a result, White students often have an unspoken advantage throughout the assessment process over students of color (Ford, 1994, 1996, 1998, 2003). Further, colorblind ideology is often seen in gifted programs and classrooms as teacher naïveté towards structural racism and unique needs of diverse students may lead to low teacher expectations, prejudice, and even disrespect towards gifted students of color (Harmon, 2001; Moore, Ford, \& Milner, 2005). To perpetuate colorblind racism in gifted programs, gifted students often internalize negative reactions from teachers as legitimate indicators of their propensity to learn (Moore, Ford, \& Milner, 2005).

Biased assessment procedures. Much of the reason that gifted students of color find themselves in PWGS can be attributed to common referral and testing procedures that are used to identify gifted students (Baker, 2005; Bodmer and Cavalli-Sforza, 1970; 
Ford, 1998; Kitano, 2003; Naglieri \& Ford, 2003; Perry, Steele, \& Hilliard, 2003). The National Association of Gifted Students (2012) reports that 49 states use some form of the IQ test as an indicator of giftedness. However, according to Callahan \& Elchner (2010), gifted education professionals agree that intelligence is multifaceted and complex, and cannot be adequately accounted for by using an IQ test. Further, because IQ tests—even nonverbal intelligence tests—require some form of recall of background knowledge, those students with experience in dominant norms have an advantage over other students (Baker, 2005). Towards the end of this chapter, I will discuss the benefits of alternate assessments such as portfolios or multiple criteria placement procedures that are being adopted by some discerning districts with great success. However, it is important to note that the majority of districts continue to rely on archaic measurements and procedures often at the detriment of bright Black students (Ford, 1994, 1996, 1998, 2003).

Internal factors that affect gifted Black and Biracial students. The previous section discussed paradigms — colorblind racism and institutional racism—-that are largely responsible for inequities in gifted education. Consequently, gifted Black and Biracial students who participate in gifted programs face unique social and psychological challenges (Andrews, 2012; Briggs, Reis, \& Sullivan, 2008; Callahan, 2005; Cohen, 1996; Ford, 1996, 1998; Sapon-Sheven, 1994). This section reviews the literature that focuses on the individual, exploring the impact of colorblindness and institutional racism on gifted students of color. Researchers such as Van Tassal-Baska (2003), Ford (1996), and Frye and Vogt (2010) posit that gifted students in general are 
more sensitive and have a heightened ability to pick up on subtleties, draw conclusions, and see relationships in words and actions that they experience. As a result, gifted Black and Biracial students are often quick to understand the discrimination and injustice that they encounter (Harmon, 2001). Moore, Ford, and Milner (2005) report that, “noncognitive variables fundamentally influence the achievement and motivation of African American students in gifted programs” (p. 62). Social and emotional challenges, as well as racial identity development issues, may impact gifted students of color at higher rates than (a) Black students who are not identified as gifted, and (b) their White gifted counterparts (Duncan \& McCoy, 2007; Ford, 1994, 1996, 1998; Grantham \& Ford, 2003).

The following section is a synthesis on the social and emotional challenges that are faced by gifted students of color. Specifically, the theory of acting White (Fordham \& Ogbu, 1986) and Othering will be discussed, as the literature reports that these two phenomena lead to social isolation for gifted students of color (Baker, 2005; Chikkatur, 2012; Conchas, 2006; King, Kozleski, \& Lansdowne, 2009). Further, racial identity will be explored because this important aspect of a young Black student's life is often in a precarious state as the student navigates a predominantly White school (Andrews, 2012; Foster, 2005).

Isolation from peers. Social acceptance and peer support are essential to the healthy educational experience of gifted students of color (Ford, Harris, \& Schuerger, 1993; Fryer, 2006; Moore, Ford, \& Milner, 2005). Unfortunately, according to researchers such as Ford, Gratham, and Whiting (2008), Huff, Houskamp, Watkins, 
Stanton, and Tavegia (2005), and Ford (1998), gifted students of color often report feelings of social isolation and alienation, often believing that they have to neglect aspects of their identity.

Acting White. Ogbu's theory of oppositional culture (1981) has played an important, albeit controversial, role in the ongoing discussion of the social isolation that Black and Biracial students may face. The theory begins with a differentiation of voluntary and involuntary minorities (Ogbu, 1995i, 1995ii). Black and brown communities are categorized as involuntary minorities, as they were originally brought to the United States against their will, as opposed to voluntary minorities such as Asian Americans who Ogbu believed came to the United States seeking opportunity. (Ogbu is of African descent, and makes the distinction that Africans whose ancestors were not enslaved by Europeans are actually voluntary minorities, meaning that they came to the United States looking for opportunity or a better way of life.)

According to Ogbu (1981, 1995i, 1995ii, 1998), involuntary minorities, especially members of the Black community, suffer oppression at the hands of the dominant class, and eventually develop their cultural identity in opposition to them. In other words, the Black community adopts behaviors and views that are un-white because any behavior that is White could very well be one that is detrimental to their race. According to the theory, the Black community is focused —and finds strength in— behaviors that define a person’s Blackness (1998). Membership in the Black community is an important aspect in the development of identity, and Ogbu (1995i) argues that these 
groups are emotionally charged and expect loyalty from members in the form of acceptable behaviors.

In 1986, Fordham and Ogbu, armed with the oppositional cultural theory, completed a case study at “Capital High,” a predominantly Black high school outside of Washington D.C.. The findings of the study indicate that academic achievement is a behavior that is associated with Eurocentric ideals, and therefore is resisted by Black and Brown students. Further, Fordham and Ogbu (1986) suggest that Black children who were academically motivated, enrolled in gifted and advanced placement (AP) courses, and overall succeeding in school are often met with accusations of acting White, or taking on Eurocentric behaviors. The theory further suggests that high achieving Black students down play their intelligence in order to avoid ridicule and isolation from their peers (Fordham \& Ogbu, 1986).

The acting White theory has been the topic of much debate since its publication. Most convincingly, critics of the theory suggest that not all Black and Brown students disengage, develop oppositional identities, or resist academic success (Akom, 2008; Andrews, 2012; Carter, 2005; Lundy, 2003; Perry, Steele, \& Hilliard, 2003). In fact, many Black students cultivate healthy psychological resistance to racism in schools, and maintain both school success and a positive racial identity (Akom, 2008; Andrews, 2012; Carter, 2005). Howard (2014) reports that while Black students recognize the existence acting White, they perceived it to be assimilation to norms of White culturedress, music, definition of success—rather than academic achievement. Further, assumptions that membership to Black community unquestionably leads to academic 
underachievement is a gross oversimplification of a complex issue, and places the responsibility on the shoulders of the student, disregarding structural forces that lead to inequities and marginalization (Akom, 2008; Lundy, 2003).

Yet another criticism of the acting White theory states that frequently only Black students’ peer group attitudes towards academic success was studied, not Whites' (Downey \& Ainsworth-Darnell, 2002). Within all groups of high achieving students, however, members experience hostility in the form of ridicule from lower-achieving peers regardless of race. These critics suggest that terms like "nerd" or "dork" are hurled at students throughout the school day without thought to race or culture (Downey \& Ainsworth-Darnell, 2002).

On the other hand, it has been a quarter of a century since Fordham and Ogbu (1986) published the findings from their study of Capitol High, and still many researchers (e.g., Moore, Ford, \& Milner, 2005) cite components of the acting White theory as one cause of social isolation of Black students. Fryer (2006) demonstrates the continued saliency of the acting White theory in the causal relationship he established between grade point average (GPA) and Black student popularity; the higher the GPA of a Black student, the lower his/her popularity among other Black students. Even President Obama referred to the need to "eradicate the slander that says that a Black youth with a book is acting white” (Keynote Address, Democratic National Convention, 2004).

In all, acting White is a theory wrought with problems mostly due to the oversimplification of the complex issue of Black students' social isolation (Andrews, 
2012; Akom, 2008; Perry, Steele, \& Hilliard, 2003). What is missing from the conversation is the normalization of White culture in classrooms and systemic racism that drives education policy, leading to marginalization of students of color (Lundy, 2003; Toshalis, 2014). What is often mistaken as opposition to academic success, could be rejection of assimilation to White norms (Akom, 2008).

Gifted education is the embodiment of the normalization of White culture (Ford, 1996; Ford, Grantham, \& Whiting, 2003). As previously mentioned policies that benefit White culture, and ideas about expectations that are rooted in the mainstream create classrooms where gifted Black and Brown students may be marginalized (Ford, 1998; VanTassel-Baska et. al, 2009). Without conscientious teachers and supportive parents, it is possible for gifted students of color to become withdrawn, depressed, or aggressive, and they may even underachieve academically (Frye \& Vogt, 2010; Moore, Ford, \& Milner, 2005).

Othering. Indeed, the possibility is great that gifted Black and Biracial students will experience stress, not only because of the potential loss of community, but also in relationship with White students and teachers within the school (Bireda, 2011; Conchas, 2006; Ford, Harris, \& Schuerger, 1993; Huff, et al. 2010; Tough, 2004). Othering is a term that was coined by Spivak (1985) and refers to the creation of unequal relationships based on dominance and submission (Garland \& Chakkraborti, 2006). While it is probable that White students and teachers do not intentionally Other Black and Biracial students who participate in gifted programs, research suggests that the gifted students of color feel different from their White peers, and report feeling misunderstood, isolated, 
and alienated, on the fringe of "the preps" or the students who prescribe to the dominant culture, often simply called "they” by gifted students of color (Neal-Barnett, Stadulis, Singer, Murray, \& Demmings, 2010; Tyson, Darity, \& Castellino, 2005). Further, they are cognizant of White superiority within the racial patterns within a school (Tyson, Darity, \& Castellino, 2005). Harmon (2001) reports that participants in her study "shared how hurt they felt when their White classmates would reject their attempts to become friends... or not acknowledge them or socialize with them outside of the classroom” (p. 71).

In sum, gifted students of color may experience challenges in regards to their social lives at the hands of their White peers and teachers, as well as within their own communities. As the next section elucidates, much of the current literature also points to challenges Gifted students of color, especially those who attend predominantly White schools, experience during the process of racial identity.

\section{Racial Identity}

Racial identity is defined by Grantham and Ford (2003) as "the extent to which people of color are aware of, understand, and value their racial background” (p. 20). It is important in the field of education because stages of racial identity development have been linked to academic achievement (Ford, Harris, \& Schuerger, 1993; Grantham \& Ford, 2003; Cross \& Vandiver, 2001). Moreover, racial identity affects Black students’ motivations, and attitudes, and is associated with social and psychological health of Black students (Fordham \& Ogbu, 1986; Grantham \& Ford, 2003; Rowley \& Moore, 2001; Moore, Ford, \& Milner, 2005). Researchers such as Conchas (2006) and 
Hensfield, Moore, and Wood (2008) posit that an unhealthy racial identity leads to low self-efficacy, self-esteem, and academic underachievement. On the other hand, healthy racial identity helps gifted Black and Biracial students deal with oppressive practices in schools and being in a constant state of the Other (Andrews, 2012; Carter, 2006; Ford, Harris, \& Schuerger, 1993).

Traditional perspectives on

Figure 3. Stages of Racial Identity Development

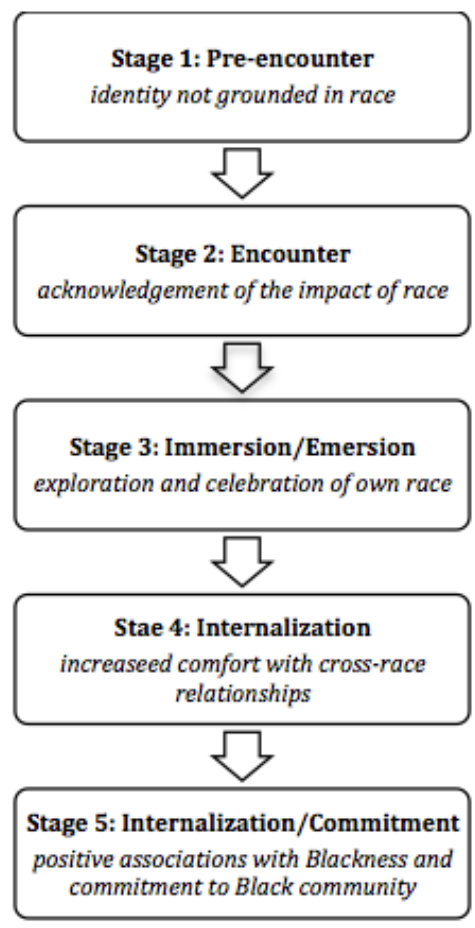
racial identity suggest that people go through a series of stages during their racial identity development, each one more discerning and healthy. Cross’ (1971) nigrescence, or the process of becoming Black, divides racial identity development, as shown in Figure 3, into five stages: preencounter, encounter, immersion/emersion, internalization, and internalization/commitment.

Stage one, pre-encounter, is a time when a Black person's identity is not grounded in race; his/her blackness is insignificant (Cross, 1994). Stage two, encounter, is brought about by events — sometimes negative — that jolt a person into acknowledging the importance of race in his/her life (Tatum, 1997). The immersion/emersion stage is an energetic, emotional time when Black students may explore their own history and 
culture, while speaking out against White culture (Cross, 1971). Stage four, internalization, is a stage marked by increase in comfort with cross-race relationships. Young people understand that they can be friends with people from other races and maintain strength in their own racial identity. Finally, internalization/commitment stage is a period in which Black students have positive associations with their race and commit to nurturing themselves as racial beings and maintaining confidence in their membership to the Black community (Cross, 1971).

However, identity is complex, and the question who am I? not only depends on messages from parents, peers, neighbors, teachers, and self, but also takes into account a myriad of categories with which a student may associate: gay, straight, athletic, with various physical and cognitive challenges, from a single-parent home, artistic, to name a few. While acknowledging the complexity of identity development as a whole, researchers (Andrews, 2012; Boykin \& Ellison, 1995; Grantham \& Ford, 2003; Harmon, 2002; Moore, Ford, \& Milner, 2005; Milner \& Ford, 2007; Rowley \& Moore, 2001) emphasize the importance for gifted students of color to maintain a healthy racial identity in order to achieve academically (Moore, Ford, \& Milner, 2005) and maintain positivity in the face of racism and prejudice (Andrews, 2012; Chikkatur, 2012).

Child development and racial identity. Racial identity is a process of discovering self as a racial being and is important in making sense of the world (Cross \& Cross, 2008). Researchers (Wright, 1998; Quintana, 2008; Quintana \& McKown, 2008) suggest that racial identity development of young children plays a role in child development and often aligns with Piagetian stages of development. Children move 
through a series of stages in which they begin to discover themselves as racial beings and become increasingly aware of racial categories and the connotations therein.

Between the ages of two and three, a stage that Piaget calls the preoperational stage, children begin to develop racial awareness (McAdoo, 2002). By preschool, children are able to categorize people into groups based on skin color (Wright, 1998). However, many preschool-aged children are misunderstood in their attempts to talk about race because at this point in their development they lack knowledge of connotations that adults use to make meaning of different racial groups (Hirschfeld, 2008). In fact, it is common among young children (up to the age of five) to believe that a person can change races and even that people of different races are "vanilla" or “chocolate” (Wright, 1998; Hirschfeld, 2008). However, it is important to note that while preschool-age children are not aware of the underlying meanings that are associated with race, they do use race as a tool to include and exclude classmates from their friend-group (Hirschfeld, 2008).

As children gain experience, they begin to understand that there is more to race than skin color (Wright, 1998). By the age of six, most children begin to understand connotations of racial categories, and around eight years old, children have developed an adult-like understanding of race, grasping connotations and subtleties. Pieget refers to this stage of child development as concrete operative. In discovering racial self, a child begins to make connections between self and culture, race, and the associated prejudice. During Piaget's concrete operative stage, many children show signs of internalized racism such as negative stereotypes and racism (Cross \& Cross, 2008). 
Parents of young children have an important role in the process of racial identity development (Cross \& Cross, 2002; Wright, 1998; McAdoo, 2002; Yip, 2008). The choice that a parent makes in emphasizing or de-emphasizing the importance of race is pivotal to how a child sees himself as a racial being (Cross \& Cross, 2008). It is entirely possible to raise a child with a healthy racial identity (Wright, 1998). However, a parent must acknowledge that young children do not view race with adult eyes and be wary of miscommunications as a result of parental misunderstanding child questions and declarations about their own and others’ race.

Research suggests that parents do well to provide opportunities for their children to engage with children of other races (Wright, 2008). Contact with members of other racial groups lowers prejudice because children are able to find commonalities with members of other groups and see them as individuals (McGlothin, Edmonds, \& Killen, 2008). Parents must also realize that they are one of the most prominent transmitters of stereotypes and work to curb these negative messages (Cross \& Cross, 2008).

Biracial identity development. The recent increase in the Biracial population in our country has done much to disrupt the dichotomy of White and people of color (Baxley, 2008; Brunsma, 2005). (While Biracial categories could be a combination of any two races, for the purposes of this study, Biracial is defined as identification with Black plus one other racial group.) It is becoming less and less simple to divide people into neat racial categories. Interracial couples and Biracial children are not a new phenomenon; however, historically the “one drop” rule required any person with as 
much as a drop of Black blood in him/her identify as Black (Baxley, 2008; Brunsma, 2005).

Biracial-ness illuminates the political nature of racial labels, as Biracial people may navigate the system, identifying themselves in ways that benefit them in a particular situation (Brunsma, 2005). For example, parents may choose to check the box on the demographic form that will get their students into the best schools and provide resources for their students (Moss \& Davis, 2008). By the year 2000, the U.S. Census allowed people to check more than one box for the first time, which made strides in alleviating stress associated with identifying with one racial category (Moss \& Davis, 2008). Because this phenomenon is still relatively new, however, there is a dearth of literature available that speaks to the impact the new recognition of multiple races on demographic forms has on the Biracial community.

Biracial young people may have unique issues to consider throughout their racial identity development and as a result, the support of thoughtful parents or caring adults is essential (Moss \& Davis, 2008). In order for children of interracial marriages to have positive experiences in their racial identity development, they must be allowed to explore all pertinent labels in a supportive home environment (Baxley, 2008). Parents who allow their children to choose to associate with the label that makes sense for them may contribute to the health of their child (Baxley, 2008). Likewise, parents who exhibit respect for both races, and model ways that children may identify with both also allow their children to reap the benefits of a rich racial identity (Moss \& Davis, 2008). 
Healthy racial identity issues go hand in hand with high self-esteem, as each promotes the other (Moss \& Davis, 2008).

Teachers also have the responsibility to promote healthy racial identity development for Biracial children (Baxley, 2008). Interracial couples have varying ways of dealing with this issue, teacher-parent communication is important, especially regarding the needs and norms of their family (Brunsma, 2005). Of course (as with other encounters with race in the classroom), teachers who are supportive of Biracial students examine their tacit understandings of race and the way that these understandings play out in their practice (Baxley, 2008; Moss \& Davis, 2008).

Identity development and Black middle class. No discussion about race is complete without considering the intersection of race and socioeconomic status. While many factors contribute to identity and impact experiences, opportunities, and material possessions (McFarlane, 2009). Recent data shows that one-third of Black students attend middle class schools and live in middle class neighborhoods despite the majority of conversations that lump Black students’ experience into one of lower class neighborhoods and poverty (Howard, 2014). Because it is important not to overgeneralize Black students’ experiences or make unfounded assumptions, the following section discusses the unique history and current issues felt by the Black middle class.

Black middle class exists relationally, as a category that is neither (a) White middle class, nor (b) Black poor (Prince, 2006). As members of the Black middle class negotiate their race within an economic framework, they often are met with questions of loyalty to 
the Black community—is it important, or even possible, to maintain ties with all members of their racial community, even those who differ in social class? (Martin, 2010).

The Black middle class originated during the enslavement of African Americans by European Americans (Roach, 2008). Superior class status was bestowed on Biracial children born of a White man and Black woman. The responsibilities of a slave and the relationship that he or she had with the White family also contributed to forming a hierarchy among them. Fast-forward to days of freedom, and the Black middle class was suddenly charged with forming an identity free from that which was offered to them by their owners.

Notable Black scholars emerged at this time, many with ideas of how to overcome oppression and raise the status of the African American community. For example, W.E.B DuBois challenged the Black community to rise above their marginalized position. To do so, DuBois suggested that the “Talented Tenth,” a group of exceptional men, prioritize education, community leadership, and politics to create avenues for success among Black people (DuBois, 1973). Racial uplift and liberation of his community was possible only through the leadership of a few exceptional men (DuBois, 1973; Battle \& Wright, 2002).

DuBois articulated a definition of Black middle class with stringent criteria, including home ownership, professional occupation, and a family unit in which the wife did not work and the children were in school (Battle \& Wright, 2002). He also suggested that many, although not all, members of the Black middle class join the 
Talented Tenth in an effort to "lift as they climb." (The distinction is made between the Black middle class and the Talented Tenth in that the latter were required to prioritize education and personal sacrifice for the race, while the former could maintain middle class status without receiving formal education (Battle \& Wright, 2002)). During this time and through the subsequent years, the Black middle class emerged in cities as entrepreneurs for Black businesses and continued gain notoriety in academe (Prince, 2006).

While many of the attributes and responsibilities of DuBois’ Black middle class remain, changes in the country resulted in a slightly different way of looking at this sector of the Black community. In the 1970s, the Black middle class was defined as those families who owned homes, valued education, and had fewer children than poor Blacks (Prince, 2004). Because of the increase in home prices and standard of living, most Black middle class families had two wage-earners, the wife joining her husband in the workforce (Pattillo, 1999). Interestingly, an article published in Ebony in 1978 suggests that Black middle class women of this time were at times better off than White middle class women in regards to gender equity and joining the workforce because they had equal status in the home, were more involved with the community, and often had experience in the professional world.

Similar to DuBois' definition of Black middle class, in the 1970s, members of this class often felt responsibility for kin and community, and were held accountable for the uplift of the community (Ladner, et al., 1973). This was primarily seen in the community involvement of the Black middle class as well as the close proximity of 
Black middle class houses to the poorer neighborhoods, and a continued priority towards education.

The Black middle class has tripled in size since the 1970s, and with an increase in size, there has also been an intensification in the economic division between middle class and poor (Hyra, 2006; Macfarlane, 2009). Currently, the Black middle class is associated with such attributes as high work ethic, strong sense of empowerment, implicit or explicit embracing of dominant norms, the ability to delay gratification (Coner-Edwards \& Spurlock, 1988; Prince, 2006). As the Black middle class continues to evolve, many worry about the impact on the Black community as a whole (Martin, 2010). Questions arise regarding the ability of Black middle class to maintain racial identity and ties to the Black community (Handerson, 2007; Lacy, 2004; Martin, 2010).

Some scholars (Henderson, 2007; Lacy, 2004; Martin, 2010) posit that Black middle class may participate in strategic assimilation, working and living within the White community while maintaining ties with the Black community. Parents often explicitly teach their children what it means to be Black using art, music, and food to strengthen the connections to the greater Black community and to distance themselves from White middle class norms. They also frequently are active in community organizations and have strong involvement in neighborhood churches (Henderson, 2007; MacFarlane, 2009; Martin, 2010).

Despite efforts to maintain ties with the greater Black community, an overlap of race and socioeconomic status often results in conflict. Some members of the Black middle class have been accused by their peers who are not as well-off of accepting 
White norms (MacFarlane, 2009; Martin, 2010). On the other side of the conversation, members of the Black middle class may blame the poor themselves for the social ills that they face, pointing to habits and lifestyle as a perpetuation of their low class status (Martin, 2010; Pattillo, 1999; Prince, 2006). Both perspectives divide the Black community between middle class and poor. In 2008, Roach's analysis of the Pew Survey found that 37 percent of African American participants reported that the class divide is so great that African American should not be thought of as a single race any longer.

Notwithstanding intragroup stressors, a common thread among the Black community is racial discrimination (Corner-Edwards \& Spurlock, 1988; hooks, 2000; Ladner, at al., 1973; Prince, 2006). The "Black tax,” or a toll that African Americans pay for oppression and injustice is felt in all sectors of everyday living--education, the workforce, housing, healthcare and more (Lawson Davis, 2013; Prince, Martin, 2010). In the face of inevitable racial oppression, the Black community holds a message that transcends conflict held between socioeconomic groups —-that of education (and professional success) for emancipation of the Black community remain, as well as racial solidarity with Black members of all SES groups (hooks, 2000; Hilliard, Perry, Steele, 2002).

\section{Social, Psychological, and Academic Health of Gifted Black and Biracial Students}

According to the National Center for Educational Statistics (2011), 83 percent of teachers are White. Moreover, nearly two thirds of teachers, or 65 percent, report having very little or no professional development or academic classes on how to best 
teach high achieving students (Thomas B. Fordham Institute, 2008). Therefore, one can assume that teachers of gifted Black or Biracial students are underprepared for meeting their needs as diverse students and as students who demand rigorous coursework, opportunities for advanced cognitive development, and celebration of curiosity.

Although teachers often feel ill-prepared to meet the needs of gifted Black and Biracial students, research suggests that they have significant impact on the academic success, as well as the social and emotional health, of these unique students (Douglas, Lewis, Douglas, Scott, Garrison-Wade, 2008; Hanssen, 1998; Harmon, 2001; Milner \& Ford, 2006; Moore, Ford, \& Milner, 2005). The following section reviews the literature that supports prioritizing student-teacher relationships, commitment to antiracist education, and rigorous and responsive curriculum that inspires healthy experiences for gifted students of color in PWGS.

Students achieve in educational environments that foster positive relationships between students and teachers (Chikkatur, 2012; Douglas, et al., 2008; Harmon, 2001; Ladson-Billings, 2009; Milner \& Ford, 2007; Moore, Ford, \& Milner, 2005; Story, 1985). In fact, researchers (Baker, 2005; Reis \& McCoach, 2000) argue that in order to retain gifted Black and Biracial students in gifted programs, it is crucial to establish bonds with teachers and other supportive adults. Healthy student-teacher relationships decrease feelings of isolation within the students, naturally increasing feelings of belonging (Moore, Ford, \& Milner, 2005).

Educational professionals who form supportive relationships with gifted Black and Biracial students affirm the students' membership in the classroom community and 
their efficacy as gifted students (Harmon, 2001; Chikkatur, 2012; Douglas, et al., 2008). They also maintain high expectations of student behavior and academic performance (Harmon, 2001; Renzulli \& Renzulli, 2010; Story, 1985). Especially in adolescence, students require close relationships with adults, which are earned when the student understands that the adult has proven him/herself trustworthy (Toshalis, 2014). Teachers may gain a gifted student's confidence through authentic engagement with the students' worlds, inquiring about their TV and music interests, visiting their homes, attending sporting events and other extracurricular activities, and holding frequent check-ins with gifted Black and Biracial students (Milner \& Ford, 2007; Moore, Ford, \& Milner, 2005). Showing a gifted Black student that "you have a responsibility to him/her, without reservations” (Douglas, et al., 2008, p. 57) leads to trusting, reciprocal, and beneficial relationships and leads to greater student success (Douglas, et al., 2008; Moore, Ford, \& Milner, 2005)

Like teacher support, strong social bonds with other students of color are essential for successful and healthy experiences in PWGSs (Ford, 1996; Hebert, 2002; Perry 2003). Findings from a recent study of 35 gifted students of color in a predominantly White school suggest that achievement is related to healthy peer relationships and the formation of community, especially when bonds are formed with other gifted students of color (Reis \& McCoach, 2000). Participants of the study claim that friendships with other gifted students of color in the school fostered school success and reaffirmed their racial identities (Reis \& McCoach, 2000). Further, establishing relationships with other Black and Biracial students in a predominantly White school 
can provide gifted students of color with reprieve from feelings of isolation and alienation (Grantham \& Ford, 2003).

Culturally responsive pedagogy. Culturally responsive pedagogy (CRP) is a multi-tiered concept that speaks to (a) institutional, (b) personal, and (c) instructional components of teaching (Richards, Brown, \& Forde, 2007). Overall, CRP is a way to minimize alienation for students from diverse communities when they participate in schooling, which is steeped in White middle class norms (Ladson-Billings, 1994). In creating a welcoming classroom culture, the contrast between school and home discourse and practice is minimalized, and all students feel welcome (Richards, Brown, \& Forde, 2007).

Ladson-Billings (1994) argues that one of the central principles of CRP is an authentic belief that racially diverse students are capable learners. This belief manifests on a personal level and involves the commitment to examine biases and assumptions, guarding against deficit thinking (Bireda, 2011; Delpit, 1995). Increased awareness of other cultures, races, and individual students also allows teachers to create welcoming and nonbiased classrooms. Villegas and Lucas (2002) suggest that teachers should learn about the history and current realities of cultures and races that are represented in their classrooms. CRP teachers also prioritize home visits and getting to know families in order to understand and celebrate a student's background.

Commitment to CRP is apparent in the instructional strategies, activities, and materials that a teacher chooses to use (Richards, Brown, \& Forde, 2007). Allowing students opportunity to share differences and have their cultural identity validated create 
safe spaces (Ladson-Billings, 1994). Education about diversity and opportunities to work for social justice also should be prevalent in a CRP classroom (Nieto, 1999).

Antiracist classrooms. Antiracism is a movement born from discontent with multiculturalism's celebration of diversity (Ladson-Billings, 2000). Antiracists acknowledge race as a legitimate (and interdependent) part of a person’s identity and recognize that despite post-racial rhetoric, inequities and injustice are prevalent (Chikkatur, 2012; Douglas, Lewis, Douglas, Scott, Garrison-Wade, 2008; Hanssen, 1998; Milner \& Ford; Moore, Ford, \& Milner, 2005).

For Whites, antiracism requires unlearning racist ideology and replacing it with tolerance, respect, and appreciation for diverse people (Gillborn, 2005). Furthermore, White antiracists must guard against 'Whites as savior'-a perspective that insists Whites can save people of color, which is ultimately nothing but dehumanizing, patronizing and undermining to the important work that marginalized groups are doing in their communities. Finally, antiracism acknowledges the pervasiveness of structural, social, and political racism (Chikkatur, 2012; Douglas, Lewis, Douglas, Scott, GarrisonWade, 2008; Hanssen, 1998; Milner \& Ford; Moore, Ford, \& Milner, 2005). Thus, the White community must understand that their own goodwill towards people of color does not eliminate racism.

In the classroom, antiracism is active — going beyond the additive curricular approach found in multicultural education by creating opportunities for students to analyze, critique, and resist racism (Ladson-Billings, 2000). While there is no magical answer, scripted curriculum, or blueprint for how to incorporate antiracist practices in 
the classroom, discussions and classroom projects should allow students to engage in important and transformative work, studying activists, creating community outreach projects, critiquing media, relying on expertise of guest speakers, and ultimately creating their own story about race and sense of agency to change injustices (Gillborn, 2005).

Antiracist teachers must recognize that classrooms are not race-neutral, and that by high school, students have had 10 to 12 years of educational experiences that may have been harmful to their sense of worth as a racial beings (Douglas, et al., 2008; Hanssen, 1998; Ladson-Billings, 2000). Antiracist teachers are committed to personal reflection, understanding that left uncorrected, their partial or misinformation about diverse populations may add to students' wounds (Kumashiro, 2004). It is easy to resist engaging in significant racial dialogue in classes because of the way it's always been done. However, incorporating antiracist practices in classrooms is important for interrupting racial injustices (Chikkatur, 2012; Douglas, Lewis, Douglas, Scott, Garrison-Wade, 2008; Hanssen, 1998; Milner \& Ford; Moore, Ford, \& Milner, 2005).

Keeping in mind the theoretical foundations of this inquiry, I use the next section as a synthesis of foundational literature used when planning the inquiry's methodology. It is organized as follows: qualitative research, case study, participant observation, interview, and survey. Because this is the last section in the literature review, a chapter summary follows.

\section{Review of Methodological Literature}

Qualitative research. Qualitative research became popular in the field of education in the 1960s and 1970s when educational researchers noticed and reacted to 
the need to move away from experimental designs that were failing to give the full picture (Schwandt \& Cash, 2014). Until that point, and even after, qualitative research was often under the scrutiny for its worth in the world of research. However, several notable scholars such as Lincoln and Guba (1985) and Stake (1995), worked diligently to construct a level of repute to qualitative research that is on par with that of quantitative research (Schwandt \& Cash, 2014).

One might say that defining qualitative research is as difficult a task as conducting it. Defining criteria are numerous—-methods of data collection, framework of assumptions and principles, and criteria for judging research quality to name a few (Lincoln \& Guba, 1985; Stake, 1995; Schwandt \& Burgon, 2006). Data collection for qualitative inquiry consists of methods such as interviews, field observations, focus groups, and document analysis. Generally, qualitative researchers assume that knowledge is co-constructed and that the role of the investigator is an influential factor in the study (Schwandt \& Cash, 2014).

When deciding between qualitative and quantitative inquiry, a researcher must consider several criteria, including type of question and level of manipulation (Merriam, 2009; Yin, 2012). Qualitative research is often most useful when the inquiry at hand focuses on exploring ordinary activities within natural settings that would not be apparent in the sterile environment necessary for quantitative research (Stake, 1995). It is also the optimal choice when questions are open-ended, complex human interactions are explored, and phenomenon is best discovered with very little, if any, manipulation of variables (Lincoln \& Guba, 1985; Merriam, 2009; Yin, 2012). 
The perception of the value of qualitative research is continuing to grow more positive in many fields, especially education (Houghton, Casey, Shaw, \& Murphey, 2013). Although historically qualitative research was argued to be less rigorous than quantitative, researchers such as Lincoln and Guba (1985) suggest that while qualitative research is different from quantitative, it is by no means less. The quality of quantitative research is typically measured in terms of validity and reliability; conversely, Lincoln and Guba (1985) suggest that the most authentic measure of the quality of a qualitative study is in its internal validity, applicability, consistency and neutrality.

Case study. One type of qualitative research method is the case study, which provides an in-depth look at a bounded system (case) in a natural setting or real life context (Creswell, 1998; Yin, 1994, 2012). It is a focus on a single phenomenon, and although it does not claim any particular methods for data collection or analysis, case study data collection most always involves multiple sources of information (Merriam, 2009; Creswell, 1998).

Participant Observation. One form of case study methodology is participant observation which focuses on making meaning of phenomenon from an insider's perspective (Jorgensen, 1989). Using participant observation, the researcher must gain entry, develop relationships, and observe phenomenon into the natural setting (Jorgenson, 1989). Participant observation is most appropriate when the research problem is concerned with a complex human interaction, and when the researcher's aim is to generate theoretical truths and hypotheses to be the basis of future research (Bogdan \& Biklen, 2003). 
Throughout the observations, researchers produce detailed and descriptive account of everyday life situations (Bogdan \& Biklen, 2003). Even with the aim of nullifying assumptions, objectivity is difficult to achieve for participant observers (Bogdan \& Bilken, 2003). In fact, Mays (2002) states that no observation is made without a filtering system, and it is impossible for a qualitative researcher to remove the lens through which the situation is seen from the observation.

Field notes, or written accounts of what the researcher sees, experiences, and thinks can be classified as either (a) descriptive, providing a detailed response of the setting, dialogue, portraits of the subjects, events, and activities, or (b) reflective, expounding on the researcher's own frame of mind, dilemmas, conflicts, and analysis (Bogdan \& Biklen, 2003).

Interview. Interviewing is one of the major approaches to data collection in qualitative inquiry, and while similarities exist between participant observation and interviewing, the distinction is made in that the researcher takes an active role in pursuing information that will speak to the purpose of his or her study (Flick, 2007; Roulston, 2011; Wolcott, 1999). This form of data collection allows a participant to share unique experiences, while the researcher gleans understanding of the topic from rich conversation between them (Kvale, 1999). As such, the researcher who uses interviews to collect data is not expecting to gather objective information, but rather work with the interviewees to co-construct meaning as a result of the discourse between the interviewer and the interviewee (Mischler, 1986). 
Kvale (1996) measured the quality of an interview by several criteria including: intentionality in design, spontaneous and rich participant answers, and follow-up and clarification of answers within the conversation. In all, quality interviews are the product of well-designed studys and competent and careful researchers (Mischler, 1986).

Survey. A survey is a systematic data collection technique that is designed to measure attitudes or behaviors (Harrison, 2014). Two essential components to surveys are (1) the question and answer format, and (2) researcher and participant have nonoverlapping roles - the researcher asks, and the participant answers (Groves, et. al., 2013). Like all data collection techniques, the survey starts with the inquiry's major objective in mind, and the researcher develops a thoughtful procedure for implementation and analysis (Harrison, 2014). As the survey is being designed, the researcher must be aware that any errors in sampling that apply to the larger study will also apply to the survey data (Groves, et al., 2013).

The participants of a survey generally are part of the participant group of the study. This means that in and of itself, the survey may not hold much interest to the respondent, but with proper communication about the role it plays in data collection for the inquiry, the respondent will see it as beneficial (Groves, et al., 2013). There are two main modes of administering a survey. During an interviewer-administered survey, the interviewer asks questions and the participant responds. Another type is the selfadministered survey, in which the respondent receives the survey via email, mail, or in paper form, and will answer the questions and return it to the researcher (Harrison, 2014). Once the deadline to complete the survey has passed, the researcher will sort 
information into discrete categories, and through data collection will produce either descriptive or analytic statistics that paint a picture of the various responses (Groves, et al., 2013).

\section{Summary}

The body of literature reviewed in this chapter illuminates the historical and current realities of gifted education, as well as the internal and external factors that are at play in gifted Black and Biracial students' educational experiences. Based on relevant research, it can be surmised that gifted Black and Biracial students have unique needs that can be met through rigorous curriculum, anti-racist classrooms and culturally responsive pedagogy. However, missing from the literature was the practices and worldviews of PWGSs and the impact they had on Black and Biracial students' racial identity development and socioemotional health.

I used the literature discussed in this review as foundational in planning and implementing the case study that aimed to fill the dearth in the literature regarding PWGSs. The literature was used to develop the research questions and data collection instruments, and was considered during the data analysis phase.

The following chapter describes the methodology that I employed throughout the data collection and analysis phases of this study, including the validity measures and limitations, as well as a description of the setting where data collection will take place. 


\section{Chapter Three: Methodology}

As O’Connor, Lewis, and Mueller (2007) suggest, "there is still much work to be done in the interest of capturing the meaning and consequences of race for educational experiences and outcomes” (p. 541). Indeed, the intersection of race and giftedness is an important area of discovery and cannot be overlooked as part of the effort to create equitable and challenging learning situations for all gifted students, and especially for gifted students of color. Therefore the research questions inquire about how race is addressed at a predominantly White gifted school (PWGS) and how Black and Biracial students who attend this school experienced (or did not experience) Othering. This chapter describes the research methods I used when conducting this inquiry.

In order to explore this topic, I used qualitative case study methodology, which is a method of research that provides an in-depth look at a bounded system in a natural setting, or real life context (Creswell, 1998; Yin 1994). I also employed tools associated with ethnographic work, including participant-observation and interpretations of patterns found in the "culture-sharing group" of Discovery School, which acted as the bound system (Creswell, 2007, p. 68). Quantitative research, which relies heavily on manipulation of variables and prediction, seemed inappropriate for this study. This type of research would neglect the complexity of the phenomenon at hand and do little to answer questions about the experiences of those who work, attend, and have children who attend Discovery School in regards to racial issues (Yin, 1994). On the other hand, qualitative techniques, specifically case study methodology, allowed me to gather robust, descriptive data about unit of analysis (Baxter \& Jack, 2008; Yin, 1994, 2012). 
Throughout this case study, I used critical race theoretical lens and considered current theories regarding gifted students of color, including the work of Donna Ford (e.g., 1994, 1996, 1998, 2003). Using these theoretical lenses, I designed the inquiry to answer the following questions:

1. How is race addressed at a PWGS?

2. How do students of color experience Otherness in PWGS?

The proceeding sections elaborate further on the setting, participants, design of my study, and the measures that were taken to ensure credibility and validity and to ensure quality of description and interpretation.

\section{Setting}

The study took place at Discovery School, an alternative school that serves students in first through eighth grade who score at least $99^{\text {th }}$ percentile on a nationally normed test for aptitude and/or achievement. Students throughout the district are given a battery of tests starting in second grade that would allow them to qualify for Talented and Gifted (TAG) programs. The district requires that each neighborhood school have a plan in place to accommodate the learning needs of TAG students. The district also offers an alternative school, Discovery School, for those students who receive the TAG label. As an alternative program, during the admission process, administrators at Discovery School carefully consider not only the advanced cognitive development of the students who apply, but also their needs, prioritizing those who have asynchronous achievement between subjects (which surprisingly enough may point to learning 
challenges and disabilities) and pay attention to those that are struggling to achieve at their neighborhood school.

The mission of the school reads: the Discovery School is committed to developing a learning environment so gifted children thrive socially, emotionally, and academically. Accelerated curriculum and project-based learning opportunities are implemented at every grade level, and the standard curriculum is one to two years ahead of that used in neighborhood schools. By the time the students graduate from Discovery School in eighth grade, many have earned high school credits in Algebra 3 and Algebra 4, as well as a freshman-level English course.

As Table 2 demonstrates, the total population of the school for the 2013-2014 year was 236 students, and of those 2.5 percent, or six students, self-identified as Black.

Table 2

Discovery School Demographics

\begin{tabular}{|c|c|}
\hline \multicolumn{2}{|c|}{$\begin{array}{c}\text { Discovery School } \\
\text { Total Students Enrolled: } 236\end{array}$} \\
\hline$\%$ of students & Subgroup \\
\hline $2.5 \%$ & African American \\
\hline $14.4 \%$ & Asian \\
\hline $4.2 \%$ & Hispanic \\
\hline $10.6 \%$ & Multi-racial \\
\hline $68.2 \%$ & White \\
\hline $100 \%$ & $\begin{array}{l}99^{\text {th }} \text { percentile on } \\
\text { nationally-normed test }\end{array}$ \\
\hline $12.3 \%$ & $\begin{array}{l}\text { Qualify for free and reduced } \\
\text { lunch plans }\end{array}$ \\
\hline $12.3 \%$ & Special Education \\
\hline
\end{tabular}

Twenty five total students, or 10.6 percent, were categorized as Multiracial. Fourteen percent (or 34) of the students who attend were Asian American, and 4.2 percent were Hispanic. The largest demographic category was White, which made up 68.2 percent of the school. Furthermore, 12.3 percent of 
students at Discovery qualified for free and reduced lunch, generally indicating that 12.3 percent of the students fell into the lower socioeconomic bracket. Twelve percent of Discovery students receive special education services.

\section{Research Design}

Case Study. Yin (1994) defines case study as an "empirical inquiry that investigates a contemporary phenomenon in depth and within the real life setting.” This design was best suited to uncover the way that race is addressed at Discovery School because it allowed me to probe deeper into surface-level conversations and day-to-day events and discover recurring themes and patterns that were relevant to the research questions. Because case study methodology falls within the constructivist paradigm, these themes and patterns emerge inductively, and are co-constructed by both researcher and participants (Corbin \& Strauss, 2008; Schwartz-Shea \& Yanow, 2013).

Following the case study methodology, I collected a wide array of data from the students and their parents, as well as educational professionals at Discovery School for many weeks while they went about their business of teaching and learning. At the school, I explored the interactions between teachers and students and among the students themselves. Relying on ethnographic data collection techniques, it was important that I spend many hours observing classes, recess, and lunchtime procedures. I became a familiar face, and many instructors and educational professionals grew comfortable with my presence, which resulted in casual and (often meaningful) interactions. While all of these encounters helped me make sense of the way that race is addressed at Discovery 
School, I was pleased that the impromptu conversations with teachers were rich with information about the culture of the school (Creswell, 1998).

Also, because the inquiry was operating under the tenants of critical race theory, I was intentional about offering as many opportunities as possible for students, teachers, and parents of color to give counternarratives, accounting for their experiences. In order to make space for these stories, I intentionally scheduled parent interviews at inhome whenever possible, so that participants would feel as comfortable as possible opening up with regards to what I anticipated being a personal and even tense subject matter. For one interview, I went to the parent participant's place of work.

In order for an inquiry to be considered case study methodology, it must have a defined unit of analysis (Creswell, 1998). For the purposes of this study, the unit of analysis was Discovery School. I believed that it was important to incorporate the perspectives of a variety of participants—students, parents, and teachers. (Each participant is discussed throughout this manuscript using a psydonym to protect his/her identity.) I also relied on my field notes and reflections as important data. Other Discovery School teachers acted as respondents, participating in the study by answering email prompts. (Using Qualtrics, the teacher respondents’ identities were kept completely anonymous.)

By using Discovery School as the unit of analysis, I could consider the policies, procedures, culture and history of the school, and attitudes of the educational professionals within it. By seeking out data from such a wide array of sources, I was able to gain insight into cultural patterns within the school and ultimately present a 
broad and thorough description the way that race is addressed at Discovery School (Maxwell, 2005).

\section{Participants}

The participant pool for this inquiry consisted of four Black or Biracial students, their parents, and three teachers at Discovery School. Other teachers acted as respondents, participating in the study through an anonymous survey. This section explains participant selection and offers a description of each participant in detail. As mentioned earlier, their names have been changed to protect their anonymity.

Selection of participants. The nature of this inquiry called for purposeful, criterion-based selection as the primary mode of choosing participants (Goetz \& LeCompte, 1984). Specifically, the criteria used to select the participants are that they must be either gifted Black students or gifted Biracial students enrolled at Discovery School who identified with Black and one other race. Student race was determined by a required demographic report collected by the school district during the school application process. Further, it was necessary that the participants attended Discovery School during the time of data collection. After student participants were selected, I chose parent participants. It was important that the parent participants be related to the student participants. Finally I chose three teacher participants based on their willingness to be interviewed and observed during my data collection.

Because I did not have legal access to information about students' self-described racial makeup at the time that I began the study, the administrator made the initial outreach efforts. In light of the criteria and the efforts of the administrator and me, four 
Black and Biracial students from Discovery School, as well as their parents, and three educational professionals were chosen.

Before data collection began, potential research participants were invited to take part in the study. Individuals who chose to participate signed a Letter of Informed Consent (see Appendix A and B), which described the purpose, activities, and potential risks and benefits for research subjects, as well as my contact information. The letter also explained that participation in the study is voluntary, and participants were able to withdraw at any time without repercussions. Only students, teachers, administrator, and parents who sign a Letter of Informed Consent were included in the data collection.

Kade. As a first grader, Kade was the youngest participant of the study. He is Biracial, with a Black mom and a White dad. He lives with his parents and his little sister in an upper-middle class neighborhood. Throughout the process, he was most animated when talking about his family—playing with his cousins (who he reported are "full Black") and going to church with his grandparents. During the time of the inquiry, Kade's mom was an educator in the district and reported being involved in TAG education at her school.

Kade was as inquisitive about me as I was about him, and upon our first encounter, he pulled a chair up close enough to touch my chair and said, "I'm ready for you to ask me questions.” I explained that I was only observing that day, but was sure to be ready with questions the next time I went to the school. I came to know Kade as an extremely bright and active kid. When asked questions in our interviews, he was 
thoughtful in his answers and divergent in his thinking. It was clear to me that Kade belonged at Discovery School.

In the classroom, Kade was boisterous and disorganized. He often did not have his homework complete, although he did participate in class. He seemed to need movement to learn and operate in the classroom, and often did his work standing up and leaning over the desk or sitting on the floor. In one of our interviews, Kade told me he liked Spanish class the most because he was good at it and sometimes was the teacher's helper. He had attended a Spanish immersion school prior to Discovery School.

On the playground, Kade would jump from activity to activity at a dizzying pace. Though he was accepted in groups that were playing wall ball, kick ball, or tag, Kade did not often have other students seek him out as a playmate. In the cafeteria, Kade most often sat by himself. The lunchroom walls had small recesses (about two feet apart) in them that were painted in primary colors. Almost everyday, Kade would wedge himself tightly in one of the recesses and eat his sandwich. The other students in the class seemed to accept Kade, but neither he nor his classmates seemed too worried about making deep connections.

Tara. At the time of the study, Tara was in $7^{\text {th }}$ grade. In my field notes, I described her as tall and lacking the usual lankiness that plagues many seventh grade girls. Tara told me that she is Black, and that her parents are from Senegal. Tara lives in an upper-middle class neighborhood with her parents. She is an only child. I noted that during my observations she was usually dressed in different colored jeans and 
converse sneakers. Her hair was dark and wavy, always pulled back tightly into a low ponytail.

Tara did not easily, if ever, warm up to me. She was gracious in answering my questions, but we did not reach a level of familiarity that I did with other participants. Tara seemed very focused on her social circle, and was more times than not leaning in to a group of girls, whispering and giggling. In fact, lunchtime and recess were almost exclusively consumed by whispering and giggling with her group of friends. The group was always the same three or four girls, and Tara was the only student of color.

During our interviews, I was struck with Tara's maturity. She spoke with an air of a person much older than she is. She told me of how much she appreciates Discovery School in comparison with her old neighborhood school because "it is more challenging and [she] likes the people there.”

As a student, Tara is quiet and cooperative. Throughout my intensive observation period, she did not once raise her hand to answer a question or participate in discussion. She was conscientious enough to never get caught when she whispered to her neighbor or passed notes back and forth. Somehow even with what appeared to be a steady stream of side conversation, she still kept up with the class discussion, offering a comment when she was called on, and completing all her assignments as directed. It was not surprising to me that her teachers reported that she is an A student.

During the data collection process, I felt very aware of ways that I might be singling her out by my observations or my requests for interviews. I was extremely worried that I would inadvertently create a situation of Othering, and thus, worked hard 
to keep a distance that would make her feel comfortable and not disrupt her vibrant social identity.

Bradley. Bradley and his sister, Saraya (discussed in the next section) agreed to participate in the study late in the data collection process. Although I did not spend as much time interviewing them as I did the other student participants, their surveys and my observations of them proved to be valuable data that added to this inquiry.

I came to know Bradley as a good-natured, active $3^{\text {rd }}$ grade student who is bright and eager to learn. He was somewhat curious about our meeting, but his quick answers and short attention span led me to believe that he did not think race was as important as play and studying. (Later the parent interview I conducted with his family confirmed my intuition.) Notwithstanding Bradley’s lack of patience for this particular project, he is an interesting, interested, bright child who is well loved by his peers and his teachers. Bradley is Biracial, and comes from a family of two moms—one White and one Black. When I visited his home for an interview with his parents, I noticed evidence of curiosity, play, and creativity. There were toys and art supplies scattered about, and the most remarkable features is the hundreds of animal figurines lining the walkway up to the front door—no doubt placed there by Bradley and his sister, Saraya.

Like Kade, Bradley had a hard time articulating what race was. I asked him if race was “defined as skin color or something else?” in order to probe further into how deep his understanding was. He said, "both, I think," with a questioning glance. He mentioned that at his home, they do not talk about race very much. 
In the classroom, Bradley is engaged and loves to raise his hand and participate in class discussions. At first I thought he might be showing off because of my presence in the room, but I soon learned that he is always energetic about learning. The teacher seemed to appreciate his presence amongst some of the other students who were not as interested in a few of the lessons. He seems to particularly love science and as his parents mentioned, Minecraft is one of his favorite pastimes.

During recess, Bradley actively participated in many games and sports. He had a permanent spot at a cafeteria table that was “claimed” by a group of boys (mostly White, one Asian student) who religiously sat there. He brought his lunch to school every day and would trade various snacks with the other boys. He seemed to have good relationships, probably because of his fun-loving attitude towards learning and playing. During his day-to-day learning and playing at the school, Bradley made no indication that race had an impact on him.

Saraya. Saraya is the sister of Bradley, but I found them to be somewhat opposite in their approach to my study. Saraya is quiet and studious and very clearly extremely intelligent. She was not entirely comfortable talking with me, although she relaxed when she realized that the questions I was asking her were not "right or wrong" but just some questions about her experience. Saraya is a light-skinned Biracial girl who lives with her brother and two moms. During the time of this inquiry, she had been at Discovery School for five years. Saraya was busy, dancing in her afterschool hours and participating in the science fair. She seemed to possess much intrinsic motivation. 
During our brief conversation, Saraya was very polite and willing to answer to my questions thoughtfully. Overall, she conveyed the message that she was very happy to be at Discovery School. Like her brother, Saraya mentioned that their family talked about race when something happened on the news or at school that might have been a problem. Saraya's sense of curiosity left an impression on me from the first moments of arriving at their house for an interview. A fierce windstorm had just occurred, and a tree was fallen down the street from her house. When I drove up, Saraya was outside investigating the tree, poking around in its branches.

Ms. R. Ms. R is the only African American teacher at Discovery School. During the time of this inquiry, she taught $7^{\text {th }}$ and $8^{\text {th }}$ grade humanities and language arts. Ms. R has been a teacher for eleven years, but has been at Discovery School for only two. During an interview, I asked Ms. R what she thought Discovery School was doing to meet the needs of students of color. She mentioned that hiring her was something that she saw as a positive move. She was keenly aware of her position as one of the few teachers of color in the building and conveyed a strong sense of responsibility to be a positive role model for students of color. "They see me, a Black teacher, and I am a leader.”

Ms. $\mathrm{R}$ is on the equity team for the school and was interested in my work, which she saw as a positive step towards meeting diverse students' needs. She mentioned that she was in TAG in her hometown, and was one of a very small handful of gifted students of color. She is aware of the issues that surround this phenomenon because of firsthand experience both as a student and a teacher. During our interviews I was struck 
with an impression that Ms. R takes her responsibility as a positive role model for students of color very seriously.

Mr. J. Mr. J has worked at Discovery School for six years. During the time I was a participant observer at the school, he was finishing his educational leadership program and was a valuable resource for me as I worked to learn the culture of the school. Mr. J taught health and PE, and I found myself drawn to the track many days to observe the children and to chat. Our chats always left me with important insight into the role that the district plays in the racial makeup of Discovery School and the policies that are implemented there. Mr. J spoke highly of his colleagues, but was candid about the issues that stem from the district administrators; namely, he spoke of problems with recruitment procedures.

During one interview, Mr. J spoke about his belief that Discovery School was supposed to serve TAG students at neighborhood schools who are not receiving services to make them successful. He was clearly frustrated that this mission, which was apparent to him and his colleagues, was not the message that was received by administration at other schools or within many communities in the area.

Mr. A. Mr. A is the upper grades science teacher who helped create the school eleven years prior. Before Discovery School was built, he worked at a private school. Mr. A is from Mexico, and presents with facial features, skin tone, and body characteristics that are stereotypically attributed to a Caucasian person. He speaks Spanish fluently, and he mentioned that he believed that to be an asset for his role as a teacher. 
Mr. A had great insight into the benefits of students of color being surrounded by peers who have similarly advanced cognitive development. In one interview, he mentioned that at Discovery School students of color are not teased for being smart, which he thought could be a factor at other schools. He also mentioned that socioeconomic status has a major impact on students-even more so than race.

It was clear to me that Mr. A is well loved and respected by both his students and his colleagues. One teacher participant mentioned with a grin that Mr. A was never allowed to leave Discovery School, because there is no one that could ever live up to his teaching.

Sandra. Sandra is the parent of Bradley and Saraya. Her openness was apparent on first meeting, as I arrived at their house on the tail end of a strong thunderstorm. Although the electricity was out, and the dogs were uneasy, she was welcoming and warm, and seemed eager to talk about her family’s experience with gifted education. I was also struck by a strong priority that both she and her wife held towards her children's educational opportunities, and even mentioned that they moved into a different district so that the children would have access to Discovery School.

During our phone calls and meeting, Sandra came across as pragmatic and graceful. She was careful to respect educational professionals, even when recounting Saraya's negative experience in her neighborhood school. She mentioned that it was not the fault of the individual teachers that Saraya's needs were not being met. She alluded to (and probably rightly so) a lack of professional development opportunities for general 
education teachers regarding talented and gifted education. Sandra was extremely pleased with the curriculum and community that Discovery School offered.

Barbara. Barbara is a mother of Saraya and Ben, and also has many years of teaching experience at the college and elementary level. As an African American, she was able to recount stories of racial microaggressions and general assumptions that she has experienced. They were especially apparent in contrast to a lack of similar experiences for her wife, Sandra, who is White. For example, Barbara said that she had been pulled over numerous times since she and her wife moved to their new area. (Sandra never has.) She mentioned that she was asked to teach African American literature course at a local college. Even though African American literature was not her focus, the leadership at the college assumed her expertise.

Like Sandra, Barbara was especially pleased with their children’s educational experiences at Discovery School. Although she spoke broadly about a lack of culturally relevant curriculum, she did not mention specific cases from the school. She did express an added responsibility that she felt towards questioning teachers' curriculum to see if it reflected her children. However, she seemed to feel overwhelming gratitude for Saraya and Bradley finding a school that met their needs.

Vanessa. Vanessa, unlike other parents that I spoke to, was unimpressed with her child, Kade’s, experience at Discovery School. As a public school teacher, Vanessa expressed a strong priority towards culturally relevant and anti-racist pedagogy. I was impressed with Vanessa’s energy as she told stories about Kade, and especially felt her strength and imagined how she must be an incredible source of comfort for her child as 
she recounted his experience being bullied by his classmates at Discovery School. Kade and Vanessa had what I perceived to be a close and open relationship, one in which conversations about race were prevalent and honest.

Vanessa spoke at length about her extended family often telling stories about Kade and his cousins. She mentioned the importance of taking Kade to a mostly Black church and how much he loves being around his family. One of my favorite moments in the interview was Vanessa telling about Kade’s desire to wear his hair in cornrows to look like his cousins. Unfortunately, the end result was not as enjoyable to hear, as it incited the only overt form of individual racism that I recorded during my data collection. Despite the negative outcome, the desire of Kade's to "look more like his cousins" was fully supported and nurtured by his mother.

As an educator in the district, Vanessa proved to have a vast understanding of the district policies and procedures that affected Discovery School. Throughout our conversations, it was clear that she held great enthusiasm for education and felt responsibility towards teaching social justice issues to her students and her own children.

While the participants described above (as well as the anonymous voices of teacher respondents) were the main sources of information in this study, my own positionality impacted the kind of information I received and the way that it was interpreted (Schwartz-Shea \& Yanow, 2012). The next section discusses my relationship to this study.

\section{Researcher Positionality}


While the realities of the participants were the focus of the study, I could not deny my own positionality. Previous studies (Milner, 2006) have elucidated the meaningful connections that are made between educational professionals who identify with communities of color and students of color because of a feeling of shared experience. As a White female researcher, I have very few shared experiences with the student participants, and therefore it is difficult to gain trust this way. Despite frequent visits to the school, I believe my positionality had a negative effect on the study because it was harder to gain trust from the student participants. In fact, during one of our meetings, the principal reported that while picking up her child from school, one parent asked "who is this White woman studying my child?”.

Moreover, I experienced a great deal of internal conflict and concern as I discovered that without careful consideration, my interviews and observations of students could be interpreted by the participants as badgering, or even worse, could introduce them to issues of race that they were not developmentally ready for. As a result of my positionality, I approached every session with participants carefully and with dutiful consideration of my research goals. I also was extremely conscientious towards the participants needs. For example, in order to obtain an interview with one participant who was especially shy, I asked her teacher to "pass her a note" on which she could check off times that she would be willing to talk with me. In giving this student choices on meeting times, I hoped that I would mitigate feelings of being singled out and raise the comfort level for this student. 
On the other hand, I believe that by scheduling the parent and teacher interviews at the family's home or within the participants' work helped me as I (co)-generated data with both the parents and the teachers (Schwartz-Shea \& Yanow, 2012). It was especially apparent with the parent participants, of whom two were (surprisingly) in the education profession. Because we were able to amicably chat about education on a macro level, we found common ground. I believe I succeeded in gaining their trust, and that they were especially willing and open as the questions zoomed in to more personal topics of their children and race. Furthermore, because I am an educator and have many years of experience teaching gifted students, I believe that the teacher participants quickly came to recognize me as trustworthy, someone who knows the system. After the data collection, I sent typed transcripts of interviews back to the participants as a way to member check. This also, I believe, maintained a high level of trust between the participants and me.

Finally, despite my consistent discomfort and worry, I operated under the belief that White women can be allies for communities of color in the quest for equitable situations. This belief gave me strength during the data collection when I grew fearful about continuing the project, and helped me focus on the importance that I ascribe to this inquiry. Clearly, my positionality affected the planning, data collection, and data analysis, but as a result of my intentionality and diligence, I believe I was able to maintain integrity in gathering, analyzing, and reporting the results.

\section{Propositions and Rival Theories}


This case study was framed by a critical race theory, which suggests that race is an important area of inquiry and discovery in all aspects of life, and particular to this study, for the field of gifted education. Other propositions for this case study included:

1. Structural ideologies, procedures, and policies are in place that send messages about race to students.

2. Though the educational experiences of gifted students of color are not inherently negative, they are unique compared to the experiences of their White counterparts. Despite these differences, it is possible for gifted students of color to have healthy and productive school experiences due to caring and insightful educational professionals, peers, and parents.

This inquiry also aimed to disprove the rival theory of colorblindness, or the idea that we live in a post-racist society (Bonilla-Silva, 2003; Carr, 1997; Brayboy, Castango, \& Maughan, 2007). Within the education field, those who subscribe to colorblind theory are often heard making such statements as "in my classroom, I don’t see color," and "Black, green, purple, or White: I treat all my students the same.” By working to disprove colorblindness as a rival theory, this study illustrates that failure to recognize race omits an important variable in the experiences of Black and Biracial gifted students, and emphasizes race as an important consideration in discussions of curricula, policies, and procedures in gifted education.

\section{Method of Data Collection}

An important feature of case study research is that it utilizes multiple data sources which establishes triangulation and allows evidence from one source to be 
corroborated with evidence from another (Yin, 2009). Thus, I developed a methodology that incorporated several sources of data, such as participant observation, email prompts, interviews, and survey. Maxwell (2005) suggests that by using a wide array of data collection techniques, a researcher may reduce bias and produce more inclusive understanding of the phenomenon. The subsequent sections describe the importance I placed on transparency throughout the data collection process, as well as each data collection technique in detail.

Transparency. I was fortunate to have the support of the administrator at Discovery School. Because of his genuine concern for matters of equity, especially those pertaining to gifted students of color, gaining entry into the setting was not difficult. Throughout the process, I was careful to maintain high levels of transparency with Discovery School staff, parents, and students. Therefore, it was important to me to begin the study with a presentation at a bi-monthly faculty meeting. I asked the principal for some space on the agenda and was able to distribute a handout explaining a brief summary of the issue and my research goals. It was important to me during this time to communicate that this inquiry was as nonjudgmental as possible, and that the goal was not to place blame or point fingers. Instead, I was intentional in presenting the inquiry in a positive light and spoke candidly to any concerns or questions that arose. I offered my contact information and made myself available for any of the teachers who had questions or concerns about my work as it progressed.

Participant Observations. In order to understand how race is addressed at a PWGS, I observed student participants and teachers at Discovery School three times a 
week for six weeks. During this time I worked with the school administrator to communicate with parents and students about the study.

Once the observation period began, I was typically in classrooms in which the participants were learning and teaching. I also observed recess and lunchtime everyday. Occasionally a special assembly or event would be scheduled that I would attend. For example, I was able to attend the eighth grade graduation ceremony in which many of my participants performed musical numbers. Throughout the observation process, my objectives were to collect data about the policies and procedures that may affect Black and Biracial students and the relationships among the students and between students and teachers, coaches, and other adults.

During observations, I took careful descriptive field notes in a journal and audio recorded most sessions. To focus my observation times, I was looking for manifestations of racial identity and race consciousness in the particular setting. Specifically, I paid attention to the configurations of social groups-acceptance within groups, tokenizing, etc. Further, I analyzed the frequency that race enters dialogue during a school day. Finally, I looked for defense mechanisms that student participants may have been exhibiting in response to difficulties with racial identity.

I also frequently audio recorded personal reflections on the day's observations in the car after each session. Though these musings felt random at first, they proved valuable during the data collection and analysis, as I was able to note various pieces of information like body language and interactions that happened outside of the classroom and interview areas that could not be recorded by an audio recorder. I was also able to 
dig into the internal conflict I was experiencing in regards to my positionality and strategize about how to proceed with data collection in ways that continued to be healthy and positive for all participants. At the end of the observation period, I transcribed and coded all audio recordings.

Interviews. I interviewed students and teachers at Discovery School and also made home and workplace visits to interview parents, using semi-structured interviews, which Kvale (2007) contends are appropriate when the issue at hand is complex and has multiple perspectives to uncover. As the name suggests, the format for semi-structured interviews is relatively loose, allowing space and flexibility for the participants to communicate their perspectives and ways of understanding the situation (Merriam, 2009). This was especially useful given the critical race theoretical framework from which the study was carried out; they allowed space for counternarratives from Black and Biracial participant students, teachers, and parents.

I used an interview protocol (see Appendix C-E) that listed the open-ended questions to be used during the interview (Creswell, 1998). These open-ended questions were reflective of my goal for the study.

Survey. A Parent/Child Survey (Appendix F) was sent home with each student participant that consisted of a Lickert Scale and two open-ended questions. The purpose of the survey was to further illuminate the experiences of the Discovery School student participants by allowing them an opportunity to self-report their experiences with a trusted adult. The survey was relatively short and easy to comprehend. I imagined that offering student and parent participants the opportunity to complete it together could 
yield valuable conversation about race and education. However, I also wanted it to be approachable for the student participant if he or she decided to complete it alone.

On the survey, the participants were asked to "strongly agree," "agree," "somewhat agree," "slightly disagree,” "disagree,” or "strongly disagree” to statements such as: I (my child) feels comfortable talking about race with his/her classmates and friends. To judge the accuracy of the instrument, after it was developed, I took it myself, critiquing it in terms of ease of understanding and clarity. Because of its simplicity, very minimal changes were made to it, and the final draft was approved. To get the surveys back from the participants, I attached a self-addressed stamped envelope directly to it, offering participants the option of mailing it or returning it to the school where I would pick it up.

Email Prompts. To advance my inquiry about the experiences of gifted Black and Biracial students at Discovery School, the teaching staff at Discovery School was asked to respond to two email prompts (see Appendix G). I wrote the prompts, with input from a colleague and fellow researcher. The prompts were sent to the staff using Qualtrics, a secure online research tool used for survey allocation, data management, and report creation. Through the responses to these email prompts, I got a view of teachers' observations of racial issues at Discovery School and the significance they place on addressing race.

To triangulate both the sources of data and the methods of data collection, a plan for data collection has been developed that employs a variety of instruments. Tables 3 outlines the types and methods of data collection. The variety of data collection 
procedures was designed to provide a full and revealing picture of the phenomena, and reduced the risk of bias (Maxwell, 2005).

Table 3

Methods of Data Collection, by Group

\begin{tabular}{|c|c|c|}
\hline Students & $\begin{array}{c}\text { Educational Professionals } \\
\text { at Discovery School } \\
\text { including Teachers and } \\
\text { Administrator }\end{array}$ & Parent/Guardian \\
\hline 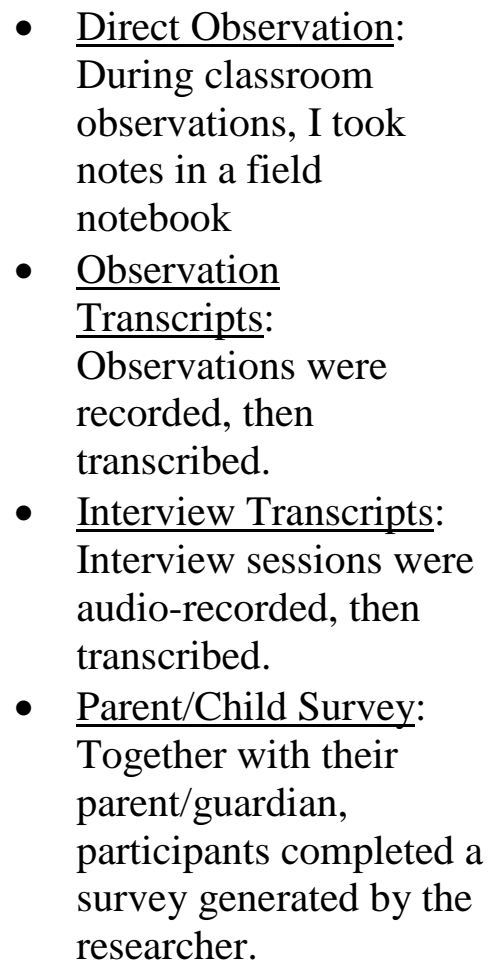 & 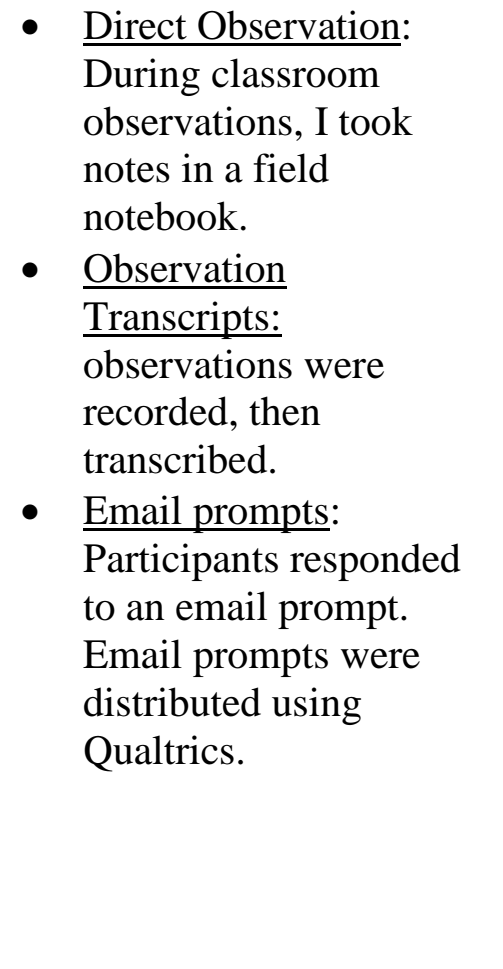 & $\begin{array}{ll}\text { - } & \text { Interviews: Interview } \\
\text { sessions were audio- } \\
\text { recorded and } \\
\text { transcribed. } \\
\text { - } \frac{\text { Parent/Child Survey: }}{\text { Together with their }} \\
\text { child participants } \\
\text { completed a survey } \\
\text { generated by the } \\
\text { researcher. }\end{array}$ \\
\hline
\end{tabular}

Note. The interview protocols, email prompts, and parent/child survey can be found in the Appendices.

\section{Data Analysis Procedures}

Qualitative analysis uncovers patterns that illuminate social realities (Zhang \& Wildemuth, 2009). Without careful and strategic analysis, the data collected during a qualitative study does very little to provide a description of the phenomenon being 
studied (Yin, 2009). Hsieh and Shannon (2005) discuss three approaches to qualitative data analysis, including directed content analysis, which was used in this inquiry. Directed content analysis suggests that an existing theory must be considered and possibly extended in the current inquiry (Hsieh \& Shannon, 2005). One proposition that drove this study is that gifted Black and Biracial students have unique educational experiences compared to their White counterparts. Thus, from the beginning of data analysis, the focus of coding was Black and Biracial gifted students' experiences at Discovery School, from which was born the category unless it is a problem. Furthermore, the tenets of critical race theory guided my coding, and CRT was the lens through which the data was understood. For example, some codes found in the initial coding stage include: microaggression, structural racism, and interest convergence.

Saldina (2009) suggests that a researcher must perform several rounds of coding to find themes and patterns within the data. I began the process by transcribing each interview, reflection, and entry in my field note journal, looking for clues into possible codes and themes. Diving in to the first cycle coding, I used the Descriptive Coding method, which I believed most appropriately aligned with my research design, especially in light of the heavy reliance on ethnographic methodology. Wolcott (1994) suggests that the goal of Descriptive Coding is ultimately for the reader to see and hear what the researcher did during the data collection period. Some of the initial codes that emerged from this work were: inclusive, rigor, open-minded, discomfort, not talk about race, positive environment, district-level, curriculum. During the first cycle coding, I found myself drawn to specific quotes in the transcripts and began incorporating In Vivo 
coding as well. By using In Vivo coding, I was able to honor the counterstories of the participants and remain true to the CRT theoretical lens. Ultimately some of these quotes (unless it's a problem, learning is happening!, it's a great fit, out of our hands) became the categories that I used to report the findings.

After the first cycle coding was complete, I recoded my data, honing some of the early codes that I used and combining others (Saldana, 2009). For the second cycle coding, I used Pattern Coding, which Miles and Huberman (1994) suggest is useful to make meaning out of the data, grouping codes into categories. It was through Pattern Coding that I was able to reassess the first cycle codes and develop categories that had clear parameters, merging categories when their boundaries overlapped, and honing and validating categories until I felt comfortable with the results (Merriam, 2009; Saldana,

Table 4

Changes to categories during data analysis

\begin{tabular}{ll}
\hline Initial Codes & Resulting Categories \\
\hline Not talk about race & Unless it's a problem \\
Discomfort & \\
Unless it's a problem & \\
\hline Positive environment & Learning is happening! \\
ARORC & \\
Neighborhood school & \\
\hline Appropriate peer group & It's a great fit \\
Inclusive & \\
\hline Communication & Out of our hands \\
Misinterpretations & \\
SES & \\
Identification & \\
Systemic belief & \\
Structural racism & \\
Interest convergence & \\
\hline
\end{tabular}

2009). As shown in

Table 4, codes such as not talk about race, discomfort, unless it's a problem became the category unless it's a problem. Although originally I developed two categories academic rigor over

racial community (ARORC) and cognitive needs being met, it was apparent that both 
categories alluded to academic rigor, and therefore were not mutually exclusive. As a result, they were combined into learning is happening!. Revision of the codes and categories was an iterative process and continued throughout the analysis period (Zhang \& Wildemuth, 2009).

\section{Credibility and Limitations}

It is my hope that this study captured an authentic portrayal of racial consciousness and racial identity issues for the gifted Black and Biracial at Discovery School. Thus, I placed at the forefront of this study respect for each student participant. I also hope that through careful documentation and analysis I produced findings that resonated with the experiences of other gifted Black and Biracial students in similar settings.

Limitations. However, by the very nature of a qualitative inquiry, this study was not without limitations. Researchers (Hammersley \& Atkinson, 1995; Lincoln \& Guba, 1985) suggest that two main threats to the internal validity of a qualitative study are (a) researcher bias, and (b) reactivity. Researcher bias refers to the preconceptions that I brought to the inquiry process. Although impossible to eliminate, or control for those threats, but they are both issues that were carefully accounted for (Maxwell, 2005). Researcher bias was minimized by member-checking and consistent, thorough reflection on and critique of my own assumptions (Maxwell, 2005).

The nature and design of qualitative inquiry are to examine a phenomenon in its natural setting (Creswell, 1998). Although it is likely the experiences that I observed mirror many of the experiences of other gifted Black and Biracial students in 
predominantly White schools, the findings of this study cannot necessarily be generalized (Maxwell, 2005). Further, because case study methodology makes it impossible to control for external variables, and because this inquiry relied on description as a means for communication, not explanation, causal relationships were not sought out (Yin, 1994). However, the findings from this study presented a descriptive picture of the experiences of the participants in a predominantly White school and could be used by other researchers who are studying a similar phenomenon.

Reactivity. Particular to this study, the influence of my presence on the participants was a very important consideration. Thus, careful attention was given to the way that I presented myself. Perry (2002) mentions three aspects of a researcher that may act as a barrier to earning the trust of student participants: age, gender, and race. I imagine there are more nuanced barriers that would cause participants to feel a sense of unease towards a researcher, but I was careful to focus on these three as I planned my direct observations and student participant interviews, hoping to mitigate any ill effects these factors may have on the study.

Perry (2002) posits that age may be a barrier to a study. I, as a thirty-three year old researcher, felt that because of my age, I could be perceived by the young participants as out of touch or untrustworthy. I worked to lessen the significance of this limitation by dressing casually in jeans and sweaters when I visit the school and having students call me by my first name. I carried a backpack instead of a briefcase and wore no jewelry. Through these measures, I worked to downplay age as a factor that could cause participants to be suspicious of me. 
Finally, my race may have been a barrier between me and the participants, a source of distrust for both student participants and parents (Perry, 2002). While this study in no way promotes a belief that membership to one racial category determines the success that one has in working with students of color, I believe it was more challenging for me to gain the trust of the participants than a researcher who shared racial characteristics with the participants. To account for this limitation, I decided to conduct interviews in-home and in other familiar settings, which I believed brought more comfort to the situation.

I also took certain measures to empower the student participants by offering them the role of expert. Throughout the study, I was clear in my message that I was there to learn from them, that there were no right or wrong answers, and that their participation was strictly voluntary, with an option to withdraw at any time. Giving the student participants this status hopefully alleviated some potential distrust.

I also felt that for the teacher participants, it was important for me to listen to their stories and respond in ways that were unbiased and nonjudgmental. I carefully maintained impartiality throughout the data collection period, resisting the urge to respond on the occasion when teacher participants asked my opinion on district and inschool policies and procedures. I also that presented my research in broad terms, saying that I was interested in exploring race and identities at Discovery School instead of mentioning specific races, or singling participants out.

Credibility. As mentioned previously, I increased the level of credibility of the study by employing triangulation of data collection tools and analysis techniques 
(Lincoln \& Guba, 1985). Using email prompts, surveys, focus groups, and observations, I worked to mitigate bias and chance associations (Maxwell, 2005). I also collected data from a variety of participants to create a strong basis for my findings, and offered participants the opportunity to review transcripts and make changes or omit sections as they saw fit (Creswell, 1998). This step reinforced meaning-making on the part of the researcher by asking participants to analyze the data that is collected for intended meaning (Lincoln \& Guba, 1985). It also provides transparency for the participants and the educational professionals at Discovery School as to the purpose of the research.

Finally, as a result of support from teachers and administrators at Discovery School, and openness of parents, I had extended opportunities for data collection. This allowed me to maintain my commitment to gathering a complete and accurate data set. For example, I conducted a lengthy participant observation in which I was in classrooms and around Discovery School several times a week (Maxwell, 2005).

A final consideration that must be accounted for in this study is the small sample size. However, I believe that because of the pervasive underrepresentation of gifted students of color in gifted education programs, situations similar to this one are prevalent throughout the U.S., making this inquiry even more critical. The small sample size allowed for deep, rich data gathering opportunities from teachers, parents, and student perspectives that might have been unwieldy or impossible with a larger group of participants. For these reasons, I saw the small sample size as a strength of the study, not a limitation. 


\section{Conclusion}

This case study was designed to explore the ways in which a PWGS addresses issues of race. Two research questions guided this inquiry. The participants were selected by their status as Black and Biracial talented and gifted students, as well as their parents and teachers. Data collection methods were triangulated to ensure credibility. They include: interviews, direct observation, parent/child survey, and teacher email prompts. Additionally, I employed member checking to increase credibility. As a result of the data collection and analysis, themes emerged that will be presented in the next chapter. They are: Unless It's a Problem, Out of My Hands, Learning is Happening!, and It’s a Good Fit. 


\section{Chapter Four: Findings}

As stated in chapter one, this study focused on the intersection of race and gifted education. Specifically, the research questions were concerned with the way that race is addressed at a predominantly White gifted school (PWGS), and also with ways that Black and Biracial students experience (or do not) experience Othering. In support of the research questions, methods were developed to observe and explore issues of race at a PWGS. Because this study operated under the tenets of critical race theory, methods were also developed to allow participants opportunity to share their counternarratives. The findings reported in this chapter present evidence of the ways that a PWGS addresses issues of race. The findings are organized around two research questions:

1. How is race addressed at a predominantly White gifted school?

2. How do students of color feel Otherness at a predominantly White gifted school?

Results described in each of these sections were generated using a combination of Descriptive and In Vivo coding followed by Pattern coding for analysis. Data sets used in the inquiry were obtained from a participant pool that consisted of four Black and Biracial (Black and one other race) students who are identified as gifted by the school district. Also included in the participant pool were the parents of the participating students and three teachers at Discovery School, a school that serves only

students who score in the $99^{\text {th }}$ percentile on an achievement or academic test given each year by the district. An email prompt was also sent out to all faculty at Discovery School. Each respondent signed a Letter of Informed Consent, and contributed to the 
inquiry by adding depth and richness to the data that was collected. During the time of the study, Discovery School served 236 students, 12 of which self-identify as either Black or Biracial (Black and one other race). Because of these numbers, Discovery School is considered a PWGS. The following sections discuss the findings, organized using the guiding research questions.

\section{How is Race Addressed at a Predominantly White Gifted School?}

Unless it's a problem. One of the major findings of this study was that White middle class status quo framed Discovery School, and that there was a general lack of resistance towards the normalization of Whiteness. The data revealed infrequent attempts to address racial issues and few examples of dialogue that celebrated diversity. The data also showed a notable divide - teachers of color reported feeling responsible for doing more to address race and were concerned about the absence of day-to-day conversations, while other participants expressed a sense that the status quo was working and to address racial issues might upset the environment. Overall, I believe the data in this section reflects Brayboy, Castango, and Maughan's (2008) argument that the Eurocentric framework utilized by most educational institutions in the United States normalizes Whiteness and leads to tacit assumptions that certain social conditions are natural.

In order to understand how important students, parents, and teachers at Discovery School thought addressing race openly was, I asked questions during parent interviews such as: "Do you think it’s important that a school like Discovery School 
address racial issues?” "What role do you think race plays in your (child's) experiences at Discovery School?” “Do you ever talk about race with your teachers?”

To further explore the perceived necessity and relevance of discussions of race, parents and children were asked to respond to survey questions such as: "My child feels comfortable talking about race with his/her classmates and friends" and "The teachers, administrators, and staff at Discovery School are knowledgeable in regards to handling issues of race that occur within the school.” The email prompt sent to the teachers of Discovery School also asked: "Do you think it is important to address issues of race at Discovery School?" and "What is being done or should be done to address issues of race?”

Throughout the interview process, each student participant commented in ways that suggested the belief that race is not an important part of conversation in school or at home unless it becomes a problem. For example, when asked if race was something that should be talked about at school, Tara, a student participant, stated, “Well, I don’t feel like there are any kids at our school who are racist or anything, but if there were, I think that we should talk about it.” When asked about whether race should be talked about at home, she also explained, "Like, if something really big happens. Like if there’s something in the news maybe about some racist, my parents would say something like, 'don’t let anyone be mean to you because of your race.’” Through these comments, Tara displayed a lack of comfort around racial issues. It is also possible that in Tara's mind, racial dialogue is inherently negative, and healthy and positive racial dialogue were not a consideration for her. 
Likewise, when asked to define race, Kade said, “I don’t know, but I do know what a racist is.” He spoke at length about the owner of a basketball team who had recently been accused of making racist comments. Next I asked him, “Do you know what some different races are at your school?” And he said, “No.” This conversation suggests that like Tara, Kade did not see race as something that garners attention unless something negative arises.

During one interview, Kade and I had the following conversation:

Clair: Do you think your classmates notice [your race]?

Kade: I don’t think so. 'Cause they don’t really talk about it that much.

Clair: People don’t talk about race?

Kade: Right.

Clair: Friends and teachers?

Kade: No.

Clair: Do you think that race should be talked about?

Kade: No. Maybe not.

Clair: Why not?

Kade: Well, I don’t know.

What is not apparent in the written form of this dialogue is Kade's body language that suggested a reluctance to talk about race with his classmates or teachers. When I asked him if race should be talked about, his arms folded in and he brought his knees up to his chest. He also spent much of the conversation chewing on his fingers and pulling his 
sleeves up over his hands. I interpreted the combination of Kade’s somewhat stilted dialogue and pensive body language as discomfort with the idea of talking about race.

Kade's attitude was reflected in other participants of this inquiry that spanned the range of age and racial makeup. For example, parents also indicated that race was not addressed at Discovery School unless it became a problem. During the interview with Bradley and Soraya’s mothers, Barbara said, “I don’t think they talk about race because it is not really a problem for them. Unless you say something, it's not really part of the curriculum.” Later in the interview, Barbara told the story of visiting her daughter's class at the beginning of February, “....and Black history month was coming up, and I always ask 'what are you doing for Black history month?' because I'm—I just want to know. And [the answer was] 'Nothing. When are you going to come in and speak?' And that's usually what it ends up being.” As the narrative continued, she told of many of her children's teachers (not just at Discovery School) asking her for suggestions for Black history month lessons.

Kade’s mother mentioned his reaction to the Martin Luther King, Jr. holiday. She said that her youngest daughter:

came home talking about Martin Luther King Jr. She’s five. And she talked about him being a man who died and he had four kids and he had a dream that his kids could go to school without being judged. And [Kade] commented sullenly, 'We didn’t get to do anything for Martin Luther King Jr.' 
Despite frequent classroom observations, I did not observe any discussions of race with students or within faculty groups. While it is entirely possible that curriculum units that include discussions of race that celebrate diversity and recognize differences as opportunities are taught outside of my observation period, this lack of evidence of day-to-day mentioning of diversity might indicate that race is infrequently and intermittently addressed. Sandra mentioned that her child came home from school one day and said that a teacher had held a "class discussion last week about racism based on a comment that a student made.” My observations combined with the described instance of a teacher confronting racism indicated that the curriculum was similar to the student participants' viewpoint—racial dialogue was saved for situations that are problematic.

Vanessa also seemed concerned with the lack of culturally responsive curriculum that Kade encountered at Discovery School. She said:

And [Kade] comments pretty frequently that the classroom space and the things that they talk about are pretty absent of Black people. Just last week he asked me if Black people even did math. And I said, ‘What do you mean, Kade?’ And he said, ‘There’s no....he’s never had a Black math teacher, and when they watch videos about mathematicians, there are no Black people.'

When asked if race plays a role in students' educational experiences in general, Sandra said, “Absolutely. One hundred percent.” The next question I asked was, "Do you think that race plays a role in your child's educational experience at Discovery 
School?” She replied, “Not as much. In a setting like Discovery School, where everyone is alike...I mean, for example, in an average classroom, something like standardized testing is a loaded issue...um...” As Sandra trailed off, I noted in my field notes that I believe she was suggesting that while race impacts students who attend heterogeneous schools, it is not as important to those who go to Discovery School. This may be related to another theme (discussed in upcoming sections) of a general sense of wellbeing and inclusiveness. Because there is a general sense of inclusiveness within the student population, the attitude may be that it is not important to talk about race.

An analysis of the survey responses showed results that were not as consistent with regards to this theme. Together with parents, one student participant "somewhat agreed” with the survey statement "My child feels comfortable talking about race with his/her classmates.” The rest of the respondents agreed with the statement, though none strongly agreed. While survey results for this particular question were mixed, it may be telling that no participant strongly agreed that they were comfortable talking about race. Responses were similarly unenthused when presented with the statement, “Teachers, administrators, and staff at Discovery School are knowledgeable in regards to handling issues of race that occur within the school.” Half the participants checked the box indicating “Unknown.”

In response to an email prompt and during a handful of interviews, several teachers also spoke about this theme. Only one teacher response indicated a sense of importance placed on incorporating race into the curriculum. Ms. R (notably the only 
African American teacher at Discovery School) summed up this attitude by saying, "I feel a challenge is that if people [at this school] don't think [race] is a problem, if they think that the status quo is ok, then they aren’t going to want to do anything about it. And then things are going to remain the same.”

An email prompt that was sent to all teachers and administrators at Discovery School asked, "Do you think that it is important to address issues of race at this school?" One teacher's anonymous response was:

I do not believe that there is anything "within” [sic] Discovery School that must be addressed. The system at large could use a review, especially to see how wide demographics and statistics compare with that of the program, its entrance requirements, options, and goals. There are many factors at play that create the program, and most of them are out of the hands of the educators. Some influencing factors that could fall under the category of institutional racism—such as access to testing, cut scores for entering the program, even one’s socioeconomic status. However, there is nothing inherent within our program, its goals, or the community that it encompasses that should address issues of race.

All but one of teacher respondent discussed the personal responsibility of educational professionals to recognize the needs of students of color in order to help them "reach their potential," use a "lens that comes from a cultural perspective," and "examine White privilege and cultural learning styles.” However, as previously mentioned, for most 
teachers at Discovery School, discussions of race that include student voices seem to be relegated to situations when race becomes a problem.

One particularly challenging moment in the data collection process came when a teacher with whom I had been working with very closely approached me and asked to talk. She mentioned that she "was just not comfortable with the study" for several reasons, one of which was that she does not like talking about "the whole race thing" and "wished that we could all just move past it." The expressions of discomfort from this teacher put an end to my formal observation period. They also illuminate the attitude echoed in other responses that if race were a topic of conversation, it must be problematic and uncomfortable.

In contrast to students, some parents, and some teachers' unwillingness to speak about race in school, there were two teachers who, when being interviewed, recounted their efforts to bring discussions of race to the foreground of their classroom. Notably, both of these teachers identified with racial communities that are underrepresented at Discovery School. Ms. R reported that she works to incorporate stories, histories, examples of people who reflect who they are and their communities, their neighborhoods. And reflect who they are in their families and who they are as individuals and show them in a positive way. That goes beyond the...you know, not that there is anything wrong with Martin Luther King, Jr. but everyone knows about Martin Luther King, Jr.. But who are these other people? You 
know, and I do bring that into my classroom, but I just think that that's probably something that all teachers here need to be aware of.

Mr. A, who identifies as a Caucasian Mexican-American, also noted that it is important to include all races in the curriculum, but did not articulate further.

Like Ms. R and Mr. A, Vanessa, the mother of Kade and a Black teacher in a neighboring district, expressed a perspective different from other parents and students on the need for racial dialogue. She stated that she doesn’t “think [Discovery School] meets [her son's] needs in regards to representing his race and culture in a way that shows value in diversity and the presence of diversity in different contexts.” She told me the story of Kade getting accepted to Discovery School, and the reservation she and her husband felt because "as somebody who works in [education] and really, you know, believes in the necessity of inclusive environments, I struggled with the idea.”

In all, the data collected around this theme, unless it's a problem, proved diametric. On the one hand, it revealed that all participants felt that conversations about race held an important place in situations when discrimination was apparent. In other words, all participants felt that it was important to react to racism. On the other hand, the data also suggested that teachers of color prioritized bringing racial dialogue and diverse representations to the forefront of classrooms and curriculum at much greater rates than other teachers, parents, and students. The data seemed to indicate that teachers of color were more comfortable being proactive about issues of race than other participants in the study. 
Out of our hands. During the observation period, I became a relatively familiar face around Discovery School. I was happy that many teachers at the school began to see me as a trusted figure, and someone with whom they could chat. Data from these informal conversations, as well as formal interviews, observations, and reflections often illuminated a frequent (and frequently frustrated) expression of helplessness on the part of the teachers as they felt the impact of systemic racism. In fact, a common outcry from teacher participants was 'it is out of my hands,' which often was followed by suggestions that issues of race that surround Discovery School are systemic, and the school is greatly influenced by policies and procedures that are mandated by the district.

District policy. Many teacher participants I interviewed, as well as an anonymous teacher who responded to the email prompt, alluded to policies and decisions that are made at the administrative and district level that affect the diversity of the school, as well as the experiences of Black and Biracial students who attend there. Most mentioned feeling that policies were vague and communication was lacking. For example, Mr. J told me "the whole topic of students of color, or at least getting more students of color at [Discovery School] is made at the administrative and district level.” He went on to say that it is "like a piece of the puzzle for me. Why doesn't anyone let our staff know why things are the way they are?” Ms. R echoed the same sentiment and added her frustration with the district admissions policy. She said, "Yeah, there is a disconnect between this program and the districts and communities. And later she reported: 
PREDOMINANTLY WHITE GIFTED SCHOOLS

I think we have a long way to go, and some of it has to do with things outside of [Discovery School]. The way that students are identifiedthat's another challenge. You have to be in the $99^{\text {th }}$ percentile. Ok $99^{\text {th }}$ percentile is really narrow and very restrictive. And then there's the other issue of how are [neighborhood] schools identifying students? What students find out about Discovery School and what families know about the process to apply?

Throughout my observation period, teachers at Discovery School often expressed an overall frustration with top-down decision making and the implications that it has for gifted Black and Biracial students. Obviously, both of the teacher participants mentioned above felt that decisions were made that were not clearly communicated, and ambiguous policies held some of the blame for the underrepresentation of gifted Black and Biracial students.

One particular policy stood out that certainly fit this theme. I spoke with Vanessa, the mother of Kade and a teacher in the district, about the $1^{\text {st }}$ and $2^{\text {nd }}$ grade classroom that Kade was a part of. She told me that district policy is not to proctor district-wide gifted placement tests to young students until the end of second grade, but Discovery School accepts students as young as first grade. She stated that the children in the first grade classroom generally come from situations of wealth and cultural capital. Because there is an overrepresentation of Black and Biracial people that live in lower socioeconomic communities, it is quite possible that they neither received 
communication about programs for their precocious young child, nor had the means to afford testing from a private psychologist.

Need for communication. The teachers also spoke of the need for communication with all neighborhoods around the area to promote the school and to clear up some misconceptions about Discovery School. During an informal chat, another teacher told me about a past experience teaching at a predominantly White gifted school in New York City. He spoke about the inequities that he saw at Discovery School were also present at his school in New York. He also talked about outreach efforts adopted by his school in New York, and the need for communication and recruitment in communities that are underrepresented at Discovery School, specifically suggesting (from experience) that churches would be good venues for getting the word out about the services that the school provides. Despite the perceived need for recruitment, several other teacher participants reported that the district had a clear stance against recruiting students for the school. Ms. R commented that “we can’t actively recruit. So, we have to find a creative way to reach out to families that are underrepresented here.” Similarly, Mr. J stated “And it is my understanding that we are not allowed to go out and recruit.” (I do, however, wonder about the success of recruiting in communities that are not traditionally served at this school if there are no seats for them in the classrooms.)

One sunny day while the students played on the playground, Mr. J and I had a conversation with a similar theme. He spoke about TAG students, identified and unidentified, in neighborhood schools. Mr. J stated: 
PREDOMINANTLY WHITE GIFTED SCHOOLS

We are supposed to be serving kids who are struggling in their neighborhood schools, and who are qualified to be here. I just feel like it...seems to be...I guess I just feel like I'm sure that there are [gifted] students of color who are struggling in their neighborhood schools. I mean don't statistics show that there is a higher suspension rate, referral rate for students of color? I believe we should be a perfect fit for those students.

Another need for communication that was voiced by several teacher participants was the need to respond to miscommunications about the school and its mission. Several teacher participants revealed their concern about the community's misconceptions regarding talented and gifted programs in general, as well as the mission of Discovery School and who is being served. During one interview, Ms. R suggested that the inequities surrounding talented and gifted programs start at an ideological level. She said:

the perception is that there are certain groups of people who are talented and gifted, and certain groups who are not. And they are relegated to basically the lower classes and lower intelligence. And that's got to change. I do know too that the idea that by getting into this program it's like you are not Black, or you are not acting Black or you are less connected to your community or your culture if you go to this school... that also has to change. 
Other teachers mentioned misperceptions that occur locally. Mr. J recounted a conversation that he had with an educational professional who worked at another school in the district. He mentioned that upon hearing where he worked she said, “'Oh, you work at that school that doesn't allow Black kids in.'” He expressed frustration with this encounter, and said, "So I'd be very interested to see...to learn more about the uh...you know, what the district does and what they would allow us to do to go out and let others know about our services.” Mr. J's frustration at this moment indicated to me that he acutely felt an absence of clear communication about the district policy for TAG students and specifically Discovery School students, and moreso for communication of a shared understanding of the mission of the school throughout the district.

Along the same lines, Ms. R stated that there was a need to: provide information that counters the false information that families have about the school here and what we do. We have to be a lot clearer about what we do here and what our mission is. We need to solidify that, too, in order to get that definition out—-to get that message out. Walking out of school one day, a parent and I began chatting casually. Through our conversation I was able to tell her about my research and after signing a letter of consent, she began telling her story of living in the area for several years before she heard about Discovery School. She mentioned that the years before her daughter was placed in the program were brutal, the effects of an ill-matched academic and cognitive curriculum on her TAG child. She stated how pleased she was that finally her child was in a program that fit her needs, and was exasperated that communication was so poor 
that although her child met all criteria, she was not aware of the program for several years.

Socioeconomic status. Although socioeconomic status was not the focus of the study, many teachers and parent participants referred to the disproportionality of students of color in low-income contexts. I did not include socioeconomic status originally in my study because as Howard (2014) says, “even the so-called privileges that accompany social and economic mobility do not seem to thwart the presence of race and racism when it comes to schooling experiences of Black males” (p. 18). Likewise, Lee, Olszewski, and Peternel (2009) state that "income does not guarantee success. There is evidence of similar academic disparities between minority and majority students with similar SES or family income level” (p. 139). However, the topic of socioeconomic status arose many times with no prompting from me. It should be noted that for this particular study, the Black and Biracial student participants all identified as middle- and upper-middle class status. Because Discovery School is situated in an upper-middle class neighborhood and because only 10 percent of the students who go there receive free and reduced lunch, the participants were similar to many of their classmates in regards to resources and opportunities typical of a middle- to upper-middle class family.

However, many conversations about race and schooling focus on poor, urban communities, and several participants made reference to the challenges presented in such environments. For example, when asked if the racial makeup of Discovery School, 
and specifically its status as a predominantly White school factored in to the decision to send the student there, Barbara said:

No. Not at all. I mean moving here from Michigan, from Detroit specifically, it’s like Wow! There are not many Black people here. And you go into a neighborhood where it is a community of Blackness, shall I say, and it’s not...I mean, you know, there are a lot of problems and a lot of kids are having problems. And my perspective is if I have a choice to put [my child] in a classroom with students who are not of color and they are succeeding versus just putting them in there because they are the same or similar color...I mean, it would kind of defeat the purpose of getting her where she needs to be.

During another parent interview, I asked Vanessa if she thought Discovery School should address racial issues.

Yeah. Yeah. I mean, I guess... you know, I guess... I think its kind of in a rock and a hard place there because I think before they address the race issue, I think they need to address the representation issue. Or maybe simultaneously? It’s hard to say that this school that's full of affluent White children should focus on race, when I know there are much more diverse schools in the district that don't talk about race either. 
When asked if it is challenging for Black and Biracial students to attend Discovery School, Mr. A said yes. He went on to say that the challenge comes from a lack of resources that most White and Asian students have. He said that because of the rigorous coursework, students at Discovery School have a lot of homework each night. This can pose a problem for some students if they do not have access to technology, places to study, family support, and time. Mr. A acknowledged that in his eleven years of experience, SES has actually been a greater factor in students' day-to-day interactions with peers and their success within the program than race.

Ms. R mentioned the misconception common among many outside communities that Discovery School is a place for "rich kids.” She said:

We really need to work on that perception that it's a school for privileged kids. That's not what this school is. This is a program that is providing a service for students who have not been serviced in their neighborhood schools. They are talented and gifted students, and there are talented and gifted students who look like many different groups of people.

\section{How Do Gifted Black and Biracial Students Feel Othering at a PWGS?}

The principle and prevailing theme in this research study was that Discovery School is positive academic community for the participants of the study. In fact, all student participants reported a sense of wellbeing as a result of being enrolled at Discovery School. Throughout the data collection process, there was only one report of a student experiencing blatant discrimination because of his race. Generally, students 
felt included in the school, and reported feeling satisfied with their position. Two prevailing themes emerged that may explain the general sense of wellbeing felt by all but one of the student participants: (a) Learning is happening! and (b) It's a great fit.

Learning is happening! The need for a challenging academic environment for gifted students has been well documented (e.g., Preckel, Gotz, \& Frenzel, 2010). Feldhusen and Moon (1992) argue that many gifted students benefit from specialized programs that are appropriately challenging, and others (Sapon-Shevin, 2003) attribute gifted programs that offer vigorous curriculum with maintaining interest and preventing boredom and frustration in gifted students.

The data collected for this inquiry reflect previous findings about the importance of challenging curriculum for gifted students. An analysis of parent responses when asked about the reasons they sent their children to Discovery School revealed that they all had positive perceptions of the school's curriculum. For example, Sandra stated that she was extremely pleased with Discovery School because of the "combination of appropriate academics and peer group.” Sandra then began recounting the story of her daughter's experience in her neighborhood school:

[Soraya's] teachers actually came to us and said 'you've got to get her out of here. We can't do anything for her.' So we sent her to private school for the rest of the year, and that was ok, but we realized that we were spending a lot of money for them to just...their strategy for her reading was to put her in the hall by herself. She went from a little girl who was excited about going to kindergarten to a kid who was getting 
PREDOMINANTLY WHITE GIFTED SCHOOLS

up in the morning and saying I don't feel good; I don't want to go to school.

Vanessa also stated that Kade, and she and her husband, initially were thrilled to be exposed to math curriculum that spoke to his needs. On our first meeting, Vanessa told me that she occasionally makes arrangements for Kade to sit in on a high school math class. Even as a young elementary student, this experience speaks to his need for advanced and stimulating curriculum. During a follow-up interview, I asked Vanessa if Kade thought the neighborhood school's classes were too easy. She said, "Yes, and at that time he was in a Spanish immersion program, and one of his teachers alerted us to the fact that he was bored. She was one of the ones that alerted us to possible cognitive and academic giftedness.”

All student participants felt satisfied with their academic experience at Discovery School and attributed it to the rigor of the curriculum. Most had no trouble articulating confidence in their academic skills and belief that authentic challenge was important to their growth. One day Tara and I walked around the playground chatting, and she mentioned that she really liked Discovery School. When asked why she likes it, Tara commented that "the school is really challenging, so I feel like I'm learning a lot more than I would at my other school. I didn't feel like my old school was challenging me that much, and I thought it was a little too easy for me.”

Likewise, Kade proudly said that "everybody has to get a 99 percentile on a test, which means we are all smart.” All student participants who were interviewed reported feeling happier with their educational experience at Discovery School than their 
previous experience in their neighborhood school. Moreover, an analysis of the parent/child survey shows that all student participants, together with their parents, reported that they strongly agreed with the statement "Discovery School is the best school to meet my [child's] needs.”

Teachers also reported a perceived positive impact that the rigor of the curriculum has on gifted Black and Biracial students at Discovery School. One teacher respondent mentioned that "the focus of the school is on learning. All students are challenged, curiosity is encouraged, and students are rarely, if ever, teased for being smart or different.” Mr. J echoed that sentiment. During one conversation about student engagement in the classroom, he stated that:

The students of color who come through Discovery School love it. They flourish here. They don't leave. I have seen students leave after one year, but I can't think of a single student of color who has left after one year.

My field notes also include observations that indicate that Black and Biracial students at Discovery School enjoy their academic work. One day I was struck with the engagement and participation that the $1^{\text {st }}$ and $2^{\text {nd }}$ grade students exhibited during a lesson on the scientific method:

"Kade raises his hand and calls the teacher over to him. He is working quietly and diligently. Many of the other students are chatty, many are sharing supplies and helping each other. There is movement. Fabric and cardboard all over the floor.” 
Another time during a $7^{\text {th }}$ grade unit on Odysseus, I recorded that Tara "sits towards the back of the room. She is very attentive with pencil in hand and notebook open. She listens attentively but does not participate with the same energy that others have. They are calling out answers rapid-fire.” I remember the discussion on this day, and many others during the observation period, being rich, abstract, humorous, and evaluative. Throughout my field observations, I made note of at least 15 separate occasions of challenging curriculum and high student engagement in my notes that can be summed up by one in particular: "learning is happening!”.

It is important to note that in a follow up interview with a Vanessa that occurred during the school year following my field observations, she expressed frustration that the rigor of the curriculum was not adequate. She mentioned, "We used to appreciate the idea that he would be receiving accelerated curriculum, but this year, for whatever reason, we've become painfully aware that he's not.”

Despite this outlier, the data still strongly points to the importance of academic rigor and accelerated pace. Within Discovery School, challenging curriculum is not just celebrated, but required to meet the needs of students. Especially interesting to me were the numerous expressions of relief from student participants and their parents during discussions of transferring to Discovery School from their neighborhood school. It was as if these students found an academic niche.

It's a great fit. While participants in the study perceived Discovery School to be a place of positive academic rigor and challenge that gifted students of color desire, the majority of student participants, parent participants, and all but two teachers also 
communicated positive feelings as a result of the inclusiveness and respectfulness that they felt from students and teachers at the school. This theme reflects previous studies that suggest that peer ability grouping results in healthy social relationships (Gross, 2003; Isaacs \& Duffus, 1995).

Mr. A, who at the time of the study had been a teacher at Discovery School for eleven years stated that he never witnessed or heard about bullying or discrimination. Another teacher in the email survey response shared this thought:

Young people today, especially at [Discovery School], are incredibly open-minded about students that are different from them in any way. They understand the global society that we live in today. At school, the impact [of race] is minimal.

When asked to comment on students' interactions with their peers, one teacher said that there was not really any difference at all between the students of color and the White students at the school. Another teacher respondent reported that "the way that this community embraces multiculturalism and the differences amongst humans should be applauded, as it is a very diverse and accepting group.” Mr. J commented on this theme, reporting that "one thing that really caught my attention, I mean, my first day at [Discovery School], is how inclusive the kids are to each other.”

Student participants also felt like race did not present challenges in their social lives. On the parent-child survey, all student participants (along with their parents) chose "Strongly Agree" when asked to respond to the statement "It is easy for my child to make friends at school.” Also, all participants who filled out the survey either 
strongly disagreed or disagreed with the statement "My child has had negative experiences at [Discovery School] because of his/her race.” On the back of the survey, student participants were given space to describe a "racialized experience" (defined for the purposes of this study as an experience, often negative, that was the outcome of racial differences) that they have had at Discovery School. There was not one response to this question, which may indicate that students do not feel like they have had a particularly discriminating experience at the school.

During one interview with Tara, she mentioned that "a lot of the kids here are really nice,” and went on to tell me a little about her friends at the school. Kade echoed this, saying that to have friends at this school, you have to be "be nice, responsible, and resourceful.” When asked if he feels like he could be friends with a person who is any color or race, he said yes, and clarified his statement by saying that "back before Martin Luther King wasn't there, it did matter. Because if he wasn't there, you couldn't be friends with White people, or you couldn't go to the same school as White people.”

Parents also agreed that their children seem to have healthy social lives at Discovery School. Sandra discussed her child's experience with friends at the neighborhood school. She said that before her daughter came to Discovery School, she had a "couple of kids come to her birthday party [who] were interested in Barbies, and she was interested in snakes and math. So you know, she felt kind of awkward.” Later in the interview, Sandra acknowledged that although most students at Discovery School do not share the same racial makeup as her child, she has good friends there. Bradley "is 
just not thinking about it. He’s thinking about Minecraft and running around, and yeah—it's not even important.”

The field notes that were often collected in the area surrounding the cafeteria and playground, also illuminate to the inclusiveness of the students at Discovery School. Some of my comments early in the data collection state "Bradley is on the play structure with four white boys." And "Soraya is talking quietly to two White girls. They seem to be very good friends. Their heads lean in together, and they are laughing.” During lunch one day I noticed that "there were two Black students sitting together. They were joined by two White girls. At the next table, there is a Biracial girl sitting with two boys. They are joined by a White parent and his daughter. The lunchroom is definitely not a segregated place at this school.”

After one observation session, I recorded my reflection from the days work. I mentioned that "I don't know if there are any obvious examples of Othering in what I have seen so far. The students seem, at least on the surface, to accept each other.” Another time I reflected on my experiences that day, stating "maybe this study will show that the teachers and students at Discovery School are doing a great job. Maybe the students of color at this school are happy and do not have any problem being one of just a few. Maybe Othering happens more at neighborhood schools?”

While there was much evidence that pointed to the positive community enjoyed Discovery School students and teachers, I also recorded a few examples of teacher concern for Black and Biracial students in the community, and one negative racialized experience. Two teachers I spoke with voiced concern regarding the experiences of 
some of the Black and Biracial students at Discovery School. Ms. R said that Black and Biracial students easily slip into the background, and it is hard to tell if their needs are being met. Likewise, Mr. J stated that "our few Black students do have friends, but seem more isolated.”

Another contrasting finding to the strong sense of community felt by many parents, teachers, and students was recounted by Vanessa during an interview that took place the school year after the observation period was complete. She told me a story about Kade wanting to get cornrows in his hair. She said:

He asked to have cornrows last weekend, so I cornrowed his hair. And he got to school and kids teased him. And told him he looked like a girl. And he told them that a lot of Black boys wear their hair like this, but a little Vietnamese student said I don't wear my hair like that, so you must be a girl. And it just points to... we had to have a conversation about that. I asked him, 'do you think that it's weird that there aren't any kids here who look like your cousins?'

And he said, 'yeah, mom, that's why I want to leave.' He went home sick last Thursday because the teasing about the hair didn’t stop. He actually took his own cornrows out, starting on Wednesday and I helped him finish. I told him, we can do whatever you want with your hair. 
But he was really upset about it. And he can’t understand why people can’t let him be Black. That was the phrase he said.

At the conclusion of our final conversation, Vanessa revealed to me that she is removing Kade from Discovery School and placing him back in his neighborhood school.

\section{Summary}

This chapter described the analysis of the data as it related to the research questions that drove this study. The themes that emerged from the analysis were: "Unless It’s a Problem,” "Out of Our Hands,” "Learning is Happening!,” and "It’s a Great Fit.” Each theme is articulated through the participants' voices and their responses on surveys and email prompts. The themes were also apparent during the direct observation phase of the inquiry.

In the following chapter, these findings will be discussed in relation to critical race theory and previous literature from the field. Assertions will be discussed and recommendations will be presented that show how the data could inform policy and practice of educational professionals who work with gifted Black and Biracial students, especially those at Discovery School. Finally, recommendations for future research will be offered. 
PREDOMINANTLY WHITE GIFTED SCHOOLS

\section{Chapter Five: Implications}

This chapter begins with an overview of the findings from data collection (discussed at length in the previous chapter) that answer the research question: How does a predominantly White gifted school address race? Making sense of the findings through the critical race theoretical (CRT) lens, I continue the discussion with implications and suggestions that could be useful to creating equitable learning environments at Discovery School or other schools that mirror the population and critical issues therein. The chapter concludes with suggestions for future research.

\section{Summary of Findings}

This case study was designed to peer into one of the most racially segregated sectors of the field of education, talented and gifted programs (Borland, 2003; Ford, 1994, 1996, 1998, 2003 Sapon-Shavin, 2003). Specifically, this inquiry explored the way that race is addressed at a predominantly White gifted school (PWGS) and how Black and Biracial students experience Othering within this context. A single case study approach was used, and data on students, parents, and teacher experiences were collected in order to create a rich, thorough picture of a PWGS from a variety of angles.

After collection and analysis of the data, several themes emerged. To answer the first research question—how is race addressed at a PWGS? — two themes emerged:

- Unless it’s a problem

- Out of our hands

The other research question—how do Black and Biracial students experience Othering? —-was explored with two emergent themes: 
- Learning is happening!

- It’s a great fit

Interestingly, the results of my data analysis frequently pointed to opposing perspectives on Discovery School and gifted education as a whole. Therefore data occasionally presents as two contrasting viewpoints. Keeping in mind the possibility of disjointedness in my findings, I believe that this contrast elucidates the way that the participants' personal philosophy and positionality impacts their perception of race and gifted education.

Assertions. Findings from my inquiry inform the following assertions:

1. Talented and gifted students thrive in programs that are uniquely tailored to meet their advanced academic and cognitive needs.

2. Certain district policies and inadequate levels of communication act as barriers for gifted Black and Biracial students.

3. Even within a largely inclusive educational community, racial microaggressions-including the silencing of racial dialogue and discrimination—continue to exist.

These assertions are important because they provide insight into current realities and focus future efforts to authenticate the unique experiences of gifted Black and Biracial students. They could be used to influence district policymakers and educational professionals within PWGSs to create positive changes. These assertions may also act as points of comparison to similar studies in the future. 
PREDOMINANTLY WHITE GIFTED SCHOOLS

The next section is organized by the four themes mentioned above. In this section each theme is discussed through (a) an explanation of beneficial practices employed by Discovery School professionals and (b) suggestions of practices and policies that could further meet the needs of gifted Black and Biracial students at PWGSs.

Unless it's a problem. Current literature suggests that silencing of race in schools is common, despite increasingly diverse student populations (Castango, 2008; Thompson, 2005). The results of this study support this claim. In fact, throughout the data collection period, no student participant ever suggested that race be a topic of discussion at Discovery School, downplaying its importance until, as Tara mentioned, "there is a problem" such as a "someone who is racist at the school."

Silence. I argue that hesitance to include racial dialogue as a natural part of dayto-day conversations may be problematic. I contend that this line of thinking privileges individualized, obvious forms of racism over systemic forms (Kitano, 2003), and legitimizes Whiteness, celebrating the dominant culture by neglecting to adequately create and foster an environment in which Black and Biracial students see themselves reflected in the curriculum and school community and all students feel comfortable openly discussing race as a positive and negative aspect of daily lives (Delgado, 1995; Tatum, 1997). Such shortcomings contribute to marginalization and perpetuation of silencing important voices (Howard, 2014). Thompson (2005) notes that "many African American students, male and female, may regard the polite avoidance of colortalk [sic] as a betrayal of trust because it denies real conflict and real relationships” (p. 537). 
However, the pertinent question is: why did Black and Biracial students choose to silence conversations about their own identity? Student participants' eschewing of racial dialogue could be attributed to the need to belong (Andrews, 2012; Carter, 2006; Tatum, 1997). Participants might have viewed talking about race as counterproductive in their efforts to fit in with peers, aversive because discussions of this sort have the potential to contribute to Othering, instead of being a way to normalize racial differences and celebrate diversity (Ford, Harris, \& Schruger, 1993). In other words, calling attention to that which makes these students different was not an attractive choice. And rightfully so! Becoming a member of a peer group is an important part of adolescence (Grantham \& Ford, 2003; Reis \& McCoach, 2000).

A synthesis of literature reviewed in chapter two pertaining to racial identity development concluded that reluctance to engage in racial dialogue is behavior that is usually associated with the pre-encounter stage of Cross' $(1971,1994)$ negriescence theory. It can be surmised that because of their adherence to White cultural norms, noted by preference in music, clothes, and vernacular, student participants are most likely experiencing some iteration of the pre-encounter stage. In this stage, adolescents minimize the significance of race and feel comfortable assimilating to dominant norms (Akos \& Ellis, 2008; Cross, 1971). Given the predominantly White environment in which they learn, the student participants appeared to chose racelessness, a general lack of association with the Black and Biracial community, over racial dialogue with the intended benefit to their social selves (Andrews, 2012; Chikkatur, 2012; Ford, Harris, \& Schruger, 1993; Fordham, 1988; Tatum, 1997). 
PREDOMINANTLY WHITE GIFTED SCHOOLS

Culturally responsive pedagogy. Luckily, teachers are well situated to correct the silencing of racial dialogue within Discovery School by including culturally responsive pedagogy (CRP) and anti-racist policies in their repertoire to build a sense of value and ease to communication of both positive and unjust aspects of race. For Black and Biracial students who attend PWGSs, CRP and anti-racist practices can lead to the development of positive racial identity, which in turn is attributed to high levels of selfrespect and resiliency in the face of prejudice (Akos \& Ellis, 2008; Ford, Harris, \& Schruger, 1993; Tatum, 2004). Toshalis (2014) suggests that CRP when done well, exposes students to political and historical content that directly addresses discrimination, stereotypes, institutional racism, and interpersonal prejudice. It gives students the context that they need to understand what they are experiencing (or perpetuating), and it provides a venue for safer explorations of how oppression might be productively resisted. (p. 217)

As discussed in chapter two, CRP ideology begins with authentically high expectations for all students (DiAngelo \& Sensoy, 2010; Ladson-Billings, 1994). The data from this survey revealed that teacher participants' personal attitudes, assumptions, and values were reflective of high expectations integral to CRP. Within every classroom I visited, academic potential was celebrated, curiosity encouraged, and rigorous coursework was implemented that appropriately challenged all learners. For example, Mr. A spoke at length in one of our interviews about how the main focus of the school is 
maintaining high academic expectations and nurturing curiosity. He stated that gifted Black and Biracial students flourish because they are encouraged to be smart, and their academic efforts are supported by their peers.

Nonetheless, in order to create a classroom context that reflects Black and Biracial students' realities, this study points to the need for culturally responsive curriculum and practices (discussed at length in chapter two) that account for diversity in the classroom. CRP explicitly teaches prevalent racial injustices and acts of social activism that fight these injustices, as well as stories of accomplishments of communities of color (Akos \& Ellis, 2008; Ford, Harris, \& Schurger, 1993; Tatum, 2004). It often includes strategies such as: forming relationships with Black and Biracial students, critiquing media in terms of obscure racial marginalization, creating a classroom climate where racial dialogue is welcomed and no one is tokenized or left out of the conversations, and building and/or fostering a highly reflective practice (Bireda, 2011; Delpit, 1995; DiAngelo \& Sensoy, 2010; Kitano, 2003; Toshalis, 2014). Throughout my observation time, I recognized opportunity for more teachers to approach their classes with priority to these practices.

Researchers (e.g., Bireda, 2011; Delpit, 1995; Ladson-Billings, 1994; Toshalis, 2014) argue that CRP is beneficial for historically marginalized communities. However, within a predominantly White school, the claim could be made that this pedagogy is irrelevant for the vast majority of students. For example, one parent participant commented that "before [Discovery School] address[es] the race issue, I think they need to address the representation issue. Or maybe simultaneously? It's hard to say that this 
school that's full of affluent White students should talk about race...” However, I assert that CRP is as essential for White students as it is for students of color. By inviting White students to join the conversation about race, not as outsiders, but as racial beings, they will may find value in exploring the impact of their Whiteness (Ambrosio, 2014).

Anti-racist practices. Using the critical race theoretical framework, this study is built on the assumption that racism is endemic and that Black and Biracial students receive different educational experiences from Whites, even when sitting in the same classroom (Delgado, 1995; Ladson-Billings \& Tate, 1995; Kitano, 2003). Thus it is important for PWGS teachers to be held accountable for intentional design of the learning environment to incorporate CRP and anti-oppressive policies. Like CRP, antiracist education is a form of education that addresses oppression. Some examples of anti-racist practices include: improving the educational experiences for historically marginalized groups, correcting misinformation about people from other groups, and challenging social dynamics that allow injustices to persist (Kumashiro, 2009), all of which should be incorporated into classroom discussions in a meaningful way that is not harmful to students of color. Incorporating CRP and anti-racist education into the advanced curriculum of a PWGS would address systemic racism, encourage healthy interracial relationships, and create a school community that represents students of color in positive ways—essential because school environment has a significant impact on racial identity development (Akos \& Ellis, 2008; Ford, Harris, \& Schurger, 1993; Tatum, 2004). 
Omitting conversations about race abandons Black and Biracial students in their important journey of racial identity development (Ladson-Billings \& Tate, 1995). On the other hand, with healthy development of racial identity, strength is garnered, which is essential for Black and Biracial students in a predominantly White gifted school (Akos \& Ellis, 2008). Teachers can be a positive influence on racial identity development by incorporating CRP and anti-racist practices.

Out of our hands. As mentioned in the previous section, teachers' classroom practices directly impact Black and Biracial student experiences. However, other aspects of Discovery School were not as within reach of teachers. In fact, the data for this study revealed numerous expressions of frustration and powerlessness from teachers when discussing issues of race at Discovery School, as they felt that district policies restricted efforts to positively address racial issues. Perhaps the most notable policy was explained by Vanessa this way:

So, the district tests all second graders for talented and gifted services. At [Discovery School], they open up in the first grade. In the kindergarten year a lot of parents and teachers, specifically from some of our more affluent schools and neighborhoods can recommend a student to be TAG tested early. And a lot of those students who are found... well, number one, the vast majority of those students who are tested early are White, and number two, a lot of families who have higher level of education achievement 
than...well, it's just above the norm, so you have a lot of students who've had a lot of [at home] frontloading.

As a result, families who are either (a) unaware of TAG testing policies, or (B) unsure of the benefits of such programs will most likely not take advantage of early TAG admissions tests. Thus, first and second grade classes fill with children from privileged situations. By the time third grade rolls around, and district-wide testing is complete, the potential to fill Discovery School classrooms with a more diversified student body is left unmet because there are very few seats left.

The results of this discriminatory practice were most apparent in my field notes, in which I often mentioned the perceived demographics of the classroom that I was observing. During an extensive observation in a combined first and second grade class, I noted only two students of color. (I did not confirm that my instincts about children’s races were correct, so my observations are based on stereotypical shared physical characteristics of groups, and are thus potentially inaccurate.) Despite optimistic and supportive reports from participants of the benefits of academic programs like Discovery School, this blatant misuse of TAG testing procedures leaves a whole in the staff's ability to create inclusive and diverse programming and leaves Black and Biracial students and their families without a community on which they could rely. The latter was most apparent to me in the interviews in which it was revealed that Black and Biracial parents did not have friendships or even know other Black and Biracial families from the school. 
Frontloading. The disproportionality in Discovery School is mirrored by the majority of gifted programs across the nation (Ford, 2003); however, there are schools and districts that have been successful in reducing institutional bias inherent in admissions policies and increasing access for underserved populations by using expanded definitions of giftedness, nonbiased admissions policies, and other creative measures. One such method is a strategy mentioned by Vanessa during her explanation of district policy—frontloading. However, in Vanessa's narrative, frontloading, or exposure to challenging curriculum such as that offered by Discovery School, was provided by parents. Some school districts have had positive outcomes taking the responsibility for frontloading in their own hands, offering opportunities for marginalized precocious students to participate in gifted programs as a precursor to identification (Tomlinson \& Jarvis, 2009).

Evidence of successful frontloading policies is also discussed in a review of gifted education programs by Briggs, Reis, and Sullivan (2008). They too note that culturally, linguistically, and ethnically diverse students who demonstrated precociousness, but lacked previous exposure to academic opportunities were asked to participate in gifted programs and often found that it was a good fit for them (Briggs, Reis, \& Sullivan, 2008; Ford, 2003).

One specific program, Project EXCITE, implements frontloading and has successfully diversified gifted programs district-wide (Olszewski-Kubilius, 2006). Based on criteria such as teacher recommendations, leadership in math and science, and problem solving, students from diverse backgrounds and traditionally underrepresented 
racial groups are invited to take part in the program and develop their talents in an appropriately challenging academic environment without receiving the official TAG label (Olszewski-Kubilius, 2006). These programs are sustained through a strong local partnership with Northwestern University.

The findings from this inquiry suggest that Discovery School, and perhaps even other PWGSs, would do well to reserve a handful of seats (I propose about six to eight) in their earliest classrooms, providing frontloading opportunities for traditionally underrepresented precocious students. Although these students will not have been offered the talented and gifted assessments, PWGSs could emulate Project EXCITE by seeking recommendations from neighborhood school teachers, parents, and counselors. Based on the results, a handful of students could be selected to participate in the highlevel program. Thus, diversity of student body could be increased and individual students from neighborhood schools could be placed in an environment specifically tailored to their cognitive needs.

In order for frontloading policies to be successful, communication across the district is essential, especially within those neighborhoods that are predominantly made up of Black and Biracial families. My data showed numerous accounts by Discovery School teachers attributing lack of communication and misunderstandings to the perpetuation of racial disproportionality within the school. For example, Mr. J recounted a conversation with another teacher in the district who exclaimed, "Oh, you work at that school that doesn't allow Black kids in.” Likewise, Ms. R communicated 
her frustration with a lack of communication around the district with this list of questions:

What students know? And what students find out about [Discovery School]? What families know about the school and the process of applying? And how are schools identifying students? There is information that we probably don't have, and we probably need to do a better job of getting it.

As noted, my findings point to frustration and feelings of powerlessness among teachers regarding inadequate communication, which was seen as a barrier for Black and Biracial gifted students admittance into Discovery School. Returning to the discussion of frontloading as an option for increasing diversity, it is suggested that communication is essential for successful programs. Therefore, in situations like Discovery School's, changes to district policies around recruitment and informative measures could potentially increase chances of success.

Furthermore, researchers who advocate for frontloading programs strongly encourage the use of appropriate scaffolding, creating supportive learning environments and avoiding "sink or swim," policies that might cause these bright students to disengage or get pushed out (Briggs, Reis, \& Sullivan, 2008; Hilliard, 2003; Jarvis, 2009; Tomlinson \& Jarvis, 2009). Thus, adoption of frontloading policies are most likely best when they are coupled with provisions for adequate support (Tomlinson \& Jarvis, 2009). Again I turn to Project EXCITE as an exceptional model for other programs hoping to diversify student population in gifted programs through 
frontloading. As mentioned previously, Project EXCITE created and sustained a strong partnership with the local university, using high achieving college students and professionals of color within the community as tutors and mentors. This strategy proved successful in the retention of Black and Biracial students in gifted education programs (Briggs, Reis, \& Sullivan, 2008; Olszewski-Kubilius, 2006).

Learning is happening!. Despite the barriers for gifted Black and Biracial students discussed above and the persistent, well documented controversy surrounding gifted education programs, (e.g., Benbow \& Stanley, 1996; Kulik \& Kulik, 1982; Rogers, 2007; VanTassel-Baska, 2003), the principle finding in this study revealed the overwhelming benefit of homogeneous learning environments for gifted students. Proponents of ability grouping highlight gifted students' need for academic rigor and cognitive challenges in order to maintain engagement and prevent frustration and boredom (Adams-Byers, Whitsell, \& Moon, 2004; Fielder, Lange, \& Winebrenner; 1993; Neihart, 2007; Preckel, Gotz, \& Frenzel, 2010). "Without regular encounters with challenging materials, gifted students fail to learn how to learn” (Fielder, Lange, \& Winebrenner, 1993, p.3).

A recent report claimed that 78 percent of educators either agreed or strongly agreed with the statement, getting underachieving students to reach "proficiency" has become so important that the needs of advanced students take a back seat (Farkas \& Duffett, 2008). This study also suggested that 58 percent of teachers surveyed reported no professional development opportunities or college courses that focused on the needs of talented and gifted students (Farkas \& Duffett, 2008). Thus, heterogeneously grouped 
classrooms often provide slower pacing and repetition of content that lock gifted students into tedious, dull educational experiences (Adams-Byers, Whitsell, \& Moon, 2004).

It is no wonder that all participants enthusiastically embraced the rigor of their classes at Discovery School. In comparing neighborhood schools to Discovery School, all student participants acknowledged that their former academic lives were unchallenging and unfulfilling. Parents also chimed in on the issue; one parent opened up about her child's early years in a neighborhood school, saying it was a disaster. Her teachers actually came to us and told us to get her out of here. We can't do anything for her. She's too far above anything we are doing. So we sent her to private school for the rest of the year, and that was ok, but we realized that...their strategy for her reading was to put her in the hall by herself. And ok, why are we spending thousands of dollars for her to sit in the hall?

This thoughtful parent was careful to remove any blame from her child's former teacher, saying “I don’t think it was the teacher’s [fault]; I mean, she had 28 other kids with vastly different needs.” However, this narrative and others ardently reinforce the assumption presented in chapter two that though popular conceptions of giftedness are often misconstrued, students with relatively advanced levels of cognition, leadership, and creativity not only exist, but also require differentiated instruction to further develop their talents (Feldhusen, 2003). It must be noted that one parent spoke out about the lack 
of academic rigor her son experienced at Discovery School, mentioning that the rigor did not meet her standards; however, all other parents, teachers, and student participants indicated that the Black and Biracial student participants were thriving at Discovery School because they felt that their cognitive and academic needs were being met.

Prioritization of gifted programs. From this inquiry, I have come to understand the value of programs like Discovery School. It is my hope that this school can maintain its status as a fundamental resource for the community, and that its teachers will uphold their obvious commitment to fostering creativity and high-level thinking for cognitively and academically high achieving students. Unfortunately, adequate resources are often elusive in the field of education, and gifted programs such as Discovery School frequently close, sending talented and gifted learners back to neighborhood schools that may not meet their needs (Farkas \& Duffett, 2008; VanTassel-Baska, 2003). The review of current national education data (found in chapter two) revealed that the state where data collection took place is one of ten states that does not provide any funding for gifted education. Despite this hardship, I believe that it is important that Discovery School continues to be prioritized by the district and provided adequate funding from a variety of sources. Ms. R summed this point up well when she said that "there is growth, but you know, it really comes from support, too. [We] have to have support from the district level to continue this program. Not just whether it is mandated by the state, but really [others] have to buy into it too.”

Teacher preparation programs. Furthermore, the continuation of gifted programs, such as Discovery School, relies on teacher preparation programs. Ford 
(2003) reports that current teacher preparation programs often place "minority students in double jeopardy — enduring the usual prejudices while their academic strengths and needs go unmet in school” (p. 154) because teachers seldom encounter coursework that targets gifted students of color. However, future teachers and administrators can positively influence the future of gifted schools and programs by being informed about the importance of meeting gifted students' needs (Feldhusen, 2003; Kitano, 2003).

Thus, I recommend that local universities' teacher preparation programs create space in the required course sequence for critical issues surrounding TAG education and culturally and racially diverse TAG students. Advocates of gifted education (Feldhusen, 2003; Ford, 1998; VanTassel-Baska, 2003) agree that teacher training is essential to help teachers provide specialized instruction appropriate (and necessary) for gifted students. Furthermore, in alignment with the tenets of critical race theory, I argue that teacher training not only expose students to knowledge of the historical underpinnings of TAG, characteristics of TAG learners, instructional strategies, and local policies, but also critically analyze definitions of intelligence, assessment procedures, retention of TAG students of color, and political trends through the social justice lens.

As mentioned in chapter two, gifted education is a paradox of inequities. That is, by offering TAG services, inequities are created because programs are predominantly White middle class; simultaneously, the result of not serving TAG students, is students with unmet cognitive potential (Borland, 2003). A university class that explores this tension and increases knowledge and awareness could offer teacher candidates opportunity to challenge current assumptions, develop a personal philosophy towards 
gifted education, and be exposed to best practices for meeting the needs of gifted Black and Biracial students.

It's a great fit. Neihart (2007) defines social self-concept as “a person's selfperception of his or her social acceptance by others, as well as his or her social skills with respect to social interactions with others.” This inquiry reflects the research (Gross, 2003; Isaacs \& Duffus, 1995) that argues that positive social self-concept in gifted students is a result of connecting with same ability peers. Many participants reported feelings of wellbeing when asked about their social lives at Discovery School. In fact, throughout my data collection there was only one narrative that indicated an explicit form of Othering. (In that particular case, the participant suffered discrimination as a result of wearing his hair in a style traditionally worn by Black males.)

In contrast to this isolated report, other student participants expressed the attitude that their race did not have an impact on friendships formed at school. For example, Tara mentioned that “I feel like people treat me well. I don’t feel like anyone is really mean to me because of my race.” One parent noted that because her children are surrounded by same-ability peers, their social lives are richer than they were at their neighborhood schools. The field notes from my observations also alluded to a great amount of inclusiveness and close friend groups for the participants despite racial differences. Likewise, teachers reported feelings of inclusiveness among students at the school.

Student participants all mentioned feeling a sense of belonging at Discovery School as a result of being surrounded with like-ability peers. Being careful not to 
dismiss the value of a strong academic community, I wanted to examine this finding using a critical lens. Literature synthesized in chapter two points to supportive relationships between Black and Biracial gifted students and same-race, same-ability peers (Ford, 1996; Grantham \& Ford, 2003; Hebert, 2002; Perry 2003; Reis \& McCoach, 2000). For instance, findings from a recent study of 35 gifted students of color in a predominantly White school suggests that achievement is related to healthy peer relationships and the formation of community, especially when bonds are formed with other gifted students of color (Reis \& McCoach, 2000). Friendships formed with other gifted Black or Biracial students may also mitigate feelings of isolation and alienation (Grantham \& Ford, 2003).

From a critical race theoretical frame, the apparent lack of Othering reported by student participants may be attributed to hegemony, as the Black and Biracial students themselves may have shunned their Black-ness in order to fit in with their classmates (Andrews, 2012; Chikkatur, 2012; Ford, Harris, \& Schruger, 1993). As mentioned previously, racelessness may have been a more attractive option for student participants, as it minimized the impact of their racial differences. Also, critical race theorists challenge claims of neutrality (Delgado, 1995; Ladson-Billings \& Tate, 1995). While students, teachers, and parents reported strong feelings of inclusiveness, there were indications of systemic racism and racial microaggressions. For example, Kade experienced discrimination from his classmates when he wore his hair in cornrows. I also documented hints of colorblindness, especially when one teacher participant questioned whether we were not past "all of this.” Colorblindness and hegemony 
misrepresent the reality of systemic racism and leaves oppression unchallenged (Delgado, 1995; Ladson-Billings \& Tate, 1995).

Despite the danger of colorblindness and hegemony, Discovery School has a reported culture of inclusivity that creates a sense of wellbeing for teachers and students. As suggested earlier, CRP and anti-racist components could further gifted Black and Biracial students' sense of belonging and wellbeing. These practices give those who work, teach, and learn in PWGSs the tools to critically interpret the overarching interplay of politics and ideology that influences the school, as well as critically reflect on one's own positionality and experiences. Furthermore, incorporating curriculum that is reflective of all students' current and historical contexts could increase students' sense of belonging.

Same-race relationships. Additionally the literature argues that same-race relationships may strengthen gifted Black and Biracial students' self-efficacy in gifted schools (Ford, 1996) and thus could further increase gifted Black and Biracial students’ sense of wellbeing. Again I return to a previous example of creative methods that increase diversity in PWGSs_-frontloading. One potential positive outcome of frontloading is the facilitation of vital same-race friendships for Black and Biracial students there (Reis \& mcCoach, 2000). With a more diverse student population, it is possible that parents of Black and Biracial students at Discovery School could form important friendships and offer support and a sounding board to each other in the face of discriminatory policies and racial microaggressions that may arise. 
In sum, my findings simultaneously reflected current literature and presented a unique perspective on the way that a PWGS addresses race and how gifted Black and Biracial students are affected. The data pointed the need for CRP and anti-racist practices in PWGSs. It also revealed the benefit of implementing methods such as frontloading to diversify student population. Finally, the findings suggested that within Discovery School, high-level academics and high teacher expectations create positive academic environments (and a sense of wellbeing) that are meeting the needs of gifted Black and Biracial students. The final section will suggest new avenues for future research.

\section{Suggestions for Future Research}

This study has touched on many aspects of gifted Black and Biracial students in PWGSs. However, it only begins to reveal the unique experiences of gifted students of color. Findings from this study suggest at least four new avenues for researching gifted students of color:

1. Because most TAG students in the Pacific Northwest region of the U.S. are placed in heterogeneous classes, repeating this study in a local neighborhood school could further illuminate the experiences of gifted students of color - this time within a general education setting. This study could be a salient component of a comparative analysis of gifted students of color in programs specifically tailored to meet the needs of high achieving cognitive and academic students and those in heterogeneous classrooms. 
2. I recommend that in future studies, the definition of gifted students is expanded to include other marginalized groups such as: Latino(a), Native American, and Southeast Asian. Results from this study could provide insight into the unique experiences of each of these racial categories and further elucidate similarities and differences regarding how gifted students from different racial groups negotiate racial identity, giftedness, and Othering.

3. Because my inquiry relied heavily on the voices of just a few students, teachers, and parents, it would be valuable to recreate this study, using a bigger participant pool. It might be beneficial to restructure the research methodology to rely more heavily on survey data and group interviews, as well as multiple sites, to incorporate as many participants as possible. Results from this study would provide a more robust perspective on the issue of talented and gifted students of color.

4. Finally, I believe it would be informative to continue this particular study, building on new theories born thereof. Specifically, I recommend implementing the previously suggested policy of inviting bright (and as of yet unidentified) students of color into Discovery School’s first/second grade classroom. By collecting data on the experiences of these students and the school-wide impact, themes could arise that speak to questions of equity of access and prior knowledge and experience.

\section{Conclusion}


Gifted education is the most segregated sector in public education (Borland, 2003; Ford, 1993, 2003; Sapon-Shavin, 2003). Thus, many gifted programs are predominantly White, normalize dominant culture, and do not adequately account for the unique needs of gifted Black and Biracial students (Ford, 1994, 1996, 1998, 2003; Ford, Grantham, \& Whiting, 2008). Presently most literature on gifted Black and Biracial students points to isolation, bullying, and stress surrounding identity development. Alternatively, this inquiry has argued that Black and Biracial gifted students value the academic rigor and social groups, thriving in programs specifically targeting their cognitive and academic propensity. However, this study also elucidated inequities in the field, which if corrected could create safer, more inclusive educational environments for gifted Black and Biracial students. For example, districts must change oppressive policies and teacher education programs must include issues of gifted education and equity. Through implementing more equitable policies, gifted Black and Biracial students who are currently not served in programs that meet their needs may find opportunities to be a part of an advanced academic community that also resonates with their selves as racial beings. Also, with increased awareness, the Black and Biracial students who attend Discovery School could feel valued as unique individuals and empowered to participate in the school community as Black and Biracial students.

The purpose of this study was to explore the ways in which a PWGS addresses issues of race. Through counternarratives, survey responses, email responses, student and teacher participants from Discovery School were able to share their experiences. Parent voices enhanced the study by adding another perspective on the challenges and 
successes of PWGS. Direct observation was also used as a way to become immersed in the setting and to cross-reference participants' responses.

As I conclude this work, I consider the numerous gifted Black and Biracial students who have been failed by the current system that, intentionally or not, overlooks, dismisses, and ignores their great potential. Interrupting the status quo begins by shining a light on current policies and procedures in gifted education, nurturing that which is working and being persistent to change that which falls short. All gifted students should feel valued, respected, and appropriately challenged by adults who have an authentic sense of deep-seated love and commitment to their potential. While work towards equity is slow and difficult, I believe that this study is a necessary step in achieving this goal. 
PREDOMINANTLY WHITE GIFTED SCHOOLS

\section{References}

Adams-Byers, J., Whitsell, S. S., Moon, S. (2004). Gifted students perceptions of the academic and social/emotional effects of homogeneous and heterogeneous grouping. Gifted Child Quarterly, 48(1), 7-20. doi:

\section{$10.1177 / 001698620404800102$}

Akom, A. A. (2008). Black metropolis and mental life: Beyond the 'burden of acting White' towards a third wave of critical racial studies. Anthropology and Education Quarterly, 39(3), 247-265. doi: 10.1111/j.1548-1492.2008.00020.x

Akos, P. \& Ellis, C. M. (2008). Racial identity development in middle school: A case for school counselor individual and systemic intervention. Journal of Counseling and Development, 86(1), 26-33. doi 10.1002/j.1556-6678.2008.tb00622.x

Alexander, J. E., O’Boyle, M. W., \& Benbow, C. P. (1996). Developmentally advanced EEG alpha power in gifted male and female adolescents. International Journal of Psychophysiology, 23(1), 25-31. doi: 1 0.1016/0167-8760(96)00031-1

Ambrosio, J. (2014). Teaching the psychosocial subject: White students and racial privilege. International journal of qualitative studies in education, 27(10), 13761394. doi: 10.1080/15210960.2010.481199

Andrews, D. J. C. (2012). Black achievers’ experiences with racial spotlighting and ignoring in a predominantly White high school. Teachers College Record, 114 (10), 1-46. Retrieved from http://www.tcrecord.org.proxy.lib.pdx.edu/library/content.asp?contentid=16780 
Baker, P. (2005). The impact of cultural biases on African American students' education. Education and urban society, 37(3), 243-256. doi: $10.1177 / 0013124504274187$

Banning, M. (1999). Race, class, gender, and classroom discourse. In L. Parker, D. Deyhele, \& S. Villenas (Eds.), Race is...race isn't: Critical race theory and qualitative studies in education (pp. 7-30). Boulder, CO: Westview Press.

Barker, P. (1999). All things to all accusers. New Statsman, 129(4429). Retrieved from http://www.newstatesman.com/node/134426

Baxter, P., \& Jack, S. (2008). Qualitative case study methods: Study design and implementation for novice researchers. The Qualitative Report, 13(4), 544-559. Retrieved from http://media.usm.maine.edu/ lenny/CAMP\%20SUSAN\%20CURTIS/baxterCASE\%20STUDY.pdf

Bell, L. A. (2003). Telling tales: What stories can teach us about racism. Race, Ethnicity, and Education, 6 (1), 3-28. doi: 10.1080/1361332032000044567

Benbow, C. P, \& Stanley, J. C. (1996). Inequity in equity: How equity can lead to inequity for high-potential students. Psychology, Public Policy, and Law, 2(2), 249-292. doi: 10.1076-8971.2.249

Bireda, M. R. (2011). Schooling poor minority children: New segregation in the postBrown era. Lanham, MD. Rowman \& Littlefield. 
Blakley, M. L. (1999). Scientific racism and the biological concept of race. Literature and Psychology: A journal of psychoanalytic and cultural criticism, 45(1), 2943.

Blank, O., Knowles, L. L., \& Prewitt, K. (1970). Institutional racism in America. Englewood Cliffs, NJ: Prentice Hall.

Blatt, S. J. (1995). The destructiveness of perfectionism: Implications for the treatment of depression. American Psychologist, 50(12), 1003-1020.

Bodmer, W. F., \& Cavalli-Sforza, L. L. (1970). Intelligence and race. Scientific American, 223(4), 19-29. doi: 10.1038/scientificamerican1070-19

Bogdan, R. C., \& Biklen, S. K. (2003). Qualitative research for education: An introduction to theories and methods ( $4^{\text {th }}$ ed.). New York: Pearson Education Group.

Bonilla-Silva, E. (2003). Racism without racists: Color-blind racism and the persistence of racial inequality in the United States. Lanham, MD: Rowman \& Littlefield.

Borg, W. R., \& Gall, M. D. (1989). Educational research: An introduction ( $5^{\text {th }}$ ed.). New York: Longman.

Borland, J. H. (1997). The construct of giftedness. Peabody Journal of Education, 72(34). 6-20. doi: 10.1080/0161956X.1997.9681863

Borland, J. H. (2003). The death of giftedness: Gifted education without gifted children. In J. H. Borland (Ed.) Rethinking gifted education (pp. 105-126). New York: Teachers College Press. 
Borland, J. H. (2009). Myth 2: The gifted constitute 3\% to 5\% of the population. Moreover, giftedness equals high IQ, which is a stable measure of aptitude: Spinal tap psychometrics in gifted education. Gifted Child Quarterly, 53(4), 236238. Retrieved from http://gcq.sagepub.com.proxy.lib.pdx.edu/content/53/4/236

Boykin, A. W. \& Ellison, C. M. (1995). The multiple ecologies of black youth socialization: An afrographic analysis. In R. T. Taylor (Ed.) African American youth: Their social and economic status in the United States (pp. 93-128). Westport, CT: Greenwood Press.

Brayboy, B. M., Castango, A. E., \& Maughan, E. (2007). Chapter 6 equality and justice for all? Examining race in education scholarship. Review of Research in Education, 31, 159-194. doi: 10.3102/0091732X07300046159

Briggs, C. J., Reis, S. M., \& Sullivan, E. E. (2008). A national view of promising programs and practices for culturally, linguistically, and ethnically diverse gifted and talented students. Gifted Child Quarterly, 52(2), 131-145 doi: $10.1177 / 0016986208316037$

Burley, H., Barnard-Brak, L., Marbley, A. F., \& Deason, C. (2010). African American millennials: A profile of promise. Gifted Child Today, 32(2), 47-54. Retrieved from http://files.eric.ed.gov/fulltext/EJ881328.pdf

Cabrera, N. L. (2012). Working through whiteness. Albany, NY: State University of New York Press. 
Callahan, C. M. (2005). Identifying Gifted Students From Underrepresented Populations. Theory into Practice, 44(2), 98-104. Retrieved from http://wwwtandfonline-com.proxy.lib.pdx.edu/doi/pdf/10.1207/s15430421tip4402_4

Callahan, C. \& Elchner, H. (2010). I.Q. tests and your child. Retrieved from http://www.nagc.org/index.aspx?id=960.

Carr, L. G. (1997). “Color-blind” racism. Thousand Oaks, CA: Sage.

Carter, P. (2005). Keepin' it real: School success beyond Black and White. New York: Oxford University Press.

Carter, P. L. (2006). Straddling boundaries: Identity, culture, and school. Sociology of Education, 79, 304-328. doi: 10.1177/003804070607900402

Castango, A. E. (2008). “I don’t want to hear that!”: Legitimating whiteness through silence in schools. Anthrolpology \& Education Quarterly, 39(3), 314-333. doi: 10.1111/j.1548-1492.2008.00024.x

Chikkatur, A. (2012). Difference matters: Embodiment of and discourse on difference at an urban public high school. Anthropology and Education, 43(1), 82-100. doi: 10.1111/j.1548-1492.2011.01158.x

Children's Defense Fund. (2011). Portrait of inequality: Black children in America. Washington, D. C.

Clark, B. (1997). Social ideologies and gifted education in today's schools. The Peabody Journal of Education, 72(3-4), 81-100. doi:

10.1080/0161956X.1997.9681867 
Cohen, L. M. (1996). Mapping the domains of ignorance and knowledge in gifted education. Roeper Review, 18(3), 183-189. doi: 10.1080/02783199609553732

Collins, P. H. (2012). Social inequalities, power, and politics: Intersectionality and American pragmatism in dialogue. Journal of Speculative Philosophy, 26(2), 442-457. Retrieved from http://muse.jhu.edu.proxy.lib.pdx.edu/journals/journal_of_speculative_philosoph y/v026/26.2.collins.html

Conchas, G. Q. (2006). The color of success: Race and high-achieving urban youth. New York: Teacher College Press.

Coner-Edwards, A. F. \& Spurlock, J. (1988). Black families in crisis: The middle class. New York: Brunner/Mazel.

Corbin, J., \& Strauss, A. (2008). Basics of qualitative research: Techniques and procedures for developing grounded theory. Thousand Oaks, CA. Sage.

Creswell, J. W. (1998). Qualitative inquiry and research design: Choosing among five traditions. Thousand Oaks, CA: Sage.

Cross, T. L. (2003). Rethinking gifted education: A phenomenological critique of the politics and assumptions of the empirical-analytic mode of inquiry. In J. H. Borland (Ed.) Rethinking gifted education (pp. 72-79). New York: Teachers College Press.

Cross, W. E. (1971). The negro to black conversion experience. New York: The East. Cross, W. E. (1994). Nigrescence theory: Historical and explanatory notes. Journal of Vocational Behavior, 44, 119-123. doi: 10.1006/jvbe.1994.1008 
Cross, W. E. \& Cross, T. B. (2008). Racial-ethnic-cultural identity development in childhood: Theory, research, and models. In C. McKown \& S. Quintana (Eds.) Handbook of race, racism, and the developing child. Hoboken, NJ: Wiley Press.

Cross, W. E., \& Vandiver, B. J. (2001). Nigrescence theory and measurement: Introducing the Cross Racial Identity Scale (CRIS). In J. G. Poterotto, J. M. Casas, L. A. Suzuki, \& C. M. Aander (Eds.). Handbook of multicultural counseling. Thousand Oaks, CA: Sage.

Dai, D. \& Renzulli, J. (2008). Snowflakes, living systems, and the mystery of giftedness. Gifted Child Quarterly, 52(2), 114-130. doi: 10.1177/0016986208315732

Davidson Institute for Talent Development. (2013). Gifted education policies for Oregon [data file]. Retrieved from http://www.davidsongifted.org/db/state_policy_oregon_10038.aspx.

Davidson, J., \& Davidson, B. (2004). [Review of the book Genius denied: How to stop wasting our brightest young minds]. Davidson Institute for Talent Development. Retrieved from http://www.davidsongifted.org/db/Articles_id_10334.aspx.

Decuir, J., \& Dixson, A. (2004). "So when it comes out, they aren’t that surprised that it is there”: Using critical race theory as a tool of analysis of race and racism in education. Educational Researcher, 33, 26-31. Retrieved from http://www.jstor.org.proxy.lib.pdx.edu/stable/3699853?seq=1\#page_scan_tab_co ntents

Delgado, R. (1995). Critical race theory: The cutting edge. Philadelphia, PA: Temple University Press. 
PREDOMINANTLY WHITE GIFTED SCHOOLS

Dennis, R. M. (1995). Social Darwinism, scientific racism, and the metaphysics of race. The Journal of Negro Education, 64(3), 243-252. Retrieved from http://www33.homepage.villanova.edu/edward.fierros/pdf/Dennis,\%20Social\%2 0Darwinism.pdf

Desai, D. (2010). The challenge of new colorblind racism in art education. Art Education, 63(5), 21-28. Retrieved from http://web.a.ebscohost.com.proxy.lib.pdx.edu/ehost/pdfviewer/pdfviewer?vid=4 \&sid=80885d84-2b73-49ce-90c2-845921f57b2d\%40sessionmgr4001\&hid=4201

DiAngelo, R. \& Sensoy, O. (2010). Ok, I get it! Now tell me how to do it!: Why we can’t just tell you how to do critical multicultural education. Multicultural Perspectives, 12(2), 97-102. doi: 10.1080/15210960.2010.481199

Dixon, D. N., \& Scheckel, J. R. (1996). Gifted adolescent suicide: The empirical base. The Journal of Secondary Gifted Education, 7(3), 386-392. doi:

\section{$10.1177 / 1932202 X 9600700303$}

Douglas, B., Lewis, C. W., Douglas, A., Scott, M. E., \& Garrison-Wade, D. (2008). The impact of White teachers on the academic achievement of Black students: An exploratory qualitative analysis. Educational Foundations, 22(1-2), 47-62. Retrieved from http://files.eric.ed.gov/fulltext/EJ839497.pdf

Downey, D., \& Ainsworth-Darnell, J. (2002). The search for oppositional culture among black students. American Sociological Review, 67(1). Retrieved from http://www.jstor.org.proxy.lib.pdx.edu/stable/pdfplus/3088939.pdf?acceptTC=tr ue 
D’Souza, D. (1995). End of racism: Principles for a multiracial society. New York: Free Press.

DuBois, W. E. B. (1973). The education of Black people: Ten critiques 1906-1960. H. Apetheker (Ed.). Amherst, MA: The University of Massachusetts Press.

Duncan, G. A. \& McCoy, H. (2007). Black adolescent racial identity and respectability. The Negro Educational Review, 58(1-2), 35-48. Retrieved from http://www.jstor.org.proxy.lib.pdx.edu/stable/pdfplus/3088939.pdf

Dutton, S. E., Singer, J. E., \& Devlin, A. S. (1996). Racial identity of children in integrated, predominantly white, and black schools. The Journal of Social Psychology, 138(1), 41-53. doi: 10.1080/00224549809600352

Farkas, S. \& Duffett, A. (2008). Results from a national teacher survey. High achieving students in the era of NCLB, 49-82. Retrieved from http://www.edexcellencemedia.net/publications/2008/200806_highachievingstud entsintheeraofnochildleftbehind/20080625-farkas-pp.pdf

Feldhusen, D. H. (2003). A developmental, evolutionary perspective on giftedness. In J. H. Borland (Ed.) Rethinking gifted education (pp. 9-33). New York: Teacher College Press.

Feldhusen, D. H., \& Moon, S. M. (1992). Grouping gifted students: Issues and concerns. Gifted Child Quarterly, 36(2), 63-67. doi: 10.1177/001698629203600202

Fieldler, E. D., Lange, R. E., Winebrenner, S. (1993). In search of reality: Unraveling the myths about tracking, ability grouping, and the gifted. Roeper Review, 16(1), 3-7. $10.1080 / 02783199309553525$ 
Fish, J. M. (2002). Race and intelligence: Separating science from myth. Mahwah, NJ: Erlbaum.

Fisher-Doiron, N., \& Irvine, S. (2009). Going beyond the basics to reach all children. Principal, 88(5). 26. Retrieved from http://web.a.ebscohost.com.proxy.lib.pdx.edu/ehost/pdfviewer/pdfviewer?vid=5 \&sid=b7cbcc15-a0b6-4af8-b2e4-ee892b3b95d1\%40sessionmgr4003\&hid=4201

Flick, U. (2007). Designing qualitative research. Thousand Oaks, CA: Sage.

Ford, D. Y. (1994). The recruitment and retention of African American students in gifted programs: Implications and recommendations. Storres, CT: The National Research Center for Gifted and Talented.

Ford, D. Y. (1996). Reversing underachievement among gifted students of color: Promising practices and programs. New York: Teachers College Press.

Ford, D. Y. (1998). The underrepresentation of minority students in gifted education: Problems and promises in recruitment and retention. The Journal of Special Education, 32 (1), 4-14. doi: 10.1177/002246699803200102

Ford, D. Y. (2003). Desegregating gifted education: Seeking equity for culturally diverse students. In J. H. Borland (Ed.) Rethinking gifted education (pp. 143-158). New York: Teachers College Press.

Ford, D. Y., Grantham, T. G., \& Whiting, G. W. (2008). Another look at the achievement gap: Learning from the experiences of gifted students of color. Urban Education, 43(2), 216-239. doi: 10.1177/0042085907312344 
Ford, D. Y., \& Harris, J. J. (1999). Multicultural gifted education. New York: Teachers College Press.

Ford, D.Y., Harris, J., \& Schuerger, J.M. (1993). Racial identity development among gifted students of color: Counseling issues and concerns. Journal of Counseling and Development, 71, 409-417. doi: 10.1002/j.1556-6676.1993.tb02657.x

Ford, D. Y., \& Whiting, G. W. (2010). Beyond testing: Social and psychological considerations in recruiting and retaining gifted students of color. Journal for the Education of the Gifted, 34(1), 131-155. doi: 10.1177/016235321003400106

Fordham, S., \& Ogbu, J. (1986). Black students' school success: Coping with 'the burden of acting white'. The Urban Review, 18(3), 176-206. doi: 10.1007/BF01112192

Foster, K. M. (2005). Diet of disparagement: the racial experiences of black students in a predominantly white university. International Journal of Qualitative Studies in Education, 18(4), 489-505. doi: 10.1080/09518390500137659

Freire, P. (2000). Pedagogy of the heart. New York: Continuum Press.

Frye, B. J., \& Vogt, H. A. (2010). The causes of underrepresentation of African American children in gifted programs and the need to address this problem through more culturally responsive teaching practices in teacher education programs. Black History Bulletin, 73(1), 11-17.

Fryer, R. G. (2006). “Acting White”: The social price paid by the best and brightest minority students. Education Next, 6(1), 52-61. Retrieved from http://www.hoover.org.proxy.lib.pdx.edu/publications/ednext/3393481.html 
Gallagher, J. J. (1988). Our love/hate affair with gifted children. Gifted Child Today, 11(1), 55-57.

Gallagher, J. J. (1996). A critique of critiques of gifted education. Journal for the Education of the Gifted, 19(2), 234-249.

Gallagher, J. J. (2000). Unthinkable thoughts: Education of gifted students. Gifted Child Quarterly, 44(1), 5-12. doi: 10.1177/001698620004400102

Gardener, H. (1983). Frames of mind: Theory of multiple intelligences. New York: Basic Books.

Garland, J. \& Chakkraborti, N. (2006). Race, space, and place. Ethnicities, 6(2), 159177.

Gillborn, D. (2005). Education policy as an act of white supremacy: whiteness, critical race theory and education reform, Journal of Education Policy, 20(4), 485-505. doi 10.1080/02680930500132346

Goetz, J. P., \& LeCompte, M. D. (1984). Ethnography and qualitative design in educational reseach. New York: Academic Press.

Grantham, T. G., \& Ford, D. Y. (2003). Beyond self-concept and self-esteem: Racial identity and gifted African American students. High School Journal, 87(1), 1829. doi 10.1353/hsj.2003.0016

Gravelee, C. C. (2009). How race becomes biology: An embodiment of inequity. American Journal of Physical Anthropology, 139(1), 47-57. doi: 10.1002/ajpa.20983

Gross, M. U. M. (2003). Exceptionally gifted students (2 ed.). London: Routledge. 
Groves, R. M., Fowler Jr, F. J., Couper, M. P., Lepkowski, J. M., Singer, E., \& Tourangeau, R. (2013). Survey methodology. John Wiley \& Sons. Hoboken, NJ: John Wiley and Sons.

Hackman, H. W. (2005). Five essential components for social justice education. Equity and Excellence in Education, 38, 103-109. doi 10.1080/10665680590935034

Hammersley, M., \& Atkinson, P. (1995). Ethongraphy. London: Routeledge.

Hanssen, E. (1998). A White teacher reflects on institutional racism. Phi Delta Kappan, 79(9), 694-698. Retrieved from http://public.hcesc.org/resources/Culturally\%20Responsive\%20Practice/Awhitet eacherreflects.pdf

Hargrove, B. H., \& Saey, S. E. (2011). School teacher perceptions of barriers that limit the participation of African American males in public schools gifted programs. Journal for the Education of the Gifted, 34(3), 434-467. doi: 10.1177/016235321103400304

Harmon, D. (2001). They won’t teach me: The voices of gifted African American innercity students. Roeper Review, 24(2), 68-75. doi 10.1080/02783190209554132

Harrison, C. H. (2014). How to frame and explain the survey data in your honors thesis. Retrieved from http://www.bibme.org/citation-guide/APA/lecture.

Hartigan, J. (2006). Saying “socially constructed” is not enough. Rethinking Race and Human Variation. Retrieved from http://www.understandingrace.org/resources/pdf/rethinking/hartigan.pdf 
Hebert, T. P. (2002). Educating gifted students from low socioeconomic backgrounds: Creating visions of a hopeful picture. Exceptionality, 10(2), 127-138. doi: 10.1207/S15327035EX1002_6

Helm, J. E. (1984). Toward a theoretical explanation of the effects of race on counseling: Model. The Counseling Psychologist, 12(4). 153-165. doi: $10.1177 / 0011000084124013$

Henderson, L. (2007). Ebony Jr! and "soul food": the construction of middle-class African American identity through the use of traditional southern food ways. MELUS, 32(4), 81-98. Retrieved from http://www.jstor.org/stable/30029833

Henfield, M. S., Moore, J. L. I. I. ., \& Wood, C. (2008). Inside and outside Gifted Education Programming: Hidden Challenges for African American Students. Exceptional Children, 74(4), 433-450.

Herrnstein, R. J., \& Murray, C. A. (1994). The bell curve: Intelligence and class structure in American life. New York: Free Press.

Hilliard, A. (2003). No mystery: Closing the achievement gap between Africans and excellence. In T. Perry, C. Steele, \& A. Hilliard (Eds.), Young, gifted, and Black: Promoting high achievement among African American students (pp. 131-165). Boston, MA: Beacon.

hooks, b. (2000). Where we stand: Class matters. New York: Routledge. Houghton, C. E., Casey, D., Shaw, D., \& Murphey, K. (2010). Ethical challenges in qualitative research. Nursing Resources, 18(1), 15-25. Retrieved from http://www.ncbi.nlm.nih.gov/pubmed/21138082 
Howard, T. C. (2002). Hearing footsteps in the dark: African American students' descriptions of effective teachers. Journal of Education for Students Placed At Risk, 7(4). 425-444. doi: 10.1207/S15327671ESPR0704_4

Howard, T. C. (2014) Black male(d): Peril and promise in the education of African American males. New York: Teachers College Press.

Hsieh, H. \& Shannon, S. E. (2009). Three approaches to qualitative content analysis. Qualitative Health Research, 46, 6-28. doi: 10.1177/104973230527668

Huff, R. E., Houskamp, B. M., Watkins, A. V., Stanton, M., \& Tavegia, B. (2005). The experiences of parents of gifted African American children: A phenomenological study. Roeper Review, 27(4), 215-221. doi 10.1080/02783190509554321

Hyra, D. S. (2006). Racial uplift? Intra-racial class conflict and the economic revitalization of Harlem and Bronzeville. City \& Community, 5(1), 71-92. doi: 10.1111/j.1540-6040.2006.00156.x

Irvine, D. J. (1991). Gifted education without state mandate: The importance of vigorous advocacy. Gifted Child Quarterly, 35(4), 196-199. doi: 10.1177/001698629103500407

Isaacs, M. L., \& Duffus, L. R. (1995). Scholars’ club: A culture of achievement among minority students. The School Counselor, 42(3), 204-210.

Jackson, P.S. (1998). Bright star — black sky: A phenomenological study of depression as a window into the psyche of the gifted adolescent. Roeper Review, 20(3), 215-221. Doi 10.1080/02783199809553894 
PREDOMINANTLY WHITE GIFTED SCHOOLS

Jarvis, J. M. (2009). Planning to unmask potential through responsive curriculum: The “Famous Five” exercise. Roeper Review, 31, 234-241. doi $10.1080 / 02783190903177606$

Jay, G. (2005). Whiteness studies and the multicultural literature classroom. MELUS, 30(2). 99-121. Retrieved from https://pantherfile.uwm.edu/gjay/www/Whiteness/whitenessandlit.pdf

Jensen, A. (1969). How much can we boost IQ and scholastic achievement? Harvard Educational Review, 39(1), 1-123. Retrieved from http://emilkirkegaard.dk/en/wp-content/uploads/How-Much-Can-We-Boost-IQand-Scholastic-Achievement-OCR.pdf

Jolly, J. L. (2009). A resuscitation of gifted education. American Educational History Journal, 36(1), 37-51.

Jorgenson, D. L. (1989). Participant observation: A methodology for human studies. Los Angeles, CA: Sage.

King, J. (1991). Dysconscious racism: Ideology, identity, and the miseducation of teachers. Journal of Negro Education, 60(2), 133-146. Retrieved from http://mcreadinglist.pbworks.com/f/King+\%281991\%29.pdf

King, K., Kozleski, E. B., \& Lansdowne, K. (2009). Where are all the students of color in gifted education? Principal, 88(5), 16-20. Retrieved from http://teachers.henrico.k12.va.us/arthur_ashe/smith_p/gifted/Websites_and_Link s_files/VAG_Summer2010.pdf 
Kitano, M. K. (2003). What's missing in gifted education reform. In J. H. Borland (Ed.), Rethinking gifted education (pp. 159-170). New York: Teachers College Press.

Kulik, C. C., \& Kulik, J. (1982). Effects of ability grouping on secondary school students: A meta-anaylsis of evaluation findings. American Educational Research Journal, 19(3), 415-428. doi: 10.3102/00028312019003415

Kumashiro, K. K. (2009). Against common sense: Teaching and learning toward social justice. New York: Routledge.

Kvale, S. (1996). InterViews: An introduction to qualitative research interviewing. Thousand Oaks, CA: Sage.

Ladner, J. A., Hare, N., Jackson, J. J., Vargus, I. D., Poussaint, A. F., \& Browne, R. S.. (1978). The Black middle class defined. Ebony, 28(10). 44-48.

Ladson-Billings, G. J. (1999). Just what is critical race theory and what's it doing in a nice field like education. In L. Parker, D. Deyhele, \& S. Villenas (Eds.), Race is...race isn't: Critical race theory and qualitative studies in education (pp. 730). Boulder, CO: Westview Press. dio: 10.1080/095183998236863

Ladson-Billings, G. J. (2000). Fighting for our lives: Preparing teachers to teach African American students. Journal of Teacher Education, 51(3), 206-214. dio: $10.1177 / 0022487100051003008$

Ladson-Billings, G. J. (2009). The dreamkeepers: Successful teachers of African American children, $2^{\text {nd }}$ edition. San Francisco, CA: Jossey-Bass. 
Ladson-Billings, G. J., \& Tate, W. F. (1995). Towards a critical race theory of education. Teachers College Record, 97(1). 47-68. Retrieved from http://www.kakali.org/edld6384/8561/readings/ladson-billings-and-tate.pdf

Lawson Davis, J. (2013). Bright, talented, and black: A guide for families of African American gifted learners. Scottsdale, AZ: Great Potential Press.

Lincoln, Y. S., \& Guba, E. G. (1985). Naturalistic inquiry. Newbury Park, CA: Sage.

Lorde, A. (1995). Age, race, class, and sex: Women redefining difference. In B. GuySheftall (Ed.) Words on fire: An anthology of African American feminist thought. New York: New Press.

Lucas, S. R., \& Beresford, L. (2010). Naming and classifying: Theory, evidence, and equity in education. Review of Research in Education, 34(1), 25-84. doi 10.3102/0091732X09353578

Lundy, G. F. (2003). The myths of oppositional culture. Journal of Black Studies, 33(4), $459-460$.

Lynch, K., \& Baker, J. (2005). Equality in education: An equality of condition perspective. Theory and Research in Education, 3(2). 131-164.doi $10.1177 / 147787850505329$

MacFarlane, A. G. (2009). Operatively white? Exploring the significance of race and class through the paradox of middle class blackness. Law and Contemporary Problems, 72(4). 1163-196. Retrieved from http://scholarship.law.duke.edu/cgi/viewcontent.cgi?article=1549\&context=lcp 
PREDOMINANTLY WHITE GIFTED SCHOOLS

MacPherson, W. (1999). The Stephen Lawrence inquiry. London, England: Stationary Office.

Marshall, C. \& Gerstl-Pepin, C. (2004). Reframing educational politics for social justice. Upper Saddle River, NJ: Pearson.

Martin, L. L. (2010). Strategic assimilation or creation of symbolic blackness: middleclass blacks in suburban contexts. Journal of African American Studies, 14(2), 234-246. doi: 10.1007/s12111-008-9075-0

Matus, C., \& Infante, M. (2011). Undoing diversity: knowledge and neoliberal discourses in colleges of education. Discourse: Studies in the Cultural Politics of Education, 32(3), 293-307. doi 10.1080/01596306.2011.573248

Maxwell, J. A. (2005). Qualitative research design: An interactive approach. Thousand Oaks, CA: Sage.

McArdle, E. (2008). Sociologists on colorblind racism. Contexts, 7(1), 34-37. doi 10.1525/ctx.2008.7.1.34

McIntosh, P. (1990). White privilege: Unpacking the invisible knapsack. Independent Schools, 49(2), 31-36. Retrieved from http://files.eric.ed.gov/fulltext/ED355141.pdf\#page $=43$

Merriam, S. B. (2009). Qualitative research: A guide to design and implementation. San Francisco, CA: Jossey-Bass.

Milner, H. R. (2006). The promise of Black teachers’ success with Black students. Educational Foundations, 20(3). 89-104. Retrieved from http://files.eric.ed.gov/fulltext/EJ794734.pdf 
Milner, H. R. \& Ford, D. Y. (2007). Cultural considerations in the underrepresentation of culturally diverse elementary students in gifted education. Roeper Review, 29(3), 166-173. doi 10.1080/02783190709554405

Mipoori, A. (October 9, 2012). Race, violence, civil society. Race Talks. Portland, OR. Mischler, E. G. (1986). Research interviewing: Context and narrative. Cambridge, MA: Harvard Press.

Moon, S. M. (1991). Case study research in gifted education. In N. K. Buchanan \& J. F. Feldhusen (Eds.) Conducting and evaluating research in gifted education: A handbook of methods and applications (pp. 157-178). New York, NY: Teachers College Press.

Moore, P. (2011). Appreciating the political ethnography of master stories and counternarratives. Cultural Studies of Science Education, 6(4). 837-840. doi 10.1007/s11422-011-9367-x

Moore, J. L., Ford, D. Y., \& Milner, R. (2005). Recruitment is not enough: Retaining African American students in gifted education. Gifted Child Quarterly, 49(1), 51-67. doi: 10.1177/001698620504900106

Morris, J. E. (2001). African American students and gifted education: The politics of race and culture. Roeper Review, 24(2). 59-62. doi 10.1080/02783190209554130

Morris, J. E. (2004). Can anything good come from Nazareth? Race, class, and African American schooling and community in urban South and Midwest. American Educational Research Journal, 41(1). 69-112. doi 10.3102/00028312041001069 
Naglieri, J. A., \& Ford, D. Y. (2003). Addressing underrepresentation of gifted minority children using the Naglieri Nonverbal Ability Test (NNAT). Gifted Child Quarterly, 47(2),155-160. doi: 10.1177/001698620304700206

Nasir, N. S. (2012). Racialized identities: Race and achievement among African American youth. Stanford, CA: Stanford Press.

National Association for Gifted Children. (2008). Gifted education in the U. S..

Washington, D. C.. Retrieved from http://www.nagc.org/index.aspx?id=532

National Association for Gifted Children. (2011). State of the nation in gifted education: A lack of commitment to talent development. Washington, D. C. Retrieved from http://www.nagc.org/uploadedFiles/Information_and_Resources/2010-

11_state_of_states/State\%20of\%20the\%20Nation\%20\%20(final).pdf

National Center for Educational Statistics. (2006). Percentage of gifted and talented children in elementary and secondary schools by sex, race/ethnicity, and state [data file]. Retrieved from http://nces.ed.gov/programs/digest/d10/tables/dt10_049.asp.

National Center for Education Statistics. (2011). Fast facts: Teacher trends [data file]. Retrieved from http://nces.ed.gov/fastfacts/display.asp?id=28.

Nayak, A. (2006). After race: Ethnography, race and post-race theory. Ethnic \& Racial Studies, 29(3), 411-430. doi: 10.1080/01419870600597818

Neal-Barnett, A., Stadulis, R., Singer, N., Murray, M. \& Demmings, J. (2005). Assessing the effects of the acting White accusation. The Urban Review, 42(2), 102-122. doi 10.1007/s11256-009-0130-5 
Neihart, M. (2007). The socioaffective impact of acceleration and ability grouping. Gifted Child Quarterly, 51(4), 330-341. doi: 10.1177/0016986207306319

Obama, B. (2004). Keynote address. Democratic National Convention. Boston, MA. O’Connor, C., Lewis, A. \& Mueller, J. (2007). Researching “Black” educational experiences and outcomes: Theoretical and methodological considerations. Educational Researcher, 36(9), 541-552.

Ogbu, J. (1981). Origins of human competence: A cultural-ecological perspective. Child Development, 52, 413-429. Retrieved from http://www.jstor.org.proxy.lib.pdx.edu/stable/pdfplus/1129158.pdf?acceptTC=tr ue

Ogbu, J. (1995). Cultural problems in minority education: Their interpretations and consequences: Part One-Theoretical background. The Urban Reviewer, 27(3). 189-205. doi: 10.1007/BF02354397

Ogbu, J. (1995). Cultural problems in minority education: Their interpretations and consequences: Part Two—Case Studies. The Urban Reviewer, 27(4), 271-297. doi: 10.1007/BF02354409

Ogbu, J. (1998). Voluntary and involuntary minorities: A cultural-ecological theory of school performance with some implications for education. Anthropology and Education Quarterly 29(2), 155-188. doi: 10.1525/aeq.1998.29.2.155

Ogbu, J. (2004). Collective identity and the burden of "acting white” in Black history, community, and education. The Urban Reviewer, 36(1). 1-35. doi:

10.1023/B:URRE.0000042734.83194.f6 
PREDOMINANTLY WHITE GIFTED SCHOOLS

Olszewski-Kubilius, P. (2006). Addressing the achievement gap between minority and non-minority children: Increasing access and achievement through Project EXCITE. Gifted Child Quarterly, 29(2), 28-37. doi: $10.1177 / 016235320402800202$

Omi, M. \& Winant, H. (1994). Racial formations in the United States from the 1960s to the 1990s. New York, NY: Routledge.

Oregon Revised Statutes. (2012). Definition of Giftedness. §§ 343.391. Retrieved from http://www.ode.state.or.us/policy/state/laws/tagors.pdf

Pattillo, M. E. (1999). Black picket fences: Privilege and peril among the Black middle class. Chicago, IL: University of Chicago Press.

Perry, P. (2002). Shades of white: White kids and racial identities in high school. Durham, NC: Duke University Press.

Perry, T. (2003). Tackling the myth of Black students' intellectual inferiority.". The Chronicle of Higher Education, 49(18), 10-13. Retrieved from https://inthenews.unt.edu/sites/default/files/PDF/2003/1/10/01_10_2003_CHE_T ackling.pdf

Perry, T., Steele, C., \& Hilliard, A. (2003). Young, Gifted, and Black: Promoting High Achievement Among African-American Students. Boston, MA: Beacon Press.

Portland Public Schools. (2013). Discovery School Alternative Program. Portland, OR. Retrieved from http://www.pps.k12.or.us/schools/Discovery School/. 
PREDOMINANTLY WHITE GIFTED SCHOOLS

Portland Public Schools. (2012). Enrollment summaries and reports. Portland, OR.

Retrieved from http://www.pps.k12.or.us/files/dataanalysis/2012_Enrollment_Summary.pdf

Preckel, F., Gotz, T., \& Frenzel, A. (2010). Ability grouping of gifted students: Effects on academic self-concept and boredom. The British Journal of Educational Psychology, 8(3), 451-472. doi: 10.1348/000709909X480716

Prince, S. (2006). Will the real Black middle class please stand up?. Monthly Review, 58(3). 67-79.

Reis, S. M. \& McCoach, D. B. (2000). The underachievement of gifted students: What do we know and where do we go? Gifted Child Quarterly, 44(3), 152-170. doi: $10.1177 / 001698620004400302$

Renzulli, J. S. (1986). The three-ring conception of giftedness: A developmental model for creative productivity. In R. J. Sternberg \& J. E. Davidson (Eds.), Conceptions ofgiftedness (pp. 53-92). New York: Cambridge University Press.

Renzulli, J. S. \& Reis, S. M. (1997). The schoolwide enrichment model: A comprehensive plan for educational excellence. Mansfield, CT: Creative Learning Press.

Renzulli, J. S. \& Renzulli, S. R. (2010). The schoolwide enrichment model: A focus on student strengths and interests. Gifted Education International, 26(2-3), 140-173.

Richardsm H. V., Brown, A. F., \& Forde, T. B. (2007). Addressing diversity in schools. Teaching exceptional children, 64-68.

Roach, R. (2008). Assessing attitudes. Issues in Higher Education, 24(26). 16-19. 
Roberts, R. A., Bell, L. A., \& Murphey, B. (2008). Flipping the script: Analyzing youth talk about race and racism. Anthropology and Education Quarterly, 39(3), 334354. dio: 10.1111/j.1548-1492.2008.00025.x

Rogers, K. B. (2007). Lessons learned about educating the gifted and talented: A synthesis of research on educational practice. Gifted Child Quarterly, 51(4), 382396.

Roithmayr, D. (1999). Introduction to critical race theory in educational research and praxis. In L. Parker, D. Deyhle, S. Villenas (Eds.). Race is...race isn't. Boulder, CO: Westview Press.

Roulston, K. (2011). Interview “problems” as topics for analysis. Applied Linguistics, 32(1), 77-94. Retrieved from http://dx.doi.org.proxy.lib.pdx.edu/10.1093/applin/amq036

Rowley, S. J. \& Moore, J. A. (2001). Racial identity in context for the gifted African American student. Roeper Review, 24(2), 63-67. doi $10.1080 / 02783190209554131$

Saldana, J. (2009). The coding manual for qualitative researchers. Los Angles, CA: Sage.

Sapon-Sheven, M. (1994). Playing favorites: Gifted education and the disruption of community. Albany, NY: State University of New York Press.

Sapon-Shevin, M. (2003). Equity, excellence, and school reform: Why is finding common ground so hard? In J. H. Borland (Ed.) Rethinking gifted education (127-142). New York: Teachers College Press. 
Schwandt, T.A., \& Burgon, H. ( 2006). Evaluation and the study of lived experience. InI. F. Shaw, J. C. Greene, \& M. M. Mark (Eds.), The sage handbook of evaluation (pp.98-117). Newbury Park, CA: SAGE.

Schwandt, T., \& Cash, T. (2014). The origins, meaning and significance of qualitative inquiry in evaluation. Qualitative Inquiry in the Practice of Evaluation. JosseyBass: San Francisco, CA

Shields, C. M. (2002). A comparative study of student perceptions in homogeneous and heterogeneous classrooms. Roeper Review, 24(3), 115-119. doi $10.1080 / 02783190209554146$

Singleton, G. \& Linton, C. (2006). Courageous conversations about race. Thousand Oaks, CA: Corwin Press.

Skiba, R. J. (2011). Race is not neutral: A national investigation of African American and Latino disproportionality in school discipline. School Psychology Review, 40(1), 85-107. Retrieved from http://youthjusticenc.org/download/educationjustice/disparities/Race\%20is\%20not\%20Neutral.pdf

Smith-Maddox, R. \& Salzano, D. G. (2002). Using critical race theory, Paulo Freire’s problem-posing methose, and case study research to confront race and racism in education. Qualitative Inquiry, 8(1), 66-84. doi: 10.1177/107780040200800105

Staiger, A. (2004). Whiteness as giftedness: Racial formation at an urban high school. Social Problems, 51(2), 161-181. doi: 10.1525/sp.2004.51.2.161

Stake, R. E. (1995). The art of case study research. Thousand Oaks, CA: Sage. 
Sternberg, R. J. (1995). A triarchic approach to giftedness. New Haven, Conn: Yale University, NRCG/T.

Story, C. M. (1985). Facilitator of learning: A micro-ethnographic study of the teacher of the gifted. Gifted Child Quarterly, 29(4), 155-159. doi: 10.1177/001698628502900403

Sullivan, S. (2006). Revealing whiteness: The unconscious habit of racial privilege. Bloomington, IN: Indiana University Press.

Sumner, W. G. (1963). Social Darwinism. Englewood Cliffs, NJ: Prentice-Hall.

Swaitek, M. A. \& Lupkowski-Shoplik, A. (2003). Elementary and middle school student participation in gifted programs: Are gifted students underserved?. Gifted Child Quarterly, 47(2), 118-130. doi: 0.1177/001698620304700203

Tarca, K. (2005). Colorblind in control: The risks of resisting difference amid demographic change. Journal of the American Educational Studies Association, 38(2), 99-120. doi: 10.1207/s15326993es3802_3

Task Force for Instruction of Talented and Gifted Children. (2012). The quiet crisis in talented and gifted education in the state of Oregon. Salem, OR: Oregon Department of Education. Retrieved from http://www.ode.state.or.us/teachlearn/specialty/tag/sb-330-tag-task-force-report-final-10-1-12-blocher.pdf

Tatum, B. (1997). Why are all the black kids sitting together in the cafeteria? And other conversations about race. New York: Basic Books. 
Tatum, B. (2004). Family life and school experiences: Factors in the racial identity development of Black youth in White communities. Journal of Social Issues, 60(1), 117-135. doi 10.1111/j.0022-4537.2004.00102.x

Taylor, E. (1999). Critical race theory and interest convergence in the desegregation of higher education. In L. Parker, D. Deyhle, S. Villenas (Eds.). Race is...race isn't. Boulder, CO: Westview Press.

Thomas B. Fordham Institute. (2008). High-achieving students in the era of NCLB. Washington, D.C.

Thompson, A. (2005). Schooling race talk. Educational Researcher, 34(6). 22-29. Retrieved from http://www.jstor.org/stable/3699807

Thompson, L. A. \& Oehlert, J. (2010). The etiology of giftedness. Learning and Individual Differences, 20. 298-307. doi: 10.1016/j.lindif.2009.11.004

Thurston, C. M. (2002). Social and emotional development of gifted children: What do we know? Chicago, IL: Sourcebooks, Inc.

Tomlinson, C. \& Jarvis, J. M. (2009). Case studies of success: Supporting the academic success for students with high potential from ethnic minority and economically disadvantaged backgrounds. Journal for the Education of the Gifted, 37(3), 191219. doi $10.1177 / 0162353214540826$

Toshalis, E. (2015). Make me: Understanding and engaging student resistance in school. Cambridge, MA: Harvard Education Press. 
Townsend, B. L. (2000). The disproportionate discipline of African American learners: Reducing schools’ suspensions and expulsions. Exceptional Children, 66(3). 381-391. doi: $10.1177 / 001440290006600308$

Tozer, S., Senese, G. B., \& Violas, P. C. (2009). School and society: Historical and contemporary perspectives. Boston, MA: McGraw-Hill.

Treviño, A., Harris, M. A., \& Wallace, D. (2008). What's so critical about critical race theory?. Contemporary Justice Review, 11(1), 7-10. doi $10.1080 / 10282580701850330$

Tyson, K., Darity, W., \& Castellino, D. R. (2005). Its not a ‘Black thing’: Understanding the burden of acting white and other dilemmas of high achievement. American Sociological Review, 70(4), 582-605. doi: 10.1177/000312240507000403

VanTassel-Baska, J. (2003). Curriculum policy development for gifted programs: Converting issues in the field to coherent practice. In J. H. Borland (Ed.), Rethinking gifted education (173-185). New York: Teachers College Press.

VanTassel-Baska, J., Feng, A., Chandler, K., Quek, C., \& Swanson, J. (2009). Academic and affective profiles of low income, minority, and twice exceptional learners: The role of gifted program membership in enhancing self. Journal of Advanced Academics 20, (4) 698-735. doi: 10.1177/1932202X0902000406

Villenas, S., Deyhle, D., \& Parker, L. (1999). Critical race theory and praxis: Chicano(a)/Latino(a) and Navajo struggles for dignity, educational equity, and social justice. In L. Parker, D. Deyhle, S. Villenas (Eds.), Race is...race isn’t. Boulder, CO: Westview Press. 
Vonnegut, K. (1968). Welcome to the monkey house. New York: Delacorte Press.

West, C. (2001). Race matters. New York: Vintage Books.

White, E. (2012). Whiteness and teacher education. New York: Routledge.

Williams, D. G., \& Land, R. R. (2006). The legitimation of Black subordination: The impact of color-blind education on African American education. The Journal of Negro Education, 75(4), 579-588. Retrieved from http://www.jstor.org/stable/40034659

Winston, C. (2004). Science success, narrative theories of personality, and race self complexity: Is pace represented in the identity construction of African American adolescents?. New Directions For Child \& Adolescent Development, 2004(106), 55-77. doi: 10.1002/cd.116

Wise, T. (2008). White like me: Reflections on race from a privileged son. Berkley, CA: Soft Skull Print.

Wolcott, H. F. (1999). Ethnography: A way of seeing. Plymoth: AltaMira Press.

Yin, R. K. (1994). Case study research design and methods, $2^{\text {nd }}$ edition. Thousand Oaks, CA: Sage.

Yin, R. K. (2012). Applications of case study research. Thousand Oaks, CA: Sage. Z. Zavellos. (2013, January 9). The other sociologist analysis of difference [web log comment]. Retrieved from: http://othersociologist.com/otherness-resources/ Zhang, Y. \& Wildemuth, B. M. (2009). Qualitative analysis of content. In B. M. Wildemuth (Ed.), Applications of social research methods to questions in information and library science (300-319). Westport, CT: Libraries Unlimited. 
Appendix A

Letter of Informed Consent

Your child is invited to participate in a research study conducted by Clair Pople, doctoral student in the Graduate School of Education, Portland State University. Through this research, I hope to gather information about the impact of race on gifted students in a predominantly White gifted school.

If your child decides to participate, he or she will be asked to take part in three focus group sessions. The sessions will take 30 minutes each. Further, you and your child will be asked to complete a survey together, and you will be asked to respond to two email prompts. I will be observing various classes around your child's school for the duration of the data collection period.

Your child's participation in this study will be kept completely confidential. Your child's name will not be on any field notes, surveys, or other data collection materials. Subject's identities will be kept confidential by assigning a code to each participant. Information that links the participants name to the code, as well as other data collection materials, will be kept in the locked filing cabinet in my office. The focus group sessions and the observation periods will be recorded. These recordings will be transcribed and the video will be destroyed immediately.

Participation is entirely voluntary. Your child's decision to participate or not will not affect this/her relationship with Discovery School, the researcher, or with Portland State University. If your child decides to take part in the study, he or she may choose to withdraw at any time without penalty. Please keep a copy of this letter for your records.

If you have any concerns or problems about your son or daughter's participation in this study or his or her rights as a research subject, please contact Human Subjects Research Review Committee, PO Box 751. Their phone number is 503-725-2227 and email, hsrrc@pdx.edu. If you have questions about the study, contact Clair Pople at (503) 5052375.

Your signature means that you have read and understand the above information and agree that your child has permission to take part in this study. Please understand that you may withdraw your consent at any time without penalty, and that, by signing, you are not waving any claims, rights or remedies. The researcher will provide you with a copy of this form for your own records.

Signature of parent

Date

Print the name of the child 
Appendix B

Letter of informed Consent (Student Version)

Student's name:

Your parent (or guardian) has said it is okay for you to take part in a project about race and gifted education. If you choose to do it, you will be asked to participate in three focus groups and complete a survey with your parent. A researcher will be at your school observing classes, also.

If you want to rest, or stop completely, just tell me -you will not get into any trouble! In fact, if you do not want to do it at all, you do not have to. Also, if you have any questions about what you will be doing, just ask me to explain.

If you do want to participate, please sign your name on the line below. Remember, you can stop to rest at any time and if you decide not to take part anymore, let me know.

Signed:

Date: 
Appendix C

Student Interview Protocol

Name of Student Participant:

Host: Clair Pople

Date:

Site: Discovery School, Room \#

\section{Materials:}

- Refreshments

- Notepads

- Markers/pens/pencils

- Script

- Clock

\section{Part 1: Introduction}

Facilitator will:

- Allow time for student to get refreshments

- Explain the objective of the interview (to hear participant's stories about their race and if it affects their experiences at Discovery School)

- Explain confidentiality procedures and discuss the recording device

\section{Part 2: Questions}

1. Tell me a little bit about your school. What do you like about your school? What is challenging about your school?

2. In what ways are people similar in your school?

3. In what ways are people at your school different?

4. What is race?

5. What are some different races that you notice at your school?

6. What race are you? What is good about your race?

7. Do you think that it is ever hard to be your race? If so, why or in what ways?

8. Do you think your classmates/teachers notice your race? If so, how do you know? If not, what makes you say that? 
9. Do you talk about race with your friends and/or teachers at your school? What are these conversations like? Can you think of (and explain) a specific conversation?

10. Is there anything you wanted to say that we didn't get to today?

\section{Part 3: Wrap-up}

Facilitator will:

- Thank participant

- Offer one last opportunity for further input

- Explain how data will be used 
Appendix D

Teacher Interview Protocol

Name of Teacher Participant:

Host: Clair Pople

Date:

Site: Discovery School, Room \#

\section{Materials:}

- Notepads

- Markers/pens/pencils

- Script

- Clock

\section{Part 1: Introduction}

Facilitator will:

- Explain the objective of the interview

- Explain confidentiality procedures and discuss the recording device

\section{Part 2: Questions}

1. What is your background and what brought you to Discovery School?

2. How long working at Discovery School?

3. What are some things that Discovery School has done to meet the needs of students of color? What is going right?

4. Do you think it is challenging here for gifted Black and Biracial students? Why or why not?

5. In their day-to-day interactions with their peers, do you notice any differences between the gifted Black and Biracial students (as a whole) and the White students?

6. What about between the gifted Black and Biracial students and other students of color?

7. Have you ever heard of any bullying or discrimination among students? 
8. What is the role of teachers/admins in this issue?

9. What is the role of parents in this issue?

\section{Part 3: Wrap-up}

Facilitator will:

- Thank participant

- Offer one last opportunity for further input

- Explain how data will be used 
Appendix E

Parent Interview Protocol

Name of Parent Participant:

Host: Clair Pople

Date:

Site:

\section{Materials:}

- Notepads

- Markers/pens/pencils

- Script

- Clock

\section{Part 1: Introduction}

Facilitator will:

- Explain the objective of the interview

- Explain confidentiality procedures and discuss the recording device

\section{Part 2: Questions}

1. Why did you make the decision to enroll your child in Discovery School?

2. What do you like about the school?

3. How is the school different from your community school?

4. Discovery School is a predominantly White school. Did this factor into your decision to enroll your child there? How?

5. Do you and your child talk about race at home? If so, it what circumstances does it come up?

6. Do you know how much your child understands about race?

7. Has race ever come up when you and your child are discussing school matters (social interactions, student/teacher interactions, curriculum)? If so, in what ways?

8. Do you think that it is important that a school like Discovery School addresses racial issues? Why or why not? 
9. In what ways does Discovery School meet (or not meet) the unique needs of your child as a student of color?

\section{Part 3: Wrap-up}

\section{Facilitator will:}

- Thank participant

- Offer one last opportunity for further input

- Explain how data will be used 
Appendix F

Parent/Child Survey

This is a checklist to find out more about you and your child's experience with race, specifically related to his/her participation at Discovery School. Read each sentence and place an $X$ in the box that most closely describes you and your child. There are no right or wrong answers. All survey responses will be kept confidential.

\begin{tabular}{|l|l|l|l|l|l|l|}
\hline & $\begin{array}{l}\text { Stron } \\
\text { gly } \\
\text { agree }\end{array}$ & Agree & $\begin{array}{l}\text { Somewha } \\
\text { t } \\
\text { Agree }\end{array}$ & $\begin{array}{l}\text { Slightly } \\
\text { Disagre } \\
\text { e }\end{array}$ & $\begin{array}{l}\text { Disagre } \\
\text { e }\end{array}$ & $\begin{array}{l}\text { Strongl } \\
\text { y } \\
\text { Disagre } \\
\text { e }\end{array}$ \\
\hline $\begin{array}{l}\text { It is easy for my child to } \\
\text { make friends at school. }\end{array}$ & & & & & & \\
\hline $\begin{array}{l}\text { DISCOVERY SCHOOL } \\
\text { is the best school to meet } \\
\text { my child's needs. }\end{array}$ & & & & & & \\
\hline $\begin{array}{l}\text { My child feels } \\
\text { comfortable talking about } \\
\text { race with his/her } \\
\text { classmates and friends. }\end{array}$ & & & & & & \\
\hline $\begin{array}{l}\text { My child has teachers who } \\
\text { support him/her. }\end{array}$ & & & & & & \\
\hline $\begin{array}{l}\text { I think it is important to } \\
\text { talk about race at home. }\end{array}$ & & & & & & \\
\hline My child notices race. & & & & & & \\
\hline $\begin{array}{l}\text { I worry about my child } \\
\text { making friends at school. }\end{array}$ & & & & & & \\
\hline $\begin{array}{l}\text { My child feels different } \\
\text { from other students at the } \\
\text { school because of his/her } \\
\text { race. }\end{array}$ & & & & & & \\
\hline $\begin{array}{l}\text { The teachers, } \\
\text { administrator, and staff at } \\
\text { DISCOVER SCHOOL } \\
\text { are knowledgeable in } \\
\text { regards to handling issues } \\
\text { of race that occur within } \\
\text { the school. }\end{array}$ & & & & & & \\
\hline $\begin{array}{l}\text { My child has had negative } \\
\text { experiences because of } \\
\text { his/her race. }\end{array}$ & & & & & & \\
\hline
\end{tabular}




\begin{tabular}{|l|l|l|l|l|l|l|}
\hline $\begin{array}{l}\text { My child feels } \\
\text { comfortable with his/her } \\
\text { race. }\end{array}$ & & & & & & \\
\hline $\begin{array}{l}\text { My child has friends } \\
\text { outside of school. }\end{array}$ & & & & & & \\
\hline
\end{tabular}

Also, please feel free to respond to the following question, and/or provide any additional information that you think is important on the back of this form.

Has your child had a "racialized" experience at school or during extracurricular activities? If so, what was his/her reaction, and how did you 
Appendix G

Teacher Email Prompts

Email Prompts for Teachers/Administrator:

1. Do you think that student-student relationships are affected by race at Discovery School?

2. Do you think that race is something that should be addressed at Discovery School? What is being done or should be done to address issues of race? 